
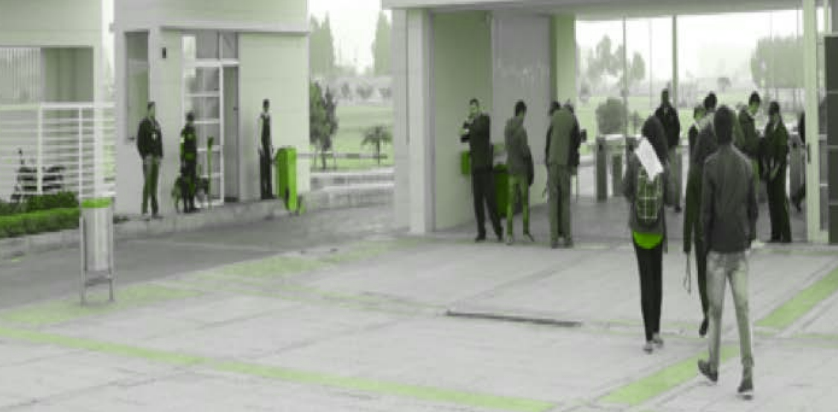

INFORME DE

SOSTENIBILIDAD

2019 
UNIVERSIDAD MILITAR NUEVA GRANADA

GRI 102-1

GRI 102-3

GRI 102-4

NIT 800.225.340-8

Sede Bogotá

Carrera 11 \# 101-80

Facultad de Medicina y Ciencias de la Salud, Transversal 3 \# 49-00

Bogotá (Colombia)

Sede Campus Nueva Granada

Kilómetro 2 vía Cajicá - Zipaquirá

Cundinamarca (Colombia)

Línea de atención: (57+1) 6500000

Portal web: www.umng.edu.co

\section{Informe de Sostenibilidad 2019}

DOI: https://doi.org/10.18359/whitepaper.5023

(c) Universidad Militar Nueva Granada,

Vicerrectoría de Investigaciones

(c) Editorial Neogranadina

editorial.neogranadina@unimilitar.edu.co

Todos los derechos reservados y se acoge

en un todo a la Ley 23 de 1982, Artículo 32.

Edición: julio 2020

Coordinación general:

Oficina Asesora de Direccionamiento Estratégico e Inteligencia Competitiva direccionamientoestrategico@umng.edu.co

Bogotá, D.C. 


\title{
INFORME DE SOSTENIBILIDAD 2019
}

\author{
UNIVERSIDAD MILITAR NUEVA GRANADA
}

Editorial

Neogranadina

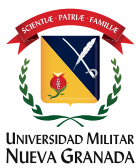




\section{CONSEJO SUPERIOR UNIVERSITARIO}

Almirante (RA) David René Moreno Moreno Viceministro del Grupo Social y Empresarial del Sector Defensa "GSED"

Doctor Víctor Hugo Malagón Basto Delegado Presidencia de la República

General Jorge León González Parra Jefe de Estado Mayor Conjunto de las FF.MM.

Doctora Adriana María López Jamboos Delegada Ministerio de Educación Nacional

Brigadier General Traslaviña Sachica Arnulfo Director Escuela Militar de Cadetes "José María Córdova"

Mayor General Helder Fernán Giraldo Bonilla Director de la Escuela Superior de Guerra

Mayor General Manuel Sanmiguel Buenaventura Representante de los ex Rectores

Doctora María Irma Botero Ospina Representante de las Directivas Académicas

Doctora Astrid Rubiano Fonseca, Ph.D. Representante de los Docentes

Doctora Wendy Kinberly Cabezas Pico Representante de los Egresados 


\section{DIRECTIVOS UMNG 2019}

Rectoría

Brigadier General (RA) Luis Fernando Puentes Torres

Vicerrectoría General

Brigadier General (RA) Alfonso Vaca Torres

Vicerrectoría Académica

Doctora Claudia Helena Forero Forero

Vicerrectoría de Investigaciones

Doctora Martha Jeaneth Patiño Barragán

Vicerrectoría General Campus Nueva Granada

Coronel (RA) Gustavo Enrique Becerra Pacheco

Vicerrectoría Administrativo

Mayor General (RA) Gustavo Adolfo Ocampo Nahar

Oficina Asesora de Direccionamiento Estratégico e Inteligencia Competitiva Coronel (RA) Jairo Alejandro Martínez Rocha 

1 A nuestros lectores

7 Acerca de este informe

13 Nuestros grupos de interés

19 Nuestros fundamentos

25 Nuestra institución

63 Nuestras funciones sustantivas en cifras

75 Educación inclusiva

95 Calidad

121 Investigación (ciencia, tecnología e innovación)

137 Pertinencia

163 Sostenibilidad

191 Índice de contenidos metodología Global Reporting Initiative GRI

205 Referencias 



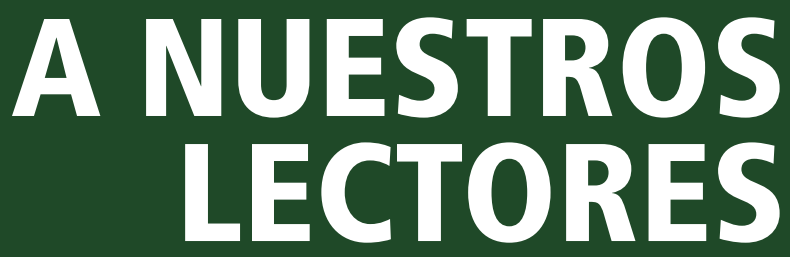





\section{GRI (102-14)}

Por segundo año consecutivo, les presentamos nuestro segundo Informe de Sostenibilidad, documento institucional que abarca las principales acciones desarrolladas en el transcurso de la vigencia 2019, concernientes a la responsabilidad social y compromiso ético; el documento nos facilitó en los 365 días robustecer la gestión de las funciones sustantivas en el orden académico y administrativo que se adelantó en la institución. Esto con el fin de mostrar el servicio en el rol de nuestra casa de estudios como agente de cambio, a través de las buenas prácticas, aportando al logro de los objetivos de desarrollo humano (oDs) propuestos por las Organizaciones de las Naciones Unidas (ONU); de la misma manera en sintonía con el propósito continuo de un mejor posicionamiento de la Universidad Militar Nueva Granada (UMNG). 
Para presentar el compromiso a nuestros grupos de interés, se requiere la participación activa de toda la comunidad neogranadina. En las siguientes páginas se apreciará información de manera exhaustiva y los datos más notables de las esferas de la ética en la gestión desde la investigación, docencia, extensión y construcción de comunidad académica, concernientes a los roles de liderazgo y la responsabilidad ante los estudiantes, docentes y administrativos; el impacto en la sociedad y en la economía, el compromiso de mejora para asegurar los escenarios de crecimiento integral y sostenido, así como la preservación en la Provincia Sabana Centro y altiplanicie, entre otros.

Es importante informar la contribución del desafío que se nos presenta, el cual se asume con el aprendizaje en la autoevaluación de las dos sedes de la universidad en relación con la ruta de la excelencia; se trata de un proceso para la renovación de la acreditación institucional multicampus, que incide de manera positiva en un progreso continuo para alcanzar una cultura propia de mejoramiento permanente en la academia, en la investigación, en la ciencia, en la innovación y en el emprendimiento, al incrementar la eficiencia en la gestión asertiva. Por consiguiente, esta actuación viene a profundizar el ser una institución más abierta, transparente, con una visión participativa y estar al servicio del sector defensa y de toda la ciudadanía. 
Están invitados a conocer este documento institucional, el Informe de Sostenibilidad 2019, que podemos considerar como una rendición de cuentas, dado que refleja el compromiso de formar profesionales con una alta calidad académica y con temple suficiente para enfrentar retos difíciles y desempeñarse en un accionar que represente una mayor contribución a la sociedad en bienestar. 



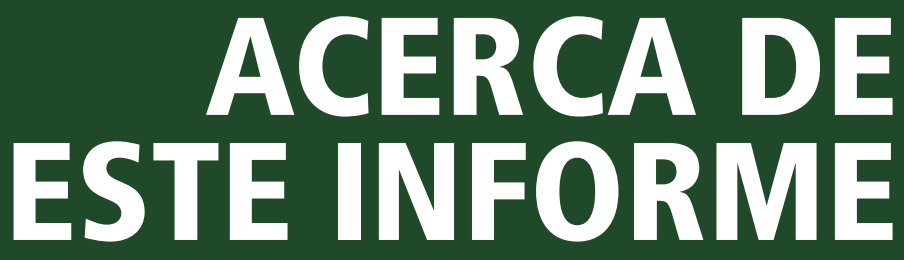





\section{GRI 102-50 \\ GRI 102-51 \\ GRI 102-52 \\ GRI 102-53 \\ GRI 102-54}

Por segundo año consecutivo el Informe de Sostenibilidad, en este caso de la vigencia 2019, se basa en la guía del marco de elaboración bajo la metodología de la Global Reporting Initiative (GRI) y en esta oportunidad se alinean con los Objetivos de Desarrollo Sostenible (oDs) (Figura 1). Se confirma la armonía con la Agenda 2030 de la Organización de las Naciones Unidas (ONU), así como con la gestión ambiental que comprenda tópicos tales como ahorro de energía, protección de ambiente y cambio climático, ahorro de agua, uso de aguas lluvias y reusó de las aguas; procesos de reciclaje, sistema de transporte que disminuya emisión de carbono y disminución de niveles 
de polución, y empoderamiento por medio de la educación ambiental, entre otros, en contexto con las estrategias sectoriales como Plan Decenal de Educación 2016-2026, Plan Nacional de Desarrollo 2018-2022 y el Acuerdo por lo Superior 2034.

FIGURA 1. Objetivos de desarrollo sostenible. Fuente: Organización de Na-

\section{(7) OBJETIVOS SOEDSERBR}

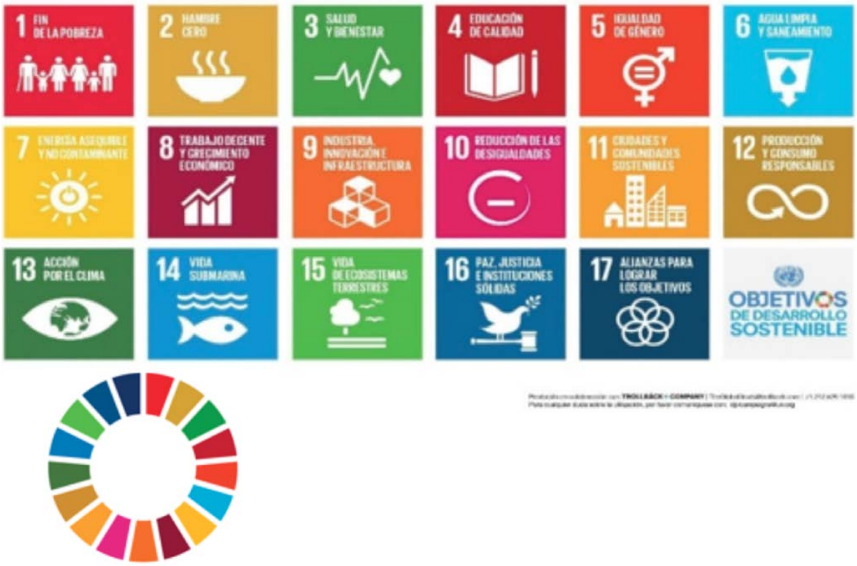

ciones Unidas $(2015,2016)$. Propiedad Intelectual ${ }^{\circledR}$

Por medio de los objetivos de la universidad se contribuye de manera directa al logro de los ons mostrados en la Figura 2.

FIGURA 2. Contribución de la Universidad Militar Nueva Granada. Fuente: 


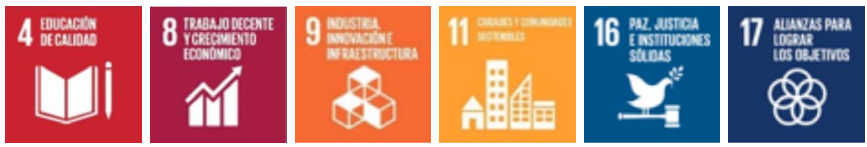

Organización de Naciones Unidas (2016). Propiedad Intelectual $®$

\section{Materialidad}

GRI 102-46

\section{GRI 102-47}

Para el caso, las temáticas y coeficientes adjuntos responden a las prioridades que considera la universidad y que nuestros grupos de interés confirmaron como relevantes en el análisis de materialidad; se revisaron sus elementos de materialidad en función de las condiciones sociales recientes y las opiniones y expectativas de sus grupos de interés. Además, la universidad tiene como objetivo crear valor identificando oportunidades y riesgos de los elementos de materialidad y el desarrollo de iniciativas correspondientes. Lo anterior representa que nuestra casa de estudios está alineada con la hoja de ruta para el desarrollo sostenible.

Con el fin de recibir mayor información respecto a este informe y obtener respuesta sobre los detalles de este, puede comunicarse con la Oficina de Direccionamiento Estratégico e Inteligencia Competitiva al correo electrónico direccionamientoestrategico@unimilitar.edu.co 
- Educación inclusiva

- Calidad

- Innovación
- Investigación

- Pertinencia

- Sostenibilidad

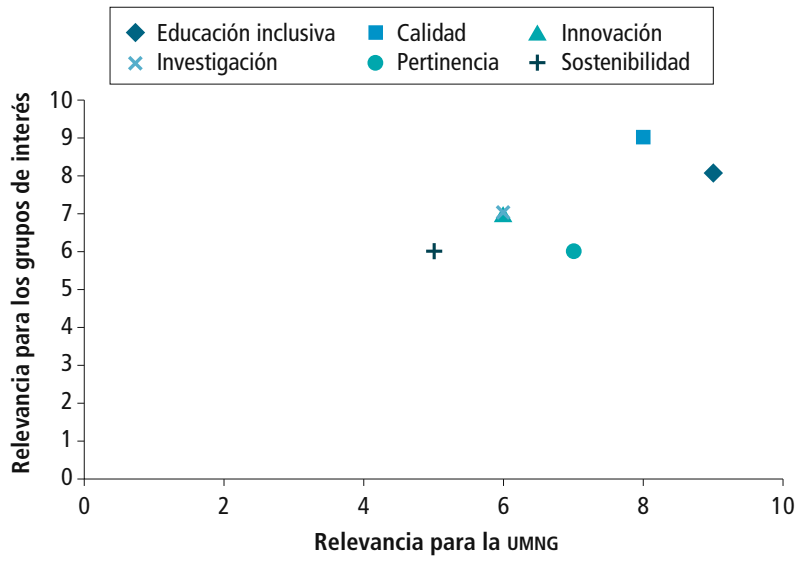

FIGURA 3. Matriz de materialidad. Fuente: elaboración propia. 


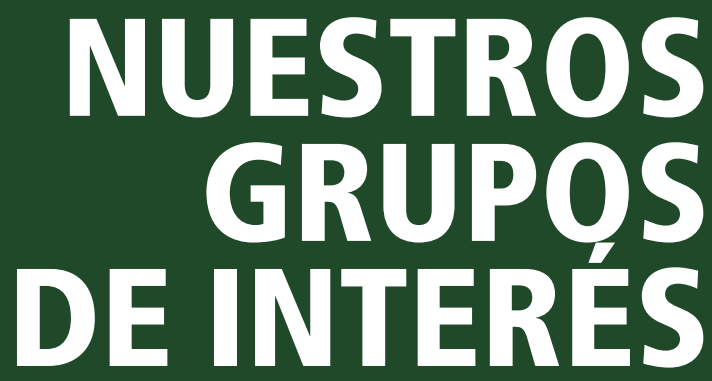





\section{GRI 102-40 \\ GRI 102-42 \\ GRI 102-43 \\ GRI 102-44}

En la interacción con los grupos de interés se encuentra lo consignado en la Tabla 1.

TABLA 1. Grupos de interés institucionales

\begin{tabular}{|l|l|}
\hline \multirow{4}{*}{ Alta Dirección } & Rector \\
& Vicerrectores \\
\hline \multirow{4}{*}{ Directivo de umNG } & Jefes de Oficinas Asesoras \\
\hline & Jefes de División \\
\hline \multirow{4}{*}{ Docentes } & Decanos \\
\hline & Jefes de Departamento \\
\hline \multirow{2}{*}{} & Jefes de Centro \\
\hline Personal administrativo & Innovadores \\
\hline \multirow{2}{*}{ Estudiantes } & Investigadores \\
\hline & Emprendedores \\
\hline \multirow{2}{*}{ Egresados } & Directores de programa \\
\hline & Pregrado \\
\hline & Posgrado \\
\hline
\end{tabular}


CONTINUACIÓN TABLA 1. Grupos de interés institucionales

\begin{tabular}{|c|c|c|}
\hline & Alcaldías y gobernaciones & Sector Sabana Centro \\
\hline & & Universidades \\
\hline & $\begin{array}{l}\text { Comunidades científicas } \\
\text { y académicas }\end{array}$ & $\begin{array}{l}\text { Instituciones de Educación Superior nacionales } \\
\text { y extranjeras }\end{array}$ \\
\hline & & Colegios \\
\hline & & Ciudadanía en general \\
\hline & & Personal en situación de vulnerabilidad \\
\hline & Sociedad & $\begin{array}{l}\text { Aspirantes (inscritos o admitidos) a programas } \\
\text { académicos de pregrado o posgrado }\end{array}$ \\
\hline & & Padres de familia \\
\hline & & Proponentes \\
\hline & & Redes de educación \\
\hline & Agremiaciones y & Corporaciones deportivas y organizaciones artísticas \\
\hline & asociaciones & Asociaciones de egresados \\
\hline & & Consultorios jurídicos \\
\hline 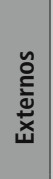 & $\begin{array}{l}\text { Agremiaciones y } \\
\text { asociaciones }\end{array}$ & $\begin{array}{l}\text { Redes universitarias y de información (Sistema } \\
\text { Universitario Estatal (Sue), Red de Información } \\
\text { Documental Agropecuaria de Colombia (Ridac) } \\
\text { y Red Universitaria Metropolitana de Bogotá } \\
\text { (Rumbo)) }\end{array}$ \\
\hline & & $\begin{array}{l}\text { Agremiaciones y asociaciones ambientales y de } \\
\text { seguridad y salud en el trabajo }\end{array}$ \\
\hline & Empleadores & $\begin{array}{l}\text { Empresas públicas o privadas contratantes de } \\
\text { egresados de la uMNG }\end{array}$ \\
\hline & & $\begin{array}{l}\text { Ministerio de Educación Nacional, de Defensa, de } \\
\text { Salud y de Transporte }\end{array}$ \\
\hline & Entidades reguladoras & Corporación Autónoma Regional (CAR) \\
\hline & gubernamentales y no & División de Impuestos y Aduanas Nacionales (DIAN) \\
\hline & gubernamentales & Contraloría General de la República \\
\hline & & Contaduría General de la Nación \\
\hline & & Secretaría de Salud \\
\hline & Sector defensa & $\begin{array}{l}\text { Fuerzas Militares (Ejército Nacional, Armada } \\
\text { Nacional, Fuerza Aérea, Escuela Superior de Guerra, } \\
\text { Batallón de Sanidad, centros carcelarios) }\end{array}$ \\
\hline & & Policía Nacional \\
\hline & & Hospital Militar \\
\hline
\end{tabular}




\begin{tabular}{|c|c|c|}
\hline \multirow{8}{*}{ 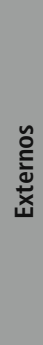 } & Proveedores & De bienes, servicios, recursos \\
\hline & \multirow{5}{*}{ Sector privado } & Empresas \\
\hline & & Hospitales \\
\hline & & Centros de salud \\
\hline & & Convenios \\
\hline & & Medios de comunicación \\
\hline & \multirow[t]{2}{*}{ Sector público } & $\begin{array}{l}\text { Instituto Colombiano de Crédito Educativo y } \\
\text { Estudios Técnicos en el Exterior (Icetex) }\end{array}$ \\
\hline & & Instituto Nacional de Vías (Invías) \\
\hline
\end{tabular}

Fuente: Oficina de Direccionamiento Estratégico e Inteligencia competitiva.

Entre los mecanismos de Atención al ciudadano se encuentra lo visible en la Figura 4.

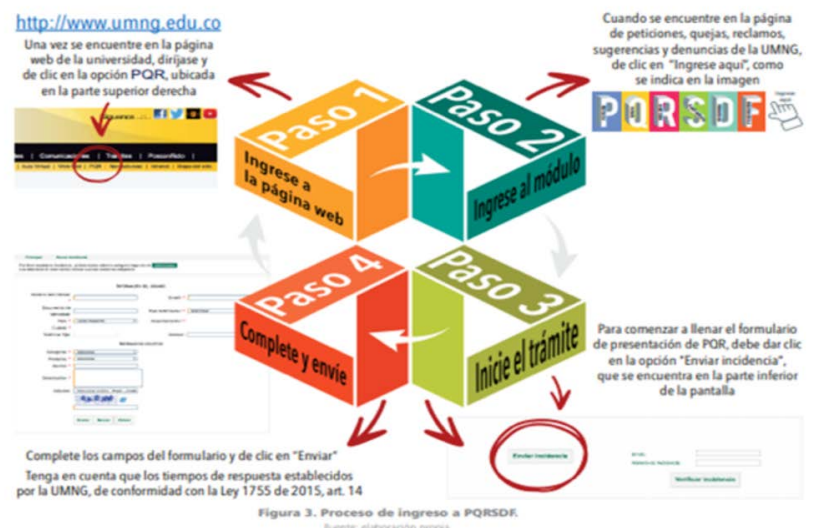

FIGURA 4. Mecanismos de atención al ciudadano. Fuente: Sección de Atención al Ciudadano de la Oficina de Direccionamiento Estratégico e Inteligencia competitiva (Universidad Militar Nueva Granada, s. f.). 


\section{Ingrese su petición, queja o reclamo:}
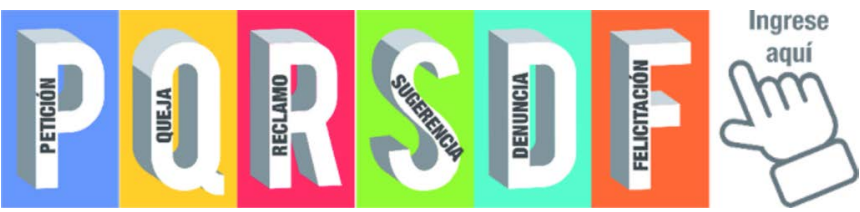

Términos para resolver la petición, de conformidad con la Ley 1755 de 2015 (artículo 14):

- Para cualquier petición: 15 días siguientes a su recepción.

- Para la petición de documentos: 10 días siguientes a su recepción.

- Consultas de materias a su cargo: 30 días siguientes a la recepción de la petición.

Si te contestamos dentro del término legal, pero la respuesta no te satisface, puedes objetarla ante nosotros mismos dentro del término de 10 días hábiles, a partir de la fecha en la que recibiste nuestra respuesta; en la que indicas que es un recurso de reposición, en subsidio de apelación.

Según la regulación interna de la Universidad Militar Nueva Granada, el tiempo para responder una queja, un reclamo, una sugerencia o un mensaje es de 10 días hábiles siguientes a su recepción. 


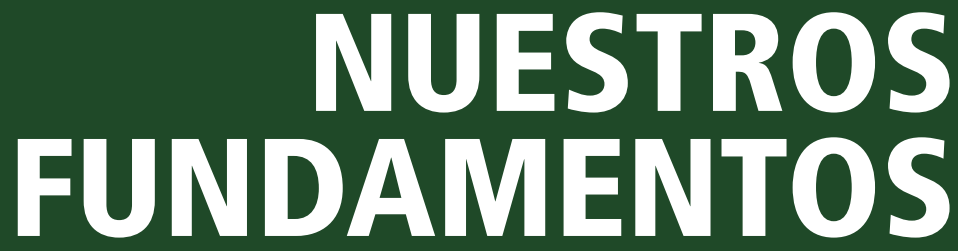



Conforme a lo dispuesto por la Ley 805 de 2003, la Universidad Militar Nueva Granada es una institución pública de educación superior, de orden nacional, con régimen orgánico especial, dedicada a la docencia, la investigación, la extensión, el desarrollo, la difusión del conocimiento y el análisis permanente de los problemas del país que afectan el bienestar de la sociedad colombiana, sirviendo de instrumento de auto renovación y desarrollo nacional.

\section{La filosofía institucional}

La filosofía institucional establece las concepciones e ideales que sustentan las acciones de la comunidad educativa neogranadina en el cumplimiento de su función educativa y pedagógica. Comprende la misión de la UMNG que es la razón de ser de la universidad, considerando su naturaleza, sus funciones, sus características y el sentido 
mismo de su existencia. En la misión de la unNG se hace un análisis del macro y micro entorno lo cual permite construir el escenario actual y posible, para ver con mayor énfasis la condición y razón de ser de la universidad. Unida a la misión, se establece la visión que permite vislumbrar el futuro y considerar los nuevos retos en el desarrollo organizacional tanto académico como administrativo, teniendo en cuenta las tendencias proyectadas desde una perspectiva global y sus implicaciones para la organización. Igualmente, la filosofía institucional contempla los principios, códigos éticos y valores institucionales de la UMNG, que fijan un derrotero en el trabajo cotidiano y dan un horizonte de sentido al quehacer diario en el interior de la universidad.

\section{Misión de la uMNG}

La Universidad Militar Nueva Granada es una institución pública del orden nacional que desarrolla las funciones de docencia, investigación y extensión; fomenta el diálogo de saberes, la construcción de comunidad académica y la autoevaluación permanente de los procesos institucionales; todo esto en el contexto de un mundo globalizado, con el fin de formar ciudadanos íntegros y socialmente responsables que promuevan la justicia, la equidad, el respeto por los valores humanos y contribuyan al progreso del sector Defensa y de la sociedad en general. 


\section{Visión de la umng}

La Universidad Militar Nueva Granada será reconocida por su alta calidad y excelencia en los ámbitos nacional e internacional mediante el fomento de la reflexión, la creatividad, el aprendizaje continuo, la investigación y la innovación desde una perspectiva global; en cumplimiento de la responsabilidad social, que le permita anticipar, proponer y desarrollar soluciones que respondan a las necesidades de la sociedad y del sector Defensa.

\section{Objetivos institucionales:}

1. Posicionar nacional e internacionalmente a la Universidad Militar Nueva Granada.

2. Mejorar la gestión académica y administrativa efectiva, con el fin de ofrecer servicios educativos de calidad.

3. Consolidar la acreditación de calidad institucional.

4. Afianzar el sistema de ciencia y tecnología e innovación científica y académica.

5. Fortalecer la interacción con el sector Defensa.

\section{Código Ético Moral}

\section{GRI 102-16}

1. Cumplir con la Misión y el Proyecto Educativo de la Universidad Militar Nueva Granada. 
2. Acatar todas las normas internas y externas que rigen nuestra institución universitaria.

3. Fomentar la excelencia.

4. Actuar con honestidad y transparencia en el desempeño de todas nuestras actividades y funciones.

5. Fomentar el sentido de pertenencia y lealtad en la comunidad académica Neogranadina.

6. Garantizar la equidad, el pluralismo y el respeto por los demás.

7. Denunciar la corrupción en cualquiera de sus manifestaciones.

8. Propender hacia la prestación de un servicio de alta calidad y eficiencia.

9. Anteponer el interés general de la institución por encima de cualquier consideración personal.

10. Mantener en alto nuestros postulados: Dios, Patria y Familia. 


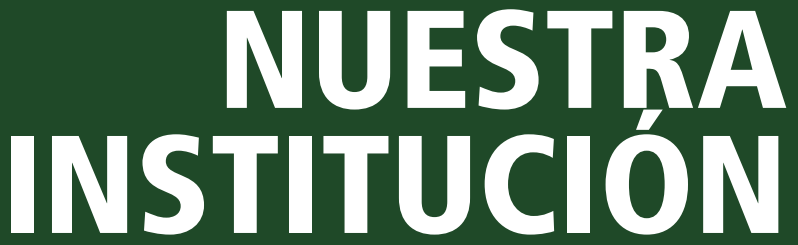





\section{Naturaleza}

\section{GRI 102-5}

La Universidad Militar Nueva Granada es un ente universitario autónomo del orden nacional, con régimen orgánico especial, cuyo objeto principal es la educación superior y la investigación, dirigidas a elevar la preparación académica de los miembros de las Fuerzas Militares y la Policía Nacional, en actividad o en retiro; de los empleados civiles del Sector Defensa; de los familiares de todos los anteriores y de los particulares que ingresen a la universidad, la cual está vinculada al Ministerio de Educación Nacional, en lo que a las políticas y a la planeación del sector educativo se refiere. 


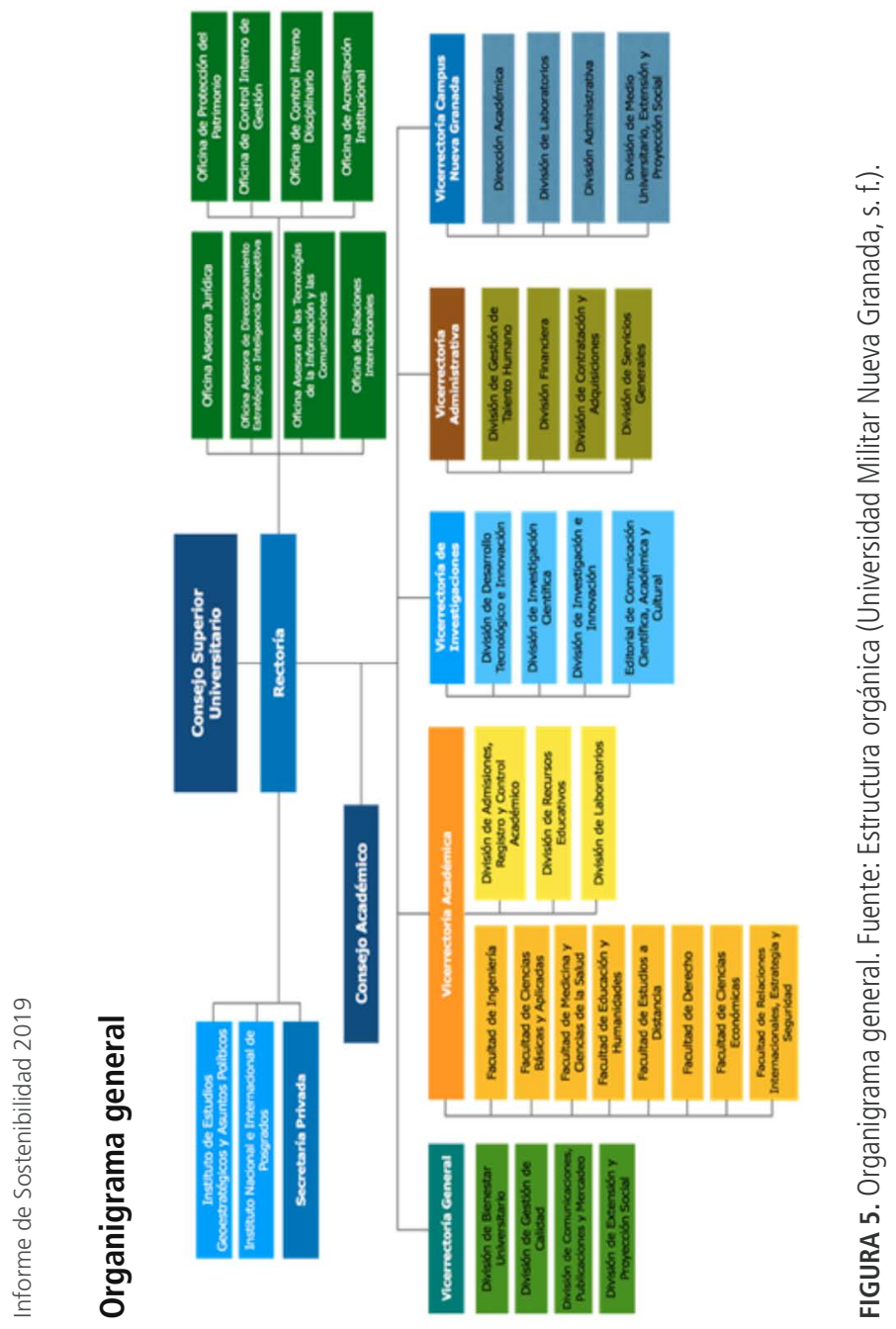


En razón de su misión y de su régimen especial, la Universidad Militar Nueva Granada es una persona jurídica, con autonomía académica, administrativa y financiera; patrimonio independiente; capacidad para gobernarse, designar sus propias autoridades, y elaborar y manejar su presupuesto de acuerdo con las funciones que le correspondan, y competencia para dictar sus normas y reglamentos conforme a la normativa nacional.

Con fundamento en lo dispuesto en el artículo 211 de la Constitución Política de Colombia, el presidente de la República podrá delegar en el ministro de Educación Nacional las funciones de inspección y vigilancia en lo que compete a la Universidad Militar Nueva Granada.

\section{Gobierno corporativo}

\section{GRI 102-18}

GRI 102-19

GRI 102-20

\section{GRI 102-22}

El gobierno de la umng se ejerce mediante los Órganos presentados en la Tabla 2. 
TABLA 2. Órganos de la Universidad Militar Nueva Granada.

\begin{tabular}{|l|l|}
\hline \multicolumn{1}{|c|}{ COLEGIADOS } & \multicolumn{1}{c|}{ UNIPERSONALES } \\
\hline $\begin{array}{l}\text { Consejo Superior Universitario UMNG, } \\
\text { constituido por once miembros. }\end{array}$ & Rector \\
\hline $\begin{array}{l}\text { Consejo Académico, está } \\
\text { constituido por diez miembros. }\end{array}$ & Vicerrectores \\
\hline $\begin{array}{l}\text { Consejo de Facultad, constituido por } \\
\text { once miembros. }\end{array}$ & $\begin{array}{l}\text { Decanos } \\
\text { Vicedecanos } \\
\text { Directores } \\
\text { Subdirectores de Instituto } \\
\text { Directores de Departamentos y Centros }\end{array}$ \\
\hline
\end{tabular}

\begin{tabular}{|c|l|}
\hline \multicolumn{2}{|c|}{ Gestión realizada por el Consejo Superior Universitario 2019} \\
\hline 7 & $\begin{array}{l}\text { Sesiones ordinarias( febrero, abril, junio, agosto, octubre, noviembre y } \\
\text { diciembre) }\end{array}$ \\
\hline 4 & Sesión extraordinaria ( virtual, otras) \\
\hline 16 & Acuerdo suscritos \\
\hline 27 & $\begin{array}{l}\text { Temas abordados } \\
\text { (Informe permanente de la ejecución presupuestal de la UMNG) }\end{array}$ \\
\hline 3 & Compromisos de informes adicionales cumplidos \\
\hline 10 & Nuevos miembros posesionados 2019 \\
\hline
\end{tabular}

Fuente: Vicerrectoría general.

De forma adicional, se encuentra el Consejo de Bienestar Universitario, constituido por nueve miembros, el cual orienta y asesora la formulación de los programas y actividades orientadas al desarrollo físico, psicoafectivo, espiritual, social y cultural de la comunidad Universitaria; también el Comité del Grupo Administrativo de Gestión Ambiental y Sanitaria \& Desarrollo Sostenible (GAGAS\&DS), constituido por nueve miembros, el cual vigila y controla los aspectos ambientales y de desarrollo sostenible derivados de las actividades de la institución. 


\section{Nuestra nueva rectoría}

\section{GRI 102-24}

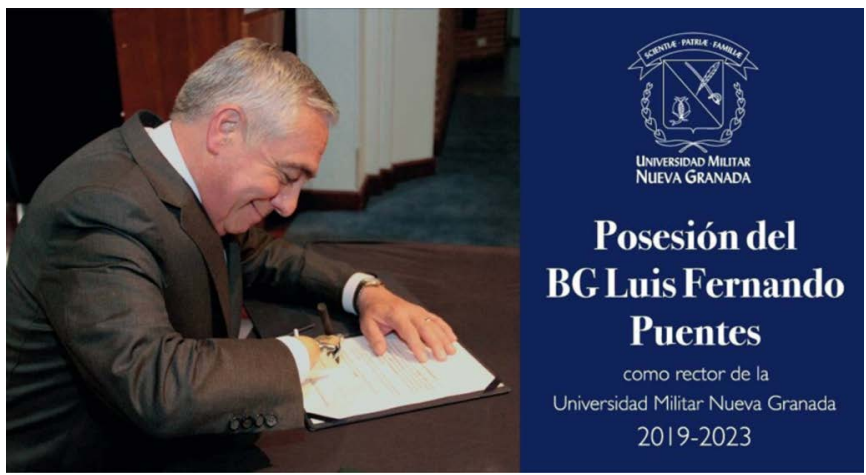

FIGURA 6. Brigadier Luis Fernando Puentes. Fuente: Vicerrectoría general, Universidad Militar Nueva Granada (2019).

El brigadier general Luis Fernando Puentes (Figura 6) es un egresado neogranadino, con amplia trayectoria académica y de investigación. La Universidad Militar Nueva Granada le dio la bienvenida al Brigadier General Luis Fernando Puentes Torres, elegido como nuevo rector por el Consejo Superior Universitario para un período de cuatro años. El Brigadier General Puentes es abogado neogranadino, Magíster en Defensa y Seguridad Nacional de la Escuela Superior de Guerra, Magíster en Derechos Humanos y Derecho aplicable a los Conflictos armados Dica y Ph. D. en Derecho Internacional de la Universidad Alfonso X el Sabio de Madrid. El nuevo rector tiene amplio conocimiento 
en planeación, gerencia de personal y administración de recursos y ejerce un quehacer infatigable en los campos académico y de la investigación. A lo largo de su carrera ha sido conferencista invitado en escenarios nacionales e internacionales, en temas de la administración jurídica y judicial, estrategia, defensa y seguridad nacional, justicia penal militar, derechos humanos y derecho internacional de los conflictos armados. Su más reciente libro se titula Reconocimiento político del conflicto por el Estado colombiano, publicado por el Grupo Editorial Ibáñez.

\section{Talento humano}

GRI 102-7

GRI 102-8

En la Tabla 3 se muestra el personal de la UnMG.

TABLA 3. Talento humano de la unMG.

\begin{tabular}{|l|l|c|}
\hline \multicolumn{3}{|c|}{ Docentes } \\
\hline \multicolumn{1}{|c|}{ Ítem } & \multicolumn{1}{c|}{ Descripción } & 2019 \\
\hline $\begin{array}{l}\text { Número de } \\
\text { docentes de planta }\end{array}$ & $\begin{array}{l}\text { Se indica el número total de docentes de planta, } \\
\text { expresado en tiempos completos equivalentes. }\end{array}$ & 431 \\
\hline $\begin{array}{l}\text { Número de } \\
\text { docentes } \\
\text { ocasionales }\end{array}$ & $\begin{array}{l}\text { Se indica el número total de docentes ocasionales, } \\
\text { expresado en tiempos completos equivalentes. }\end{array}$ & 158 \\
\hline
\end{tabular}




\begin{tabular}{|l|l|c|}
\hline \multicolumn{2}{|c|}{ CONTINUACIÓN TABLA 3. Talento humano de la UNMG. } \\
\hline \multicolumn{1}{|c|}{ Docentes } & \multicolumn{1}{|c|}{ Descripción } \\
\hline $\begin{array}{l}\text { Número de } \\
\text { docentes de cátedra }\end{array}$ & $\begin{array}{l}\text { Fórmula que indica el número de docentes de } \\
\text { cátedra equivalentes en tiempo completo; la } \\
\text { fórmula es: (total de horas cátedra al semestre / } \\
\text { (semanas de vinculación del docente catedrático } \\
\text { al semestre por dieciséis horas de docencia a la } \\
\text { semana). }\end{array}$ & 689 \\
\hline $\begin{array}{l}\text { Total de horas } \\
\text { cátedra al semestre }\end{array}$ & $\begin{array}{l}\text { Indica la sumatoria de todas las horas cátedra de } \\
\text { un semestre, es decir, la sumatoria de todas las } \\
\text { horas dictadas por todos los docentes catedráticos } \\
\text { de la universidad en un semestre académico. }\end{array}$ & 209.378 \\
\hline $\begin{array}{l}\text { Número de } \\
\text { semanas al } \\
\text { semestre de } \\
\text { vinculación un } \\
\text { docente de cátedra }\end{array}$ & $\begin{array}{l}\text { Indica el número de semanas por las que se } \\
\text { contrata un docente de cátedra en un semestre del } \\
\text { año; generalmente está entre dieciséis y veintiún } \\
\text { semanas. }\end{array}$ & 19 \\
\hline
\end{tabular}

\begin{tabular}{|c|c|c|c|c|c|}
\hline & Formación docente & $\begin{array}{l}\frac{\pi}{\stackrel{2}{ \pm}} \\
\frac{\pi}{\alpha}\end{array}$ & 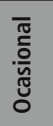 & 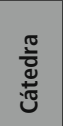 & $\frac{\sim}{\infty}$ \\
\hline $\begin{array}{l}\text { Número de } \\
\text { docentes con } \\
\text { doctorado }\end{array}$ & $\begin{array}{l}\text { Indica, para la vigencia 2019, el } \\
\text { número de docentes vinculados a la } \\
\text { universidad con formación máxima } \\
\text { de doctorado, según su modalidad de } \\
\text { contratación. }\end{array}$ & 131 & 11 & 20 & 162 \\
\hline $\begin{array}{l}\text { Número de } \\
\text { docentes con } \\
\text { maestría }\end{array}$ & $\begin{array}{l}\text { Indica, para la vigencia 2019, el } \\
\text { número de docentes vinculados a la } \\
\text { universidad con formación máxima } \\
\text { de maestría, según su modalidad de } \\
\text { contratación. }\end{array}$ & 252 & 91 & 467 & 810 \\
\hline
\end{tabular}

continúa 
CONTINUACIÓN TABLA 3. Talento humano de la UNMG.

\begin{tabular}{|c|c|c|c|c|c|}
\hline & Formación docente & $\begin{array}{l}\stackrel{\pi}{ \pm} \\
\frac{\pi}{2}\end{array}$ & 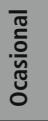 & 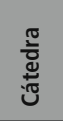 & ำ \\
\hline $\begin{array}{l}\text { Número de } \\
\text { docentes con } \\
\text { especialización }\end{array}$ & $\begin{array}{l}\text { Indica, para la vigencia 2019, el } \\
\text { número de docentes vinculados } \\
\text { a la universidad con formación } \\
\text { máxima de especialización, según su } \\
\text { modalidad de contratación. }\end{array}$ & 49 & 51 & 505 & 605 \\
\hline $\begin{array}{l}\text { Número de } \\
\text { docentes con } \\
\text { pregrado }\end{array}$ & $\begin{array}{l}\text { Indica, para la vigencia 2019, el } \\
\text { número de docentes vinculados a la } \\
\text { universidad con formación máxima } \\
\text { de título profesional, según su } \\
\text { modalidad de contratación. }\end{array}$ & 7 & 8 & 53 & 68 \\
\hline
\end{tabular}

Fuente: División de gestión del talento humano.

\section{Infraestructura}

\section{GRI 102-10}

Adecuación de la infraestructura de la sede Bogotá calle 100

La División de Servicios Generales adecuó parcialmente la infraestructura de la Universidad Militar Nueva Granada, así:

- Adecuación de la subestación eléctrica en SF6, para dar cumplimiento a la Norma Retie.

- Reparaciones locativas de la Oficina del Centro de Investigaciones de la Facultad de Ingeniería.

- Adecuación de filtros y drenajes perimetrales de los edificios que tienen sótanos, Bloques A, B, C, D, E y Aula Máxima. 
- Interventoría a la Adecuación de filtros y drenajes perimetrales de los edificios que tienen sótanos, Bloques A, B, C, D, E y Aula Máxima.

- Diseño de laboratorio, sótano A, sede Bogotá calle 100.

- Adecuación de área diseño y publicaciones, tercer piso Aula Máxima.

- Adecuación y mobiliario para el comedor externo.

- Adecuación para un aula especial del Edifico Bloque D, segundo piso; antiguas oficinas del Centro de Orientación, Acompañamiento y Seguimiento Estudiantil (Coase).

- Reparaciones locativas de la oficina y mobiliario para el programa de administración de empresas.

- Consultoría sobre el estado estructural y estudio de suelos del tanque de agua ubicado en medio de los Bloques B y C, debajo del domo del comedor de la plazoleta de comidas, sede Bogotá calle 100.

- Modernización y actualización de la oficina de la Vicerrectoría de Investigaciones.

- Equipamiento del área asignada para la sala amiga de la familia lactante.

- Adecuación locativa y suministro de mobiliario para la oficina de salud seguridad en el trabajo y medio ambiental de la sede Bogotá calle 100.

- Adecuación - arreglos de consultorio médico y odontológico de la sede Bogotá. 
Adecuación de la infraestructura de la Facultad de Medicina La División de Servicios Generales adecuó parcialmente la infraestructura de la Universidad Militar Nueva Granada en la sede Facultad de medicina y ciencias de la salud, así:

- Adecuación de la subestación eléctrica en SF6, para dar cumplimiento a la norma Retie.

- Reparaciones locativas para la actualización y modernización de laboratorios de medicina.

- Suministro e instalación de mobiliario de laboratorios de Medicina.

- Interventoría técnica administrativa, financiera y ambiental de laboratorios de Medicina.

- Suministro y cambio de tubería para la actualización y cumplimiento de las normas ambientales en la Facultad de Medicina y Ciencias de la salud.

Adecuación y modernización de la infraestructura física - Sede Campus Nueva Granada

La Dirección Administrativa y la División de Laboratorios del Campus Nueva Granada desarrollaron las siguientes actividades de la adecuación de la infraestructura:

- Dotación del edificio de laboratorios, fase i de campus (asignado).

- Traslado de laboratorio de simulación APH al nuevo edificio de laboratorios, fase II.

- Adecuación de hub de innovación. 


\section{Contratación}

\section{GRI 102-9}

Durante la vigencia del 2019, la UMNG desarrolló los procesos de contratación requeridos por las unidades académico administrativas, que representan la gestión contractual que se presenta a continuación. El plan de contratación final para la Universidad Militar Nueva Granada, vigencia 2019, fue de $\$ 59.592 .569 .718$ de acuerdo a la tabla que se muestra a continuación; se puede evidenciar que durante la vigencia 2019 se alcanzó una ejecución equivalente al $93,20 \%$, de la manera en que se muestra en la Tabla 4.

TABLA 4. Resumen de ejecución, vigencia 2019

\begin{tabular}{|l|r|r|r|}
\hline \multicolumn{1}{|c|}{ Concepto } & $\begin{array}{c}\text { Valor Plan de } \\
\text { Contratación }\end{array}$ & \multicolumn{1}{|c|}{ Ejecutado } & \multicolumn{1}{c|}{$\begin{array}{c}\text { Porcentaje } \\
\%\end{array}$} \\
\hline $\begin{array}{l}\text { Valor de registro } \\
\text { presupuestal Mayor } \\
\text { Cuantía }\end{array}$ & 0 & $\$ 29.078 .365 .946$ & $81,10 \%$ \\
\hline $\begin{array}{l}\text { Menor valor aprobado } \\
\text { y adjudicado Mayor } \\
\text { Cuantía }\end{array}$ & 0 & $\$ 3.898 .173 .850$ & $10,90 \%$ \\
\hline Mayor Cuantía & $\$ 35.873 .149 .586$ & $\$ 32.976 .539 .796$ & $91,90 \%$ \\
\hline Menor Cuantía & $\$ 11.609 .422 .364$ & $\$ 11.151 .442 .064$ & $96,10 \%$ \\
\hline Mínima Cuantía & $\$ 10.437 .573 .823$ & $\$ 9.902 .894 .177$ & $94,90 \%$ \\
\hline $\begin{array}{l}\text { Transferencias Menor } \\
\text { Mínima Cuantía }\end{array}$ & $\$ 1.487 .623 .945$ & $\$ 1.480 .523 .378$ & $99,50 \%$ \\
\hline Caja menor & $\$ 184.800 .000$ & $\$ 27.063 .416$ & $14,60 \%$ \\
\hline Total ejecutado & $\$ 59.592 .569 .718$ & $\$ 55.538 .462 .831$ & $93,20 \%$ \\
\hline
\end{tabular}

Fuente: División de contratación y adquisiciones. 
En la Figura 7 se puede evidenciar el peso porcentual por cuantías, respecto del valor del plan de contratación vigencia 2019.
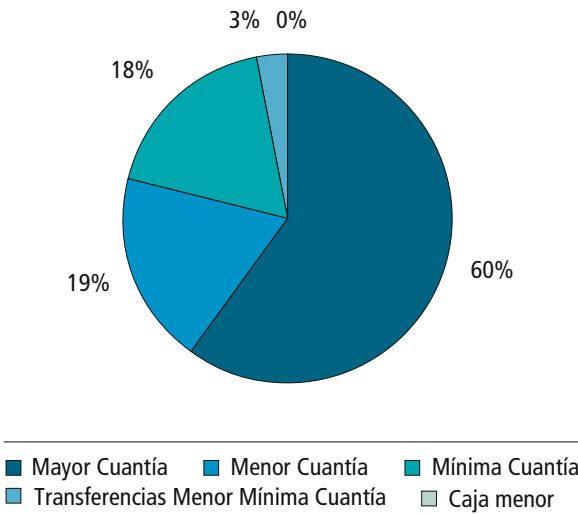

FIGURA 7. Peso porcentual por cuantías. Fuente: División de contratación y adquisiciones.

De acuerdo a la Figura 7, el mayor peso del presupuesto de la División de Contratación y Adquisiciones recae en el procedimiento de mayor cuantía, con un $60 \%$ del valor a ejecutar.

TABLA 5. Ahorro en el Plan de Contratación

\begin{tabular}{|l|c|r|}
\hline \multicolumn{3}{|c|}{ Ahorros por menores valores apropiados y adjudicados } \\
\hline Menores valores apropiados & 36 & $\$ 835.246 .828$ \\
\hline Menores valores resultado de adjudicaciones & 39 & $\$ 3.062 .927 .022$ \\
\hline Total & & $\$ 3.898 .173 .850$ \\
\hline
\end{tabular}

Fuente: División de contratación y adquisiciones. 
El ahorro en la ejecución del plan de contratación (Tabla 5) fue del 10,9\%, que corresponde al menor valor apropiado o adjudicado en los respectivos procesos contractuales de mayor cuantía sobre el presupuesto oficial asignado.

TABLA 6. Comportamiento de ejecución en las dos Sedes

\begin{tabular}{|l|l|r|r|}
\hline \multicolumn{2}{|c|}{ Concepto } & \multicolumn{1}{c|}{ Ejecutado } & \multicolumn{1}{c|}{$\%$} \\
\hline \multirow{2}{*}{$\begin{array}{l}\text { Sede } \\
\text { Bogotá }\end{array}$} & Calle 100 & $\$ 24.317 .376 .404$ & 43,78 \\
\cline { 2 - 4 } & Facultad de Medicina y Ciencias de la Salud & $\$ 4.718 .506 .461$ & 8,5 \\
\hline Sede Campus Nueva Granada & $\$ 26.502 .579 .966$ & 47,72 \\
\hline TOTAL & $\$ 55.538 .462 .831$ & \\
\hline
\end{tabular}

Fuente: División de contratación y adquisiciones.

La sede de mayor incidencia en la ejecución de bienes y servicios es Campus Nueva Granada en Cajicá con un 47,72\% (Tabla 6).

\section{Plan de desarrollo Institucional (Tablas 7 a 11)}

En el horizonte 2009-2019 del Plan de Desarrollo Institucional, la vigencia 2019 atiende a la puesta en marcha de los objetivos estratégicos en cuanto a megaproyectos, proyectos, actividades, tareas, recursos, productos e indicadores, con la siguiente estructura:

Cuatro objetivos estratégicos que representan el quehacer institucional, así como los ejes sobre los cuales se ejecuta la gestión institucional. 
Diez megaproyectos que se refieren a los aspectos que la UMNG identifica como pilares para el desarrollo de procesos de innovación en el marco de las prácticas institucionales.

Dieciséis proyectos institucionales, con ámbitos de gestión, integración y correlación que permiten la ejecución de políticas y estrategias que apalancan el cambio y orientación del crecimiento y desarrollo institucional.

TABLA 7. Plan de Desarrollo Institucional

\begin{tabular}{|c|c|c|c|c|}
\hline & Objetivo estratégico & $\begin{array}{c}\text { Apropiación } \\
\text { definitiva }\end{array}$ & Ejecución & $\begin{array}{c}\text { \% de } \\
\text { Ejecución }\end{array}$ \\
\hline 1 & $\begin{array}{l}\text { Posicionar nacional e } \\
\text { internacionalmente a } \\
\text { la Universidad Militar } \\
\text { Nueva Granada. }\end{array}$ & $\$ 2.444 .570 .907$ & $\$ 1.735 .135 .009$ & 71 \\
\hline 2 & $\begin{array}{l}\text { Mejorar la gestión } \\
\text { efectiva académica y } \\
\text { administrativa para } \\
\text { ofrecer servicios } \\
\text { educativos de calidad. }\end{array}$ & $\$ 30.006 .586 .335$ & $\$ 24.077 .027 .182$ & 80 \\
\hline 3 & $\begin{array}{l}\text { Consolidar la } \\
\text { acreditación de calidad } \\
\text { en la institución. }\end{array}$ & $\$ 249.973 .392$ & $\$ 214.005 .289$ & 86 \\
\hline 4 & $\begin{array}{l}\text { Afianzar el sistema de } \\
\text { ciencia, tecnología e } \\
\text { innovación científica y } \\
\text { académica. }\end{array}$ & $\$ 13.477 .467 .215$ & $\$ 13.477 .467 .215$ & 100 \\
\hline \multicolumn{2}{|c|}{$\begin{array}{l}\text { Total de Plan de Inversión } \\
\text { Vigencia } 2019\end{array}$} & $\$ 46.178 .597 .849$ & $\$ 39.503 .634 .695$ & 86 \\
\hline
\end{tabular}

Fuente: Sección de planes y proyectos especiales de la Oficina asesora de direccionamiento estratégico e inteligencia competitiva. 
TABLA 8. Principales acciones desarrolladas en el Plan de desarrollo institucional

\begin{tabular}{|l|}
\hline \multicolumn{1}{|c|}{ Para el Objetivo estratégico 1} \\
\hline La Universidad Militar Nueva Granada, en su función de agente transformador \\
del conocimiento, visualizó la necesidad de proyectar su campo de actuación \\
bajo dos horizontes claramente definidos: el posicionamiento nacional \\
y la proyección internacional. Para el cumplimiento de estas intenciones \\
formuló dos megaproyectos: ampliación de la cobertura y proyección social e \\
internacionalización
\end{tabular}

Fuente: Sección de planes y proyectos especiales de la Oficina asesora de direccionamiento estratégico e inteligencia competitiva.

La creación de nuevos programas académicos, en la cual se presentaron las siguientes acciones:

- Visita de pares académicos al programa de doctorado en Ingeniería.

- Documento maestro de la maestría en Seguridad y Gestión de Riesgos.

- Visita de pares académicos al programa de pregrado en Ingeniería química.

- Documento maestro de la maestría en Gestión de Tecnologías de la Información y las Comunicaciones.

- Estudio de factibilidad de la especialización en Gerencia de la Calidad a Distancia.

- Documento maestro de la especialización en Gerencia de la Calidad a Distancia.

- Estudio de factibilidad de la especialización en Gerencia Integral de Proyectos a Distancia. 
- Documento maestro de la especialización en Gerencia Integral de Proyectos a Distancia.

- Estudio de factibilidad de la especialización en Planeación Ambiental y Manejo Integral de Recursos Naturales.

- Documento maestro de la especialización en Planeación Ambiental y Manejo Integral de Recursos Naturales.

- Estudio de Factibilidad de la maestría en Derecho.

- Maestría en Derecho con dos enfoques: investigación y profundización

La UMNG y su entorno, actividades de educación continuada por parte de la División de Extensión y proyección social con la participación de la Facultad de Derecho, Facultad de Ciencias Básicas y Aplicadas, Facultad de Educación y Humanidades y Facultad de Ciencias Económicas, tal y como se especifica a continuación:

- Programa de articulación entre la UMNG y la educación media para el desarrollo de competencias laborales en el área de la horticultura.

- Programa Sembrando ilusiones - Días de campo; primera y segunda infancia.

- Unidad Productiva Acuaponia.

- Unidad Productiva Hongos Comestibles y Medicinales.

- Informe sobre biocontroladores. 
- Informe de Acción social.

- Informe de posicionamiento clínica legal de investigación y acción social Clias.

- Informe de Identificación de comunidad vulnerable.

- Revisión de propuestas de emprendimiento de Dirección Centro de Rehabilitación Inclusiva DCRI.

- Participación de los emprendedores de dirección centro de rehabilitación inclusiva DCRI en las ferias empresariales.

- Capacitación en temas jurídicos a personas en condición de discapacidad (auditiva y visual).

- Talleres de emprendimiento (área jurídica) para personas en condición de discapacidad (auditiva y visual).

El Plan de Mercadeo y Comunicaciones Estratégicas. Se presentaron actividades referentes a pautas publicitarias como se describe a continuación:

- Pautas publicitarias: 126 pautas en medios convencionales y 224 pautas en medios no convencionales.

- Fortalecimiento de la comunicación interna: 8.657 visitas en promoción y plan alianza.

El desarrollo de acuerdos de colaboración y transferencia para programas conjuntos, en el cual se presentaron actividades de internacionalización. 
El objetivo principal del reconocimiento internacional de calidad es operacionalizar y apoyar la movilidad de los miembros de la comunidad neogranadina hacia el exterior y de extranjeros hacia la universidad, de manera que se permita y apoye la participación en diferentes tipos de actividades académicas, investigativas o pertenecientes al campo de la gestión administrativa; se obtuvieron los siguientes logros:

- 32 movilidades académicas.

- 28 profesores visitantes.

- 164 estudiantes en cursos como opción de grado.

- 1 asistente de idioma.

La gestión de asociaciones y redes de servicios académicos, en la cual se presentaron varias actividades de internacionalización como se especifica a continuación.

\section{La visibilidad y proyección estratégica internacional}

Se crea un plan a través de la gestión y participación en eventos, programas y capacitaciones en torno a la internacionalización de la educación superior; esto con el fin de gestionar alianzas estratégicas de cooperación internacional que fortalezcan las funciones sustantivas de la universidad. Dentro del plan, desarrollar procesos y proyectos que permitan la visibilidad internacional de la universidad a través de la suscripción y ejecución de alianzas 
de cooperación académica internacional. De acuerdo a lo anterior se desarrollaron las siguientes tareas:

- 3 eventos internacionales.

- 109 docentes desplazados al exterior.

- 393 estudiantes desplazados al exterior.

- 35 estudiantes extranjeros recibidos.

- 74 docentes extranjeros recibidos.

- 13 administrativos desplazados al exterior.

TABLA 9. Principales acciones desarrolladas en el Plan de desarrollo institucional

\begin{tabular}{|l|}
\hline \multicolumn{1}{|c|}{ Para el Objetivo estratégico 2} \\
\hline Una organización de conocimiento es una organización que se encuentra en \\
permanente aprendizaje. Este planteamiento supone que, para tal fin, se deben \\
conjugar componentes clave que permitan la viabilidad de un proyecto institucional \\
orientado a la excelencia, con una fuerte y constante capacidad de creación, y \\
que incorporen reformas significativas que conduzcan a la transformación del \\
conocimiento, como fruto de su proceso de autoevaluación y autorregulación \\
\hline
\end{tabular}

Fuente: Sección de planes y proyectos especiales de la Oficina asesora de direccionamiento estratégico e inteligencia competitiva.

La gestión del desarrollo físico para la integración científica y social, en la cual se presentaron actividades desarrolladas en el Proyecto Campus como se especifica a continuación.

Construcción del Campus Nueva Granada

Con el Campus Nueva Granada se busca ampliar la planta física de la universidad mediante la construcción de 
infraestructura para conjugar de forma equilibrada y armoniosa, la funcionalidad de los espacios académicos y de investigación, con los servicios comunes, las zonas de bienestar universitario y el paisaje natural.

Asimismo, se busca mejorar la oferta en programas académicos integrales de acuerdo con la demanda de la comunidad estudiantil para fortalecer sus competencias y poder garantizar a los estudiantes una incorporación productiva a su vida laboral; esto mediante el desarrollo de programas profesionales, técnicos y tecnológicos con características de calidad e investigación que contribuyan al desarrollo y progreso de la población, y por ende, a las estrategias planteadas por el Gobierno Nacional en beneficio de un desarrollo sostenible. Para esto se ejecutarán las siguientes tareas:

- Construcción de aulas II de ingeniería.

- Interventoría para la construcción de aulas ir de ingeniería.

- Construcción de laboratorios de Ingeniería fase II.

- Interventoría para la construcción de laboratorios de Ingeniería fase II.

- Interventoría para la construcción de Aula Libre.

- Construcción de hangar del centro de Geotecnia y Cimentaciones.

- Interventoría para la construcción de hangar del centro de Geotecnia y Cimentaciones. 
- Dotación de laboratorios de Ingeniería fase II.

- Dotación de talleres y mantenimiento.

- Dotación de segunda fase de aulas II de Ingeniería.

- Dotación de laboratorios de Ingeniería fase ir.

- Dotación de cafetería de cuarto piso, edificio aulas II

La gestión de contenidos y recursos pedagógicos, en la cual se presentaron varias actividades académicas como se especifica a continuación.

- Elaboración del material de estudio de las asignaturas del plan de estudios de los programas de la facultad de estudios a distancia de 596 contenidos.

- Realización del diseño instruccional para los recursos educativos digitales RED del programa de facultad de estudios a distancia de 596 contenidos.

- Integración y desarrollo de medios multimediales para los recursos educativos digitales RED de los programas de la facultad de estudios a distancia.

- Producción de audio y video hipermedia para los programas de facultad de estudios a distancia de 596 contenidos.

- Revisión de calidad para los objetos virtuales de aprendizaje ova desarrollados para los programas de la facultad de estudios a distancia de 596 contenidos.

- Dirección pedagógica, autores, asignaturas de la facultad de estudios a distancia de 145 materias. 
La gestión para el soporte institucional, informática y comunicaciones, en la cual se presentaron diversas actividades como se especifica a continuación.

- Implementación de solución de cableado del edificio A, sótano, segundo y tercer piso, y oficina en remodelación con 300 puntos de red.

- Renovación por obsolescencia de la red wifi de la Facultad de Medicina y Ciencias de la Salud. ampliación de densidad para 6 AP en las sedes Campus y Bogotá. La instalación incluye licencias.

- Dotación de sistema de video conferencia para auditorios.

- Implementación de portal web corporativo UMNG, con micrositios, soporte de seguridad más optimización.

- Implementación y puesta en marcha del sistema de Gestión de Identidad.

La cualificación y desarrollo profesional: docentes y administrativos, en la cual se presentaron varias actividades de capacitación formal y no formal como se especifica a continuación.

\section{Educación formal}

La División de Gestión del Talento Humano tiene como fundamento el avanzar en el proceso de crecimiento y cualificación profesional determinando, a partir del conjunto 
de las competencias institucionales, el perfil necesario tanto de docentes como administrativos. Ello con el fin de focalizar el quehacer y la transformación institucional en la generación de cambios y de prácticas innovadoras. Asimismo, ha conformado comités de asignación de cupos para los docentes y administrativos de la UMNG.

- Formación de administrativos; comité: ocho funcionarios con apoyo.

- Formación de administrativos en proceso: 27 funcionarios con apoyo.

- Formación de docentes; comité: tres funcionarios con apoyo.

- Formación de docentes en proceso: trece funcionarios con apoyo.

Educación para el trabajo y el desarrollo humano

\section{GRI 102-8}

La Capacitación para el Trabajo y el Desarrollo Humano se aplica a los docentes de carrera y administrativos de carrera que cumplan con los requisitos estipulados en la normatividad; mediante cupos distribuidos estratégicamente en cada vigencia, con el fin de lograr en el personal que trabaja en la universidad la más alta calidad profesional, científica y administrativa, desarrollando todas sus capacidades como contribución a un mejor desarrollo institucional. 
La División de Gestión del Talento Humano desarrolló las tareas establecidas mediante ejes como se muestra a continuación.

- Eje Administrativo: se realizó la capacitación de 173 funcionarios.

- Eje de Sistemas de gestión: se realizó la capacitación de 268 funcionarios.

- Eje de Internacionalización: se realizó capacitación de 24 funcionarios.

- Eje de Gestión de investigaciones: se realizó la capacitación de 28 funcionarios.

- Eje de Gestión del cambio: se realizó capacitación de 48 funcionarios.

- Eje de Pedagogía y didáctica: se realizó la capacitación de 129 funcionarios.

- Eje de Tic, Tac, Tep: se realizó la capacitación de 27 funcionarios.

- Eje de Gestión académica: se realizó la capacitación de 453 funcionarios.

- Eje de Seguridad social: se realizó la capacitación de 8 funcionarios.

- Eje de Gestión documental: se realizó la capacitación de 74 funcionarios.

- Eje de Plan de retiro: se realizó la capacitación de 20 funcionarios. 
- Eje de Evaluación del desempeño: se realizó la capacitación de 44 funcionarios.

El Sistema Integrado de Gestión Institucional, con el desarrollo de las siguientes actividades:

- Proyecto de innovación social.

- Actualización de normas de la Vicerrectoría Administrativa.

TABLA 10. Principales acciones desarrolladas en el Plan de desarrollo institucional

\section{Para el Objetivo estratégico 3}

Las dinámicas de cualificación institucional, ya sea el número de programas acreditados, y la cantidad de estudiantes matriculados, los docentes con formación avanzada, de los artículos indexados en revistas reconocidas internacionalmente, la cantidad y calidad de los laboratorios, entre otros, han obligado a las Instituciones de Educación Superior (IIE) a formular estrategias de cualificación permanente que les permitan enfrentar con éxito los procesos de calidad.

Fuente: Sección de planes y proyectos especiales de la Oficina asesora de direccionamiento estratégico e inteligencia competitiva.

La consolidación de la acreditación de calidad en la institución, en la cual se tenía previsto el desarrollo de las siguientes actividades: elaboración de informes de evaluación, autoevaluación institucional con fines de re-acreditación 2021, jornadas de socialización, plan de mejoramiento y desarrollo del programa Saber Pro. 
Desarrollo del plan de mejoramiento 2018-2019

La Oficina de Acreditación Institucional estableció las tareas del plan de mejoramiento institucional con sus responsables, dentro de la matriz diseñada para elaborar el seguimiento a su cumplimiento para las vigencias 2019 y 2020, con objeto de realizar seguimiento a las acciones de cada uno de los factores para consolidar el cumplimiento de las actividades programadas. Estas son:

- Reestructuración del modelo de evaluación del desempeño de personal docente e informe de seguimiento de evaluación del desempeño docente.

- Avances en el uso de lenguas extranjeras.

- Análisis y seguimiento de los resultados en las pruebas Saber pro.

- Seguimiento a resultados de deserción y permanencia estudiantil.

- Planificación de actividades en el plan de mejoramiento.

- Recolección de información acerca del desarrollo de actividades del plan de mejoramiento. institucional. Apoyo en actividades de autoevaluación.

- Jornada de reflexión sobre reacreditación de multicampus.

- Jornadas de socialización con profesores, estudiantes, egresados, funcionarios administrativos, directivos, 
investigadores y responsables de convenios y proyectos de desarrollo social ligados a la universidad.

\section{Hacia la excelencia académica}

El modelo Saber Pro unNG - Hacia la excelencia académica se diseñó con el propósito de mejorar el desempeño de los estudiantes en las pruebas Saber Pro; este se encuentra integrado por tres ejes (currículo, estudiantes y profesores) y tres estrategias (reconocimiento institucional Saber Pro, relación curricular Saber Pro y formulación de políticas Saber Pro); se tienen los siguientes avances:

- Licencia Wiris Math.

- Caracterización de ingreso de estudiantes.

- Competencias genéricas estratégicas.

Acreditación internacional del programa de Administración de Empresas

\section{GRI 102-13}

Como objetivo principal la universidad trabaja mancomunadamente para obtener la certificación internacional (ACBSP) Accreditation Council for Business Schools and Programs para el programa de administración de empresas. Para lograrlo se realizó el trámite correspondiente para la afiliación como miembro de la ACBSP, se efectuó el pago requerido para la aceptación como miembro, se 
diligenciaron y firmaron los formatos de afiliación exigidos por la entidad y se anexaron los documentos requeridos.

La gestión y evaluación macro y micro curricular con base en competencias, en la cual se presentaron diversas actividades como se especifica a continuación.

- Definición de la Política Curricular de la umng.

- Documentación de referentes curriculares por competencias en la UMNG y de referentes para la evaluación por competencias en la UMNG y logro de la impregnación curricular de los referentes pedagógicos y de formación por competencias y de los referentes para la evaluación por competencias en las Facultades de la UMNG.

TABLA 11. Principales acciones desarrolladas en el plan de desarrollo institucional

\section{Para el Objetivo estratégico 4}

La relación entre conocimientos e investigación, y el efecto que esta ejerce en los componentes curriculares, es en sentido estricto lo que diferencia a un proceso innovador de aquel que solo intenta serlo. Por ello es importante tener claro cuál es el campo de actuación de la institución como un ente que genera conocimiento, pues es este el que da origen a distintas dinámicas en torno a la innovación en la transformación del conocimiento.

Fuente: Sección de planes y proyectos especiales de la Oficina asesora de direccionamiento estratégico e inteligencia competitiva.

Fortalecimiento del Sistema de Ciencia Tecnología e Innovación; presenta un avance cuantitativo de 100\%. En él participaron los siguientes proyectos: 


\section{GRI 102-15}

- 186 proyectos de iniciación científica.

- 2 jóvenes investigadores Colciencias.

- 65 proyectos de investigación científica.

- 15 proyectos de alto impacto.

- 10 revistas de facultades.

- Asistentes graduados.

\section{Gestión del riesgo y calidad}

\section{GRI 102-11}

Alineación de los objetivos
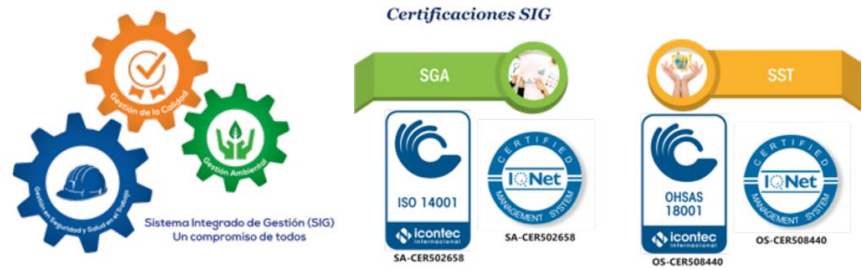

Certificaciones SIG
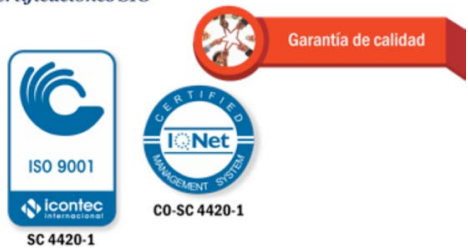

FIGURA 8. Certificaciones sistema integral de gestión. Fuente: División de gestión de calidad (Universidad Militar Nueva Granada, s. f.). 


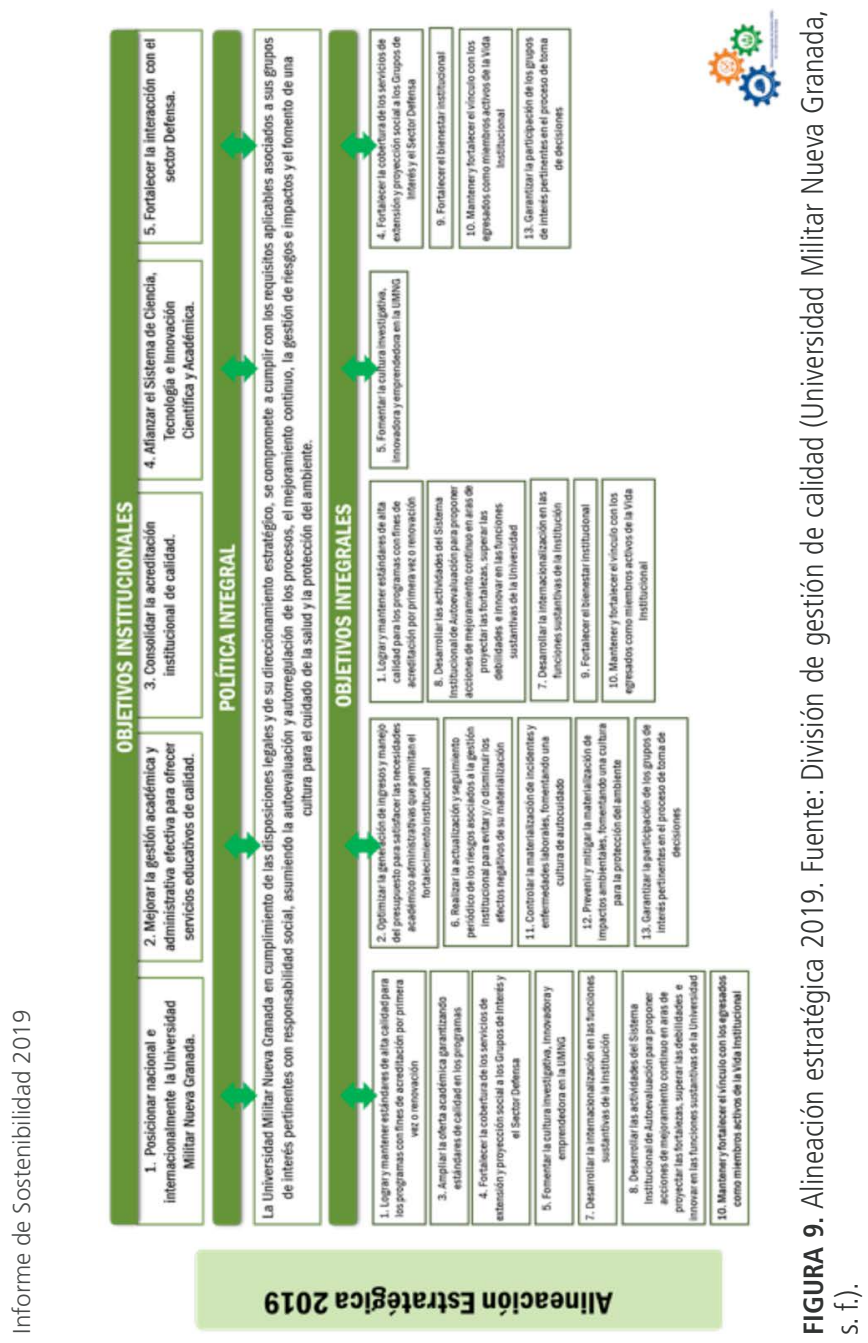


TABLA 12. Objetivos integrales

\begin{tabular}{|c|c|c|}
\hline Indicadores asociados a los objetivos integrales & Cantidad & Porcentaje \\
\hline Eficiencia & 1 & $2,70 \%$ \\
\hline Efectividad & 36 & $97,30 \%$ \\
\hline Total & 37 & $100,00 \%$ \\
\hline
\end{tabular}

Fuente: División de gestión de calidad.

\section{Mapa de macroprocesos}
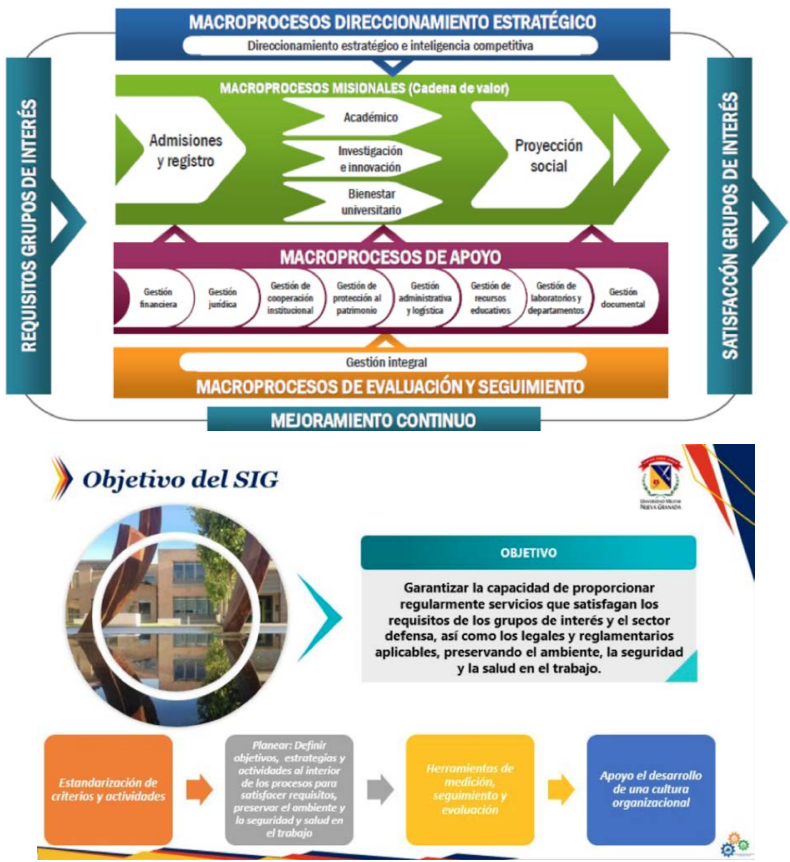

FIGURA 10. Objetivos del sistema integral de gestión. Fuente: División de gestión de calidad, Presentación del Sistema Integrado de Gestión (Universidad Militar Nueva Granada, s. f.). 
TABLA 13. Documentos del Sistema Integrado de Gestión

\begin{tabular}{|l|c|}
\hline \# normogramas & 31 \\
\hline \# Caracterizaciones & 31 \\
\hline \# Manuales & 24 \\
\hline \# Procedimientos & 146 \\
\hline \# Planes & 13 \\
\hline \# Programas & 5 \\
\hline \# Protocolos & 20 \\
\hline \# Instructivos & 21 \\
\hline \# Formatos & 342 \\
\hline Total de documentos & 633 \\
\hline
\end{tabular}

Fuente: División de gestión de calidad.

TABLA 14. Auditorías Internas

\begin{tabular}{|l|c|}
\hline \# jornadas de auditoría & 51 \\
\hline \# auditorías con cumplimiento oportuno & 51 \\
\hline$\%$ de cumplimiento & $100 \%$ \\
\hline
\end{tabular}

Fuente: División de gestión de calidad.

TABLA 15. Hallazgos del Sistema Integral de Gestión (sIG):

\begin{tabular}{|c|c|}
\hline \# Fortalezas & 216 \\
\hline \# No conformidades & 318 \\
\hline \# Observaciones & 56 \\
\hline \# Procesos con no conformidades sistema de gestión de la calidad sGC & 13 \\
\hline \# Procesos con no conformidades sistema de gestión ambiental sGA & 5 \\
\hline $\begin{array}{l}\text { \# Procesos con no conformidades sistema de gestión de seguridad } \\
\text { y salud en el trabajo SGSST }\end{array}$ & 10 \\
\hline
\end{tabular}

Fuente: División de gestión de calidad. 
TABLA 16. Auditoría externa - Instituto Colombiano de Normas Técnicas y Certificación (Icontec)

\begin{tabular}{|l|c|c|}
\hline Hallazgos: & & \\
\hline \# Fortalezas & 42 & para SGC, SGA y SGSST \\
\hline \# No conformidades & 5 & para SGC, SGA y SGSST \\
\hline \# Observaciones & 22 & para SGC, SGA y SGSST \\
\hline \# Procesos con no conformidades & 4 & para SGC, SGA y SGSST \\
\hline
\end{tabular}

Fuente: División de gestión de calidad.

TABLA 17. Indicadores de gestión

\begin{tabular}{|l|c|}
\hline \# indicadores del Sistema Integrado de Gestión & 160 \\
\hline Porcentaje de cumplimiento de metas asociadas a los indicadores & $86,36 \%$ \\
\hline
\end{tabular}

Fuente: División de gestión de calidad.

TABLA 18. Indicadores de gestión por tipo y por año

\begin{tabular}{|l|r|r|r|r|r|}
\hline \multicolumn{1}{|c|}{ Tipo de Indicador } & \multicolumn{1}{c|}{2015} & \multicolumn{1}{c|}{2016} & \multicolumn{1}{c|}{2017} & \multicolumn{1}{c|}{2018} & \multicolumn{1}{c|}{2019} \\
\hline Eficacia & 58 & 50 & 50 & 53 & 51 \\
\hline Eficiencia & 26 & 27 & 22 & 22 & 25 \\
\hline Efectividad & 26 & 35 & 41 & 51 & 51 \\
\hline Total & 110 & 112 & 113 & 126 & 127 \\
\hline
\end{tabular}

Fuente: División de gestión de calidad.

TABLA 19. Salidas no conformes

\begin{tabular}{|l|c|}
\hline \multicolumn{1}{|c|}{ Se identifican } & \\
\hline \# servicios no conformes & 23 \\
\hline \# servicios no conformes con tratamiento y cerrados & 0 \\
\hline
\end{tabular}

Fuente: División de gestión de calidad. 
Para 2019-2 con el procedimiento actualizado se identificaron 23 Sistema de Gestión de la Calidad SNC de las cuales se han materializado 0.

TABLA 20. Servicios no conformes identificados y cerrados por el año

\begin{tabular}{|l|c|c|c|c|c|}
\hline \multicolumn{1}{|c|}{ Concepto } & 2015 & 2016 & 2017 & 2018 & 2019 \\
\hline Identificado & 70 & 75 & 79 & 81 & 23 \\
\hline Cerrado & 55 & 74 & 79 & 81 & 23 \\
\hline Abierto & 15 & 1 & 0 & 0 & 0 \\
\hline Total & 70 & 75 & 79 & 81 & 23 \\
\hline
\end{tabular}

Fuente: División de gestión de calidad.

A partir del año 2019 se modifican el procedimiento, alcance y criterio de las salidas no conformes.

TABLA 21. Planes de mejoramiento

\begin{tabular}{|l|c|c|c|c|}
\hline \multicolumn{1}{|c|}{ Resumen 2019} & $\begin{array}{c}\text { SGC: ISO } \\
9001\end{array}$ & $\begin{array}{c}\text { SGA: ISO } \\
14001\end{array}$ & $\begin{array}{c}\text { Salud y seguridad } \\
\text { en el trabajo SYSO } \\
\text { occupational } \\
\text { health and safety } \\
\text { assessment series } \\
\text { OHSAS } 18001\end{array}$ & Integrales \\
\hline Acciones correctivas & 36 & 15 & 20 & 0 \\
\hline Acciones de mejora & 38 & 11 & 5 & 0 \\
\hline Total & 74 & 26 & 25 & 0 \\
\hline
\end{tabular}

Fuente: División de gestión de calidad. 
Gestión del riesgo 2019

\section{GRI 102-15}

Fomentar el control de los riesgos institucionales mediante la implementación de un procedimiento para realizar seguimiento a los controles, actualización y documentación de actividades y planes de mejoramiento de la gestión del riesgo institucional; también el uso de herramientas que conforman el sistema de administración del riesgo, evaluando el impacto del dinamismo interno, rapidez del cambio y cultura organizacional en el contexto organizacional y realizando los informes pertinentes solicitados por las diferentes oficinas en relación con la gestión de riesgos.

Disponer que todas las actividades, proyectos y procesos deben tener un análisis planificado de cambio con su correspondiente análisis de riesgos y oportunidades, articulando la materialización de las salidas no conformes de los procesos con la gestión del riesgo.

Establecer las fases estructuradas para determinar y gestionar los cambios estratégicos de alto impacto y los conocimientos en la Universidad Militar Nueva Granada, de forma planificada y sistemática, a fin de cumplir con los objetivos planteados generando valor agregado en la gestión estratégica institucional. 
Situación actual gestión del riesgo 2019

\begin{tabular}{|l|c|c|}
\hline \multirow{2}{*}{ ZONA DE RIESGO } & $\mathbf{2 0 1 8}$ & $\mathbf{2 0 1 9}$ \\
\cline { 2 - 3 } & $\begin{array}{c}\text { RIESGO } \\
\text { INHERENTE }\end{array}$ & $\begin{array}{c}\text { RIESGO } \\
\text { INHERENTE }\end{array}$ \\
\hline ZONA EXTREMA & 14 & 12 \\
\hline ZONA ALTA & 34 & 30 \\
\hline ZONA MODERADA & 13 & 25 \\
\hline ZONA BAJA & 1 & 3 \\
\hline Total & 62 & 70 \\
\hline
\end{tabular}

\begin{tabular}{|l|c|c|}
\hline ZONA DE RIESGO & $\begin{array}{c}\mathbf{2 0 1 8} \\
\text { RIESGO } \\
\text { RESIDUAL }\end{array}$ & $\begin{array}{c}\text { 2019 } \\
\text { RIESGO } \\
\text { RESIDUAL }\end{array}$ \\
\hline ZONA EXTREMA & 0 & 0 \\
\hline ZONA ALTA & 0 & 7 \\
\hline ZONA MODERADA & 18 & 15 \\
\hline ZONA BAJA & 44 & 48 \\
\hline Total & 62 & 70 \\
\hline
\end{tabular}

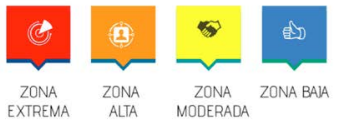

FIGURA 11. Situación actual gestión del riesgo 2019. Fuente: Sección gestión para el cambio y el conocimiento de la oficina asesora de direccionamiento estratégico e inteligencia competitiva. 


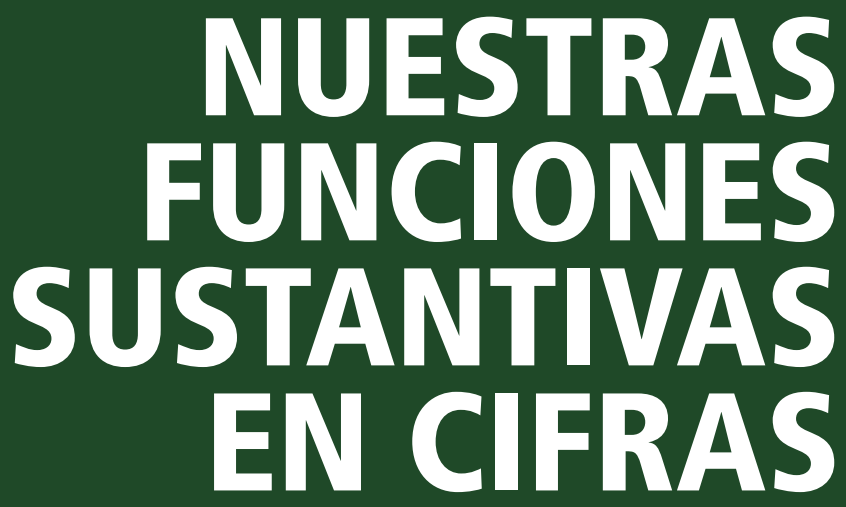





\section{GRI 102-2}

\section{Gestión de la academia}

GRI 102-6

\section{Soplos} cardiacos/ Patologia
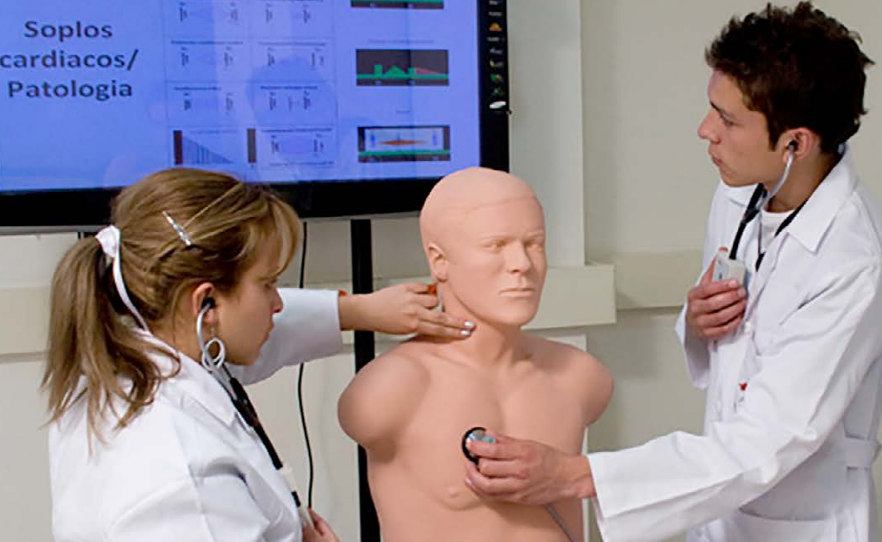
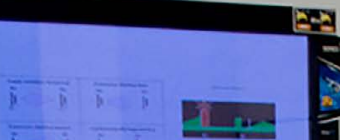


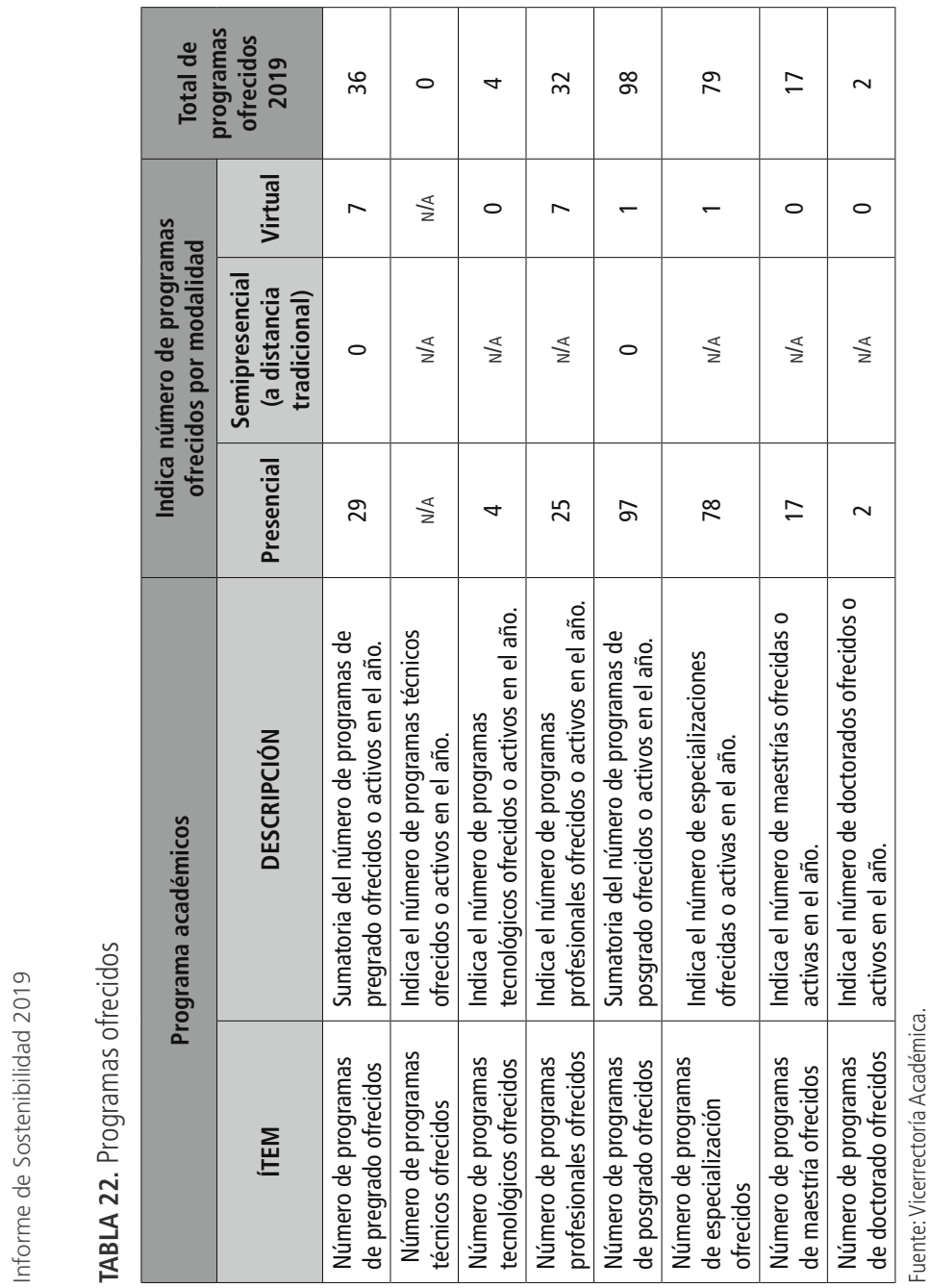




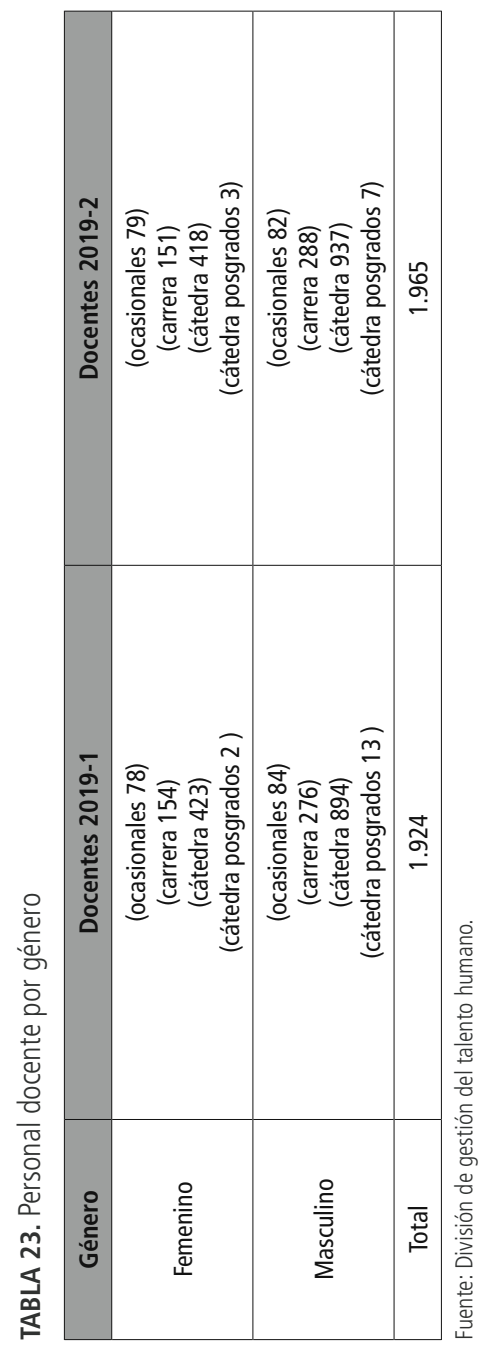

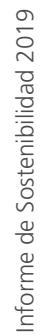




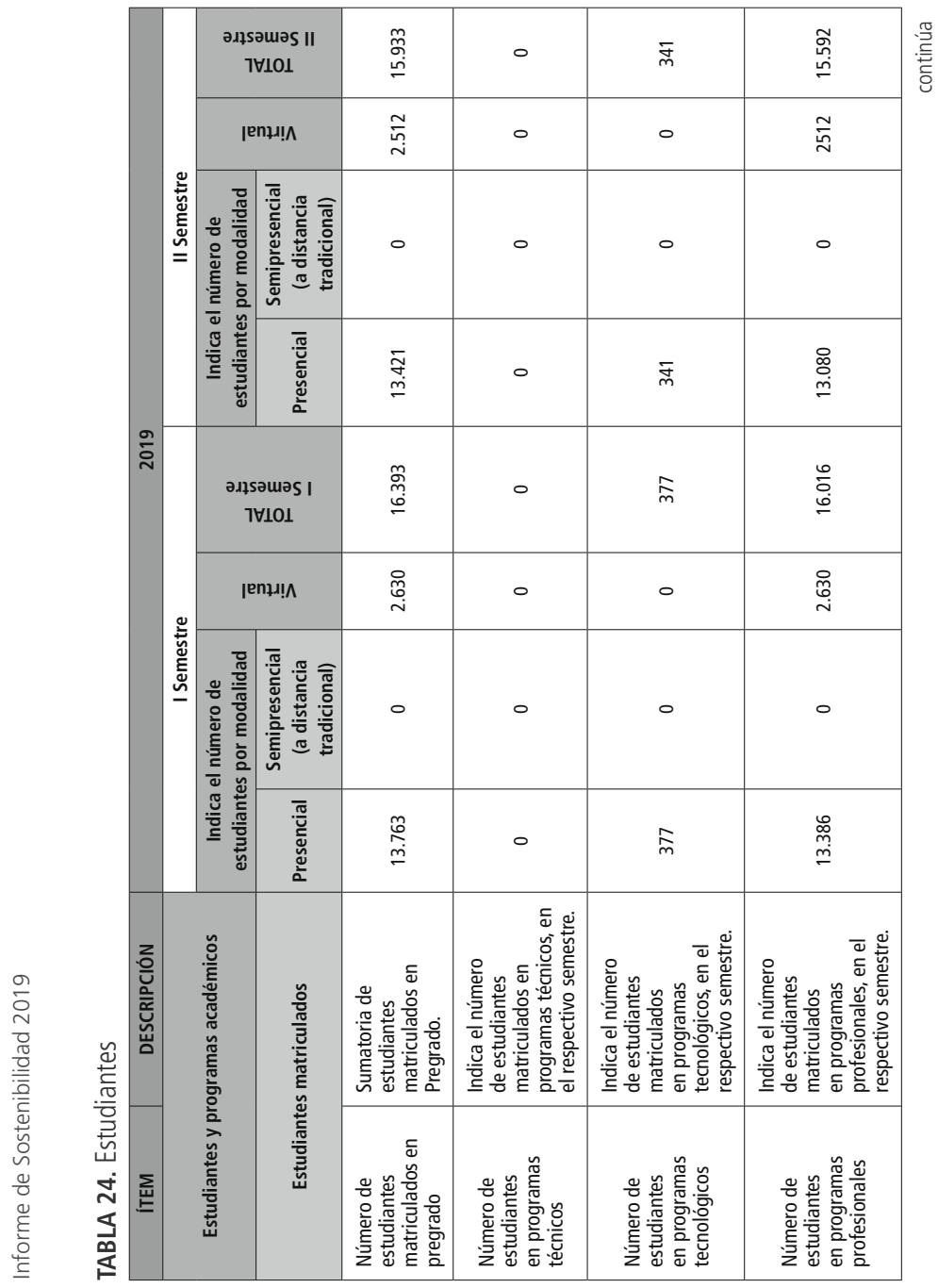




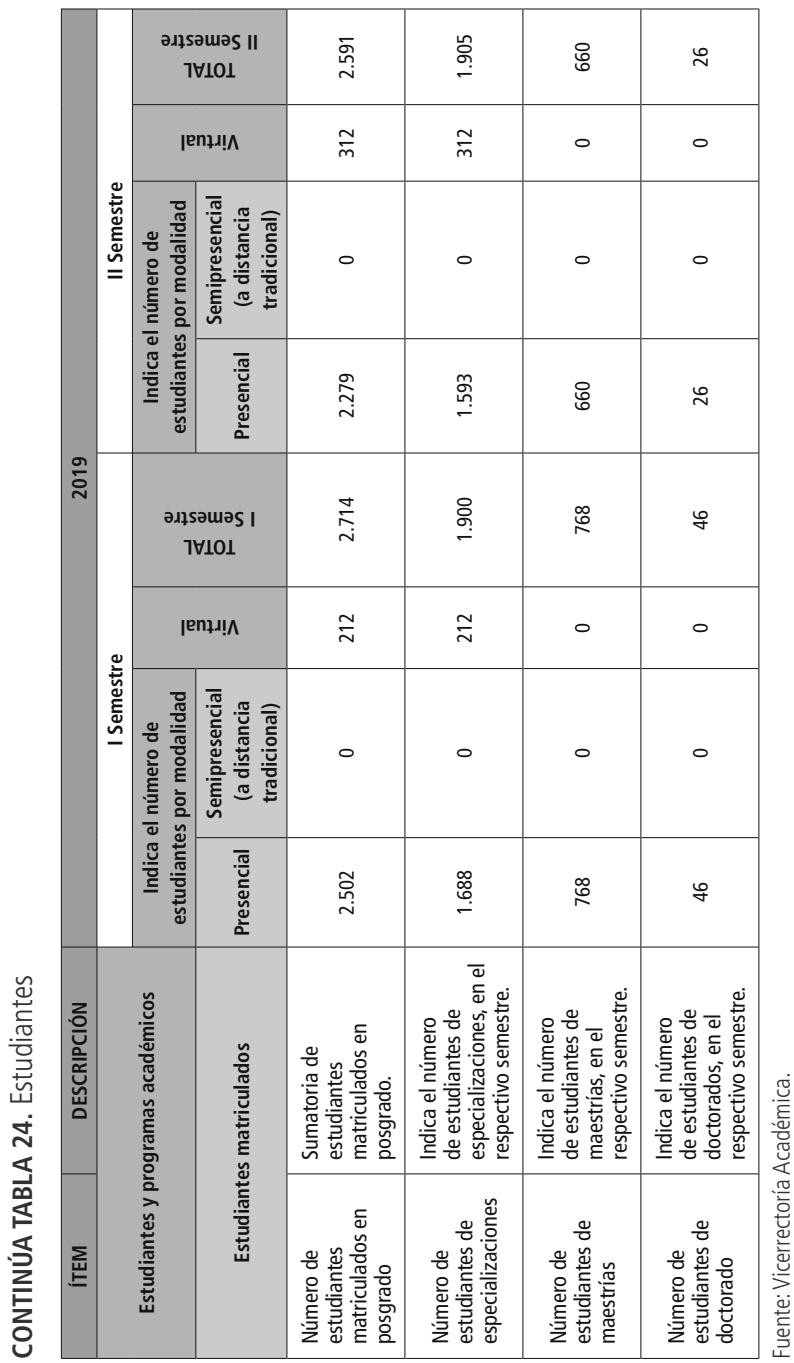

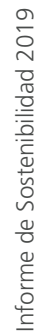


TABLA 25. Estudiantes graduados

\begin{tabular}{|c|c|c|}
\hline \multicolumn{3}{|c|}{ Estudiantes graduados } \\
\hline Ítem & Descripción & 2019 \\
\hline $\begin{array}{l}\text { Número de estudiantes de } \\
\text { pregrado graduados año }\end{array}$ & $\begin{array}{l}\text { Indica el número de estudiantes } \\
\text { graduados en la vigencia } 2019 \text { en } \\
\text { programas de pregrado. }\end{array}$ & 2.283 \\
\hline $\begin{array}{l}\text { Número de estudiantes de } \\
\text { posgrado graduados año }\end{array}$ & $\begin{array}{l}\text { Indica el número de estudiantes } \\
\text { graduados en la vigencia } 2019 \text { en } \\
\text { programas de posgrado. }\end{array}$ & 1.818 \\
\hline Ítem & Descripción & $\begin{array}{l}\text { Acumulado } \\
\text { hasta } 2019\end{array}$ \\
\hline $\begin{array}{l}\text { Número total de } \\
\text { estudiantes de pregrado } \\
\text { graduados (acumulado) }\end{array}$ & $\begin{array}{l}\text { Indica el número total de } \\
\text { estudiantes graduados en la } \\
\text { universidad en programas de } \\
\text { pregrado. (Acumulado de todos los } \\
\text { años incluyendo la vigencia 2019) }\end{array}$ & 26.858 \\
\hline $\begin{array}{l}\text { Número total de } \\
\text { estudiantes de posgrado } \\
\text { graduados (acumulado) }\end{array}$ & $\begin{array}{l}\text { Indica el número total de } \\
\text { estudiantes graduados en la } \\
\text { universidad en programas de } \\
\text { posgrado. (Acumulado de todos los } \\
\text { años incluyendo la vigencia 2019) }\end{array}$ & 24.209 \\
\hline
\end{tabular}

Fuente: Vicerrectoría Académica.

TABLA 26. Personal

\begin{tabular}{|c|c|c|c|}
\hline Tipo & Femenino & Masculino & TOTAL \\
\hline Administrativos & 453 & 346 & 799 \\
\hline Supernumerarios & 4 & 2 & 6 \\
\hline Trabajador oficial & 4 & 13 & 17 \\
\hline Contratos por prestación de servicios & 6 & 11 & 17 \\
\hline Orden de prestación de servicios & 307 & 507 & 814 \\
\hline Total & 774 & 879 & 1.653 \\
\hline
\end{tabular}

Fuente: Vicerrectoría Académica. 
TABLA 27. Investigación

\begin{tabular}{|c|c|c|}
\hline Ítem & Descripción & 2019 \\
\hline $\begin{array}{l}\text { Total de grupos de } \\
\text { investigación }\end{array}$ & $\begin{array}{l}\text { Indica el número total de grupos de investigación } \\
\text { conformados formalmente en la universidad }\end{array}$ & 70 \\
\hline $\begin{array}{l}\text { Grupos de investigación } \\
\text { reconocidos por } \\
\text { Colciencias }\end{array}$ & $\begin{array}{l}\text { Sumatoria que indica el número total de grupos } \\
\text { de investigación conformados formalmente en } \\
\text { la universidad y reconocidos por Colciencias } \\
\text { (Convocatoria } 833 \text { de 2018) }\end{array}$ & 64 \\
\hline Número de grupos A1 & $\begin{array}{l}\text { Indica el número de grupos clasificados en } \\
\text { categoría A1. }\end{array}$ & 5 \\
\hline Número de grupos $\mathrm{A}$ & $\begin{array}{l}\text { Indica el número de grupos clasificados en } \\
\text { categoría A. }\end{array}$ & 7 \\
\hline Número de grupos B & $\begin{array}{l}\text { Indica el número de grupos clasificados en } \\
\text { categoría B. }\end{array}$ & 12 \\
\hline Número de grupos $C$ & $\begin{array}{l}\text { Indica el número de grupos clasificados en } \\
\text { categoría C. }\end{array}$ & 39 \\
\hline $\begin{array}{l}\text { Número de grupos } \\
\text { reconocidos no } \\
\text { categorizados }\end{array}$ & $\begin{array}{l}\text { Indica el número de grupos no categorizados pero } \\
\text { reconocidos por Colciencias. }\end{array}$ & 1 \\
\hline $\begin{array}{l}\text { Número de docentes } \\
\text { investigadores }\end{array}$ & $\begin{array}{l}\text { Sumatoria que indica el número total de } \\
\text { investigadores reconocidos por Colciencias }\end{array}$ & 199 \\
\hline $\begin{array}{l}\text { Número de } \\
\text { investigadores emérito }\end{array}$ & $\begin{array}{l}\text { Indica el número de investigadores clasificados } \\
\text { como emérito }\end{array}$ & 0 \\
\hline $\begin{array}{l}\text { Número de } \\
\text { investigadores senior }\end{array}$ & $\begin{array}{l}\text { Indica el número de investigadores clasificados } \\
\text { como senior }\end{array}$ & 14 \\
\hline $\begin{array}{l}\text { Número de } \\
\text { investigadores asociado }\end{array}$ & $\begin{array}{l}\text { Indica el número de investigadores clasificados } \\
\text { como asociado }\end{array}$ & 56 \\
\hline $\begin{array}{l}\text { Número de } \\
\text { investigadores junior }\end{array}$ & $\begin{array}{l}\text { Indica el número de investigadores clasificados } \\
\text { como junior }\end{array}$ & 129 \\
\hline $\begin{array}{l}\text { Revistas indexadas por } \\
\text { Colciencias }\end{array}$ & $\begin{array}{l}\text { Indica el número de revistas de la universidad } \\
\text { indexadas por Colciencias. }\end{array}$ & 7 \\
\hline $\begin{array}{l}\text { Artículos publicados en } \\
\text { revistas indexadas }\end{array}$ & $\begin{array}{l}\text { Indica el número de artículos publicados por } \\
\text { docentes o funcionarios de la universidad en } \\
\text { revistas indexadas. }\end{array}$ & 31 \\
\hline $\begin{array}{l}\text { Artículos publicados } \\
\text { en los índex } \\
\text { internacionales }\end{array}$ & $\begin{array}{l}\text { Indica el número de artículos publicados por } \\
\text { docentes o funcionarios de la universidad en } \\
\text { revistas científicas e índices internacionales. }\end{array}$ & 101 \\
\hline
\end{tabular}

Fuente: Vicerrectoría de Investigaciones. 
TABLA 28. Propiedad intelectual

\begin{tabular}{|l|l|c|c|}
\hline \multicolumn{2}{|c|}{ Propiedad intelectual } & Nacional & Internacional \\
\hline Otorgados & $\begin{array}{l}\text { Sumatoria del número de patentes, } \\
\text { diseños industriales, marcas y } \\
\text { otros otorgados. }\end{array}$ & 3 & 0 \\
\hline $\begin{array}{l}\text { Número de patentes } \\
\text { de invención } \\
\text { otorgadas }\end{array}$ & $\begin{array}{l}\text { Indica el número de patentes de } \\
\text { invención que han sido otorgadas } \\
\text { a la universidad hasta la fecha. }\end{array}$ & 3 & 0 \\
\hline En trámite & $\begin{array}{l}\text { Sumatoria del número de patentes, } \\
\text { diseños industriales, marcas y } \\
\text { otros en trámite. }\end{array}$ & 1 & 0 \\
\hline $\begin{array}{l}\text { Número de Patentes } \\
\text { de invención en } \\
\text { trámite }\end{array}$ & $\begin{array}{l}\text { Indica el número de patentes de } \\
\text { invención que se encuentran en } \\
\text { trámite por parte de la institución. }\end{array}$ & 1 & 0 \\
\hline
\end{tabular}

Fuente: Vicerrectoría de Investigaciones.

\section{TABLA 29. Acreditación y calidad}

\begin{tabular}{|c|c|c|}
\hline \multicolumn{3}{|c|}{ Acreditación y Calidad } \\
\hline ÍTEM & DESCRIPCIÓN & 2019 \\
\hline $\begin{array}{l}\text { Universidad con } \\
\text { acreditación } \\
\text { institucional }\end{array}$ & $\begin{array}{l}\text { Indica si la universidad cuenta con el } \\
\text { reconocimiento de acreditación institucional de } \\
\text { alta calidad }\end{array}$ & sí \\
\hline $\begin{array}{l}\text { Fecha de acreditación } \\
\text { institucional }\end{array}$ & $\begin{array}{l}\text { Indica la fecha en que la universidad recibió } \\
\text { la acreditación de alta calidad }\end{array}$ & $\begin{array}{c}16 \text { de } \\
\text { julio } \\
\text { de } \\
2015\end{array}$ \\
\hline $\begin{array}{l}\text { Número de años de } \\
\text { acreditación institucional }\end{array}$ & $\begin{array}{l}\text { Indica el número de años por los que le fue } \\
\text { otorgada la acreditación de alta calidad }\end{array}$ & 6 \\
\hline $\begin{array}{l}\text { Universidad con } \\
\text { acreditación } \\
\text { internacional }\end{array}$ & $\begin{array}{l}\text { Indica si la universidad cuenta con el } \\
\text { reconocimiento de acreditación internacional }\end{array}$ & No \\
\hline $\begin{array}{l}\text { Número de programas de } \\
\text { pregrado acreditados }\end{array}$ & $\begin{array}{l}\text { Indica el número de programas de pregrado } \\
\text { acreditados }\end{array}$ & 13 \\
\hline $\begin{array}{l}\text { Número de programas de } \\
\text { pregrado acreditables }\end{array}$ & $\begin{array}{l}\text { Indica el número de programas de pregrado } \\
\text { acreditables (que pueden ser acreditados) }\end{array}$ & 23 \\
\hline
\end{tabular}




\begin{tabular}{|l|l|c|}
\hline \multicolumn{2}{|c|}{ ÍTEM } & \multicolumn{1}{|c|}{ DESCRIPCIÓN } \\
\hline $\begin{array}{l}\text { Número de programas de } \\
\text { posgrado acreditables }\end{array}$ & $\begin{array}{l}\text { Indica el número de programas de posgrado } \\
\text { acreditables (que pueden ser acreditados) }\end{array}$ & 34 \\
\hline $\begin{array}{l}\text { Número de programas de } \\
\text { pregrado en proceso de } \\
\text { acreditación }\end{array}$ & $\begin{array}{l}\text { Indica el número de programas de pregrado en } \\
\text { proceso de acreditación }\end{array}$ & 8 \\
\hline $\begin{array}{l}\text { Número de programas de } \\
\text { posgrado en proceso de } \\
\text { acreditación }\end{array}$ & $\begin{array}{l}\text { Indica el número de programas de posgrado en } \\
\text { proceso de acreditación }\end{array}$ & 22 \\
\hline $\begin{array}{l}\text { Número de laboratorios } \\
\text { acreditados }\end{array}$ & $\begin{array}{l}\text { Indica el número de laboratorios de la } \\
\text { universidad acreditados }\end{array}$ & No \\
\hline $\begin{array}{l}\text { Universidad con } \\
\text { certificación de gestión } \\
\text { de calidad }\end{array}$ & $\begin{array}{l}\text { Indica si la universidad para el respectivo año } \\
\text { contaba con Certificación de Gestión de Calidad } \\
\text { o Norma de Gestión Pública NTCGP 1000 }\end{array}$ & Sí \\
\hline
\end{tabular}

Fuente: Oficina de Acreditación Institucional.

TABLA 30. Internacionalización

\begin{tabular}{|l|l|c|}
\hline \multicolumn{1}{|c|}{ ÍTEM } & \multicolumn{1}{|c|}{ DESCRIPCIÓN } & 2019 \\
\hline $\begin{array}{l}\text { Movilidad } \\
\text { estudiantes } \\
\text { colombianos }\end{array}$ & $\begin{array}{l}\text { Indica el número de estudiantes de la universidad que se } \\
\text { desplazaron a otros países a realizar prácticas, pasantías, } \\
\text { intercambios o capacitaciones. }\end{array}$ & 394 \\
\hline $\begin{array}{l}\text { Movilidad } \\
\text { estudiantes } \\
\text { extranjeros }\end{array}$ & $\begin{array}{l}\text { Indica el número de estudiantes de otros países que } \\
\text { se desplazaron a la universidad a realizar prácticas, } \\
\text { pasantías, intercambios o capacitaciones. }\end{array}$ & 34 \\
\hline $\begin{array}{l}\text { Movilidad } \\
\text { docentes }\end{array}$ & $\begin{array}{l}\text { Indica el número de docentes de la universidad que se } \\
\text { desplazaron a otros países a realizar prácticas, pasantías, } \\
\text { intercambios o capacitaciones. }\end{array}$ & 111 \\
\hline $\begin{array}{l}\text { Movilidad } \\
\text { funcionarios } \\
\text { administrativos }\end{array}$ & $\begin{array}{l}\text { Indica el número de funcionarios administrativos de la } \\
\text { universidad que se desplazaron a otros países a realizar } \\
\text { prácticas, pasantías, intercambios o capacitaciones. }\end{array}$ & 13 \\
\hline
\end{tabular}

Fuente: Oficina de relaciones internacionales. 



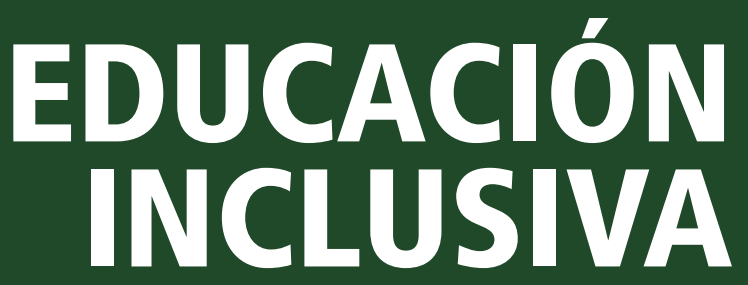





\section{CONTENIDO}

78 Proceso de Admisiones y Registro Académico 2019

82 Población estudiantil

84 Bienestar Universitario

90 Reconocimiento de la excelencia académica

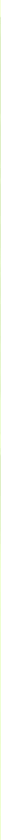


Enuchets

DeCLIDS पli
GRI 103-1

GRI 103-2

GRI 103-3

\section{Proceso de Admisiones y Registro Académico 2019}

El proceso de admisión de estudiantes nuevos a los diferentes programas académicos de pregrado y posgrado de la Universidad Militar Nueva Granada se encuentra definido por criterios de admisión acordes con las competencias establecidas para las diferentes áreas del conocimiento.

Este proceso incluye inscripción, selección, admisión efectiva y matrícula de los interesados, de conformidad con lo dispuesto por los reglamentos generales estudiantiles de pregrado y posgrado.

Admisión de nuevos estudiantes

Los procesos de admisión durante el 2019 para los diferentes niveles de formación en la UMNG, se dieron como se muestra en la Tabla 31. 


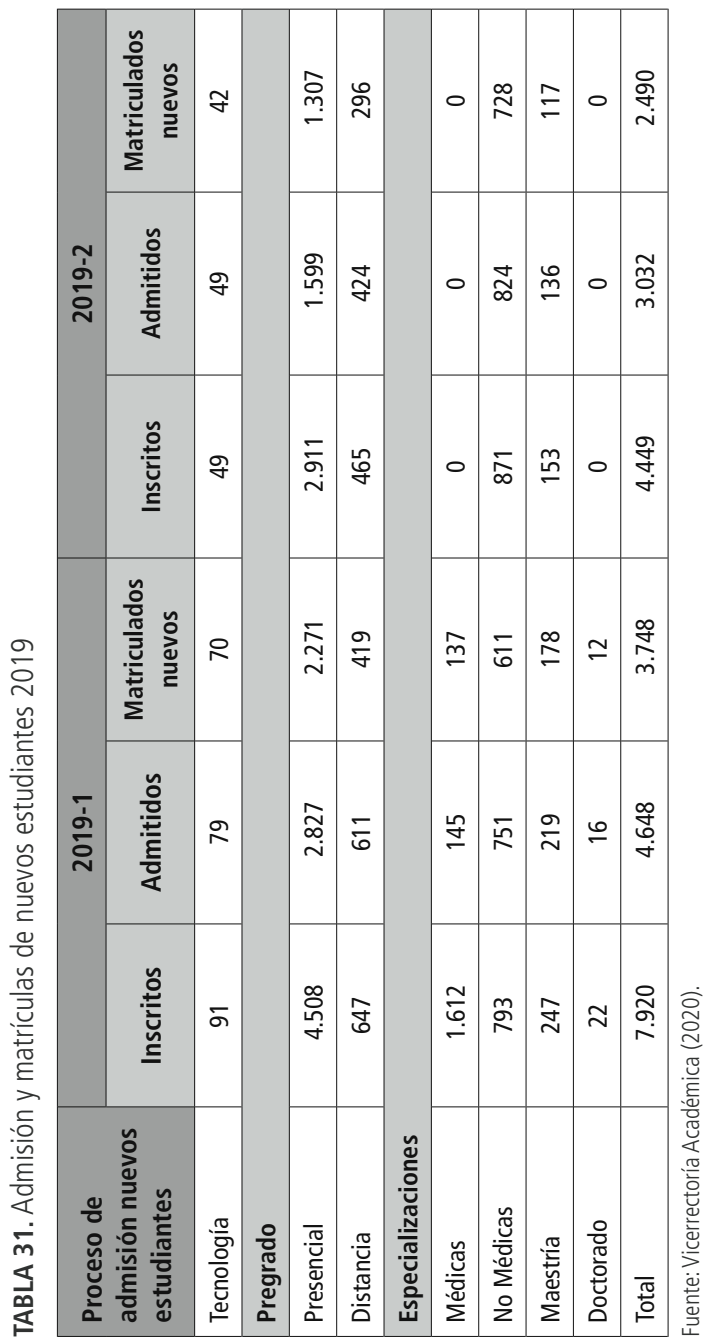


Institucionalmente el proceso de admisiones y matrículas para estudiantes nuevos presentó el comportamiento general que se puede evidenciar en la Figura 12.

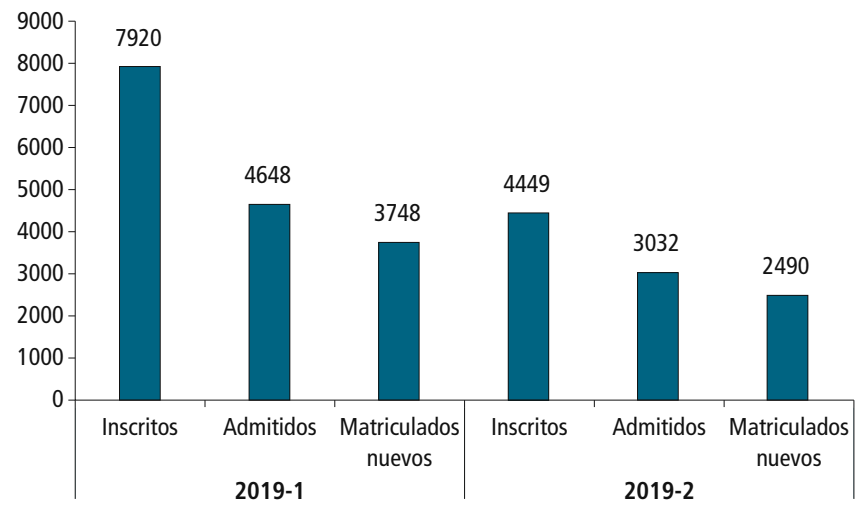

FIGURA 12. Admisión y matrículas de nuevos estudiantes 2019. Fuente: Vicerrectoría Académica (2020).

Indicadores de selectividad y absorción

En las Tablas 32 y 33 se registran los resultados de los indicadores Índice de Selectividad e Índice de Absorción para cada uno de los períodos académicos del 2019, con base en los siguientes criterios:

Índice de selectividad: dato porcentual resultado de dividir el número de admitidos entre el total de apoblación inscrita para un período académico. 
Índice de absorción: dato porcentual resultado de dividir el número de matriculados entre el número de admitidos para un período académico.

TABLA 32. Índice de selectividad y de absorción para el 2019-1

\begin{tabular}{|c|c|c|c|c|c|}
\hline \multirow[b]{2}{*}{ Nivel de formación } & \multicolumn{5}{|c|}{ 2019-1 } \\
\hline & 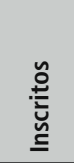 & 苍 & 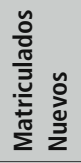 & 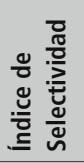 & 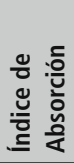 \\
\hline Tecnología & 91 & 79 & 70 & $87 \%$ & $89 \%$ \\
\hline Pregrado presencial & 4.508 & 2.827 & 2.271 & $63 \%$ & $80 \%$ \\
\hline Pregrado distancia & 647 & 611 & 419 & $94 \%$ & $69 \%$ \\
\hline Especialización médicas & 1.612 & 145 & 137 & $9 \%$ & $94 \%$ \\
\hline Especialización no médicas & 793 & 751 & 661 & $95 \%$ & $88 \%$ \\
\hline Maestría & 247 & 219 & 178 & $89 \%$ & $81 \%$ \\
\hline Doctorado & 22 & 16 & 12 & $73 \%$ & $75 \%$ \\
\hline
\end{tabular}

Fuente: Vicerrectoría Académica (2020).

TABLA 33. Índice de selectividad y de absorción para el 2019-2

\begin{tabular}{|c|c|c|c|c|c|}
\hline \multirow[b]{2}{*}{ Nivel de formación } & \multicolumn{5}{|c|}{ 2019-1 } \\
\hline & 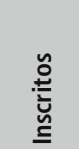 & 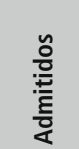 & 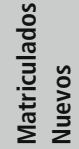 & 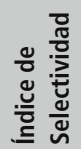 & 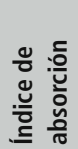 \\
\hline Tecnología & 49 & 49 & 42 & $100 \%$ & $86 \%$ \\
\hline Pregrado presencial & 2.911 & 1.599 & 1.307 & $55 \%$ & $82 \%$ \\
\hline Pregrado distancia & 465 & 424 & 296 & $91 \%$ & $70 \%$ \\
\hline Especialización No médicas & 871 & 824 & 728 & $95 \%$ & $88 \%$ \\
\hline Maestría & 153 & 136 & 117 & $89 \%$ & $86 \%$ \\
\hline
\end{tabular}

Fuente: Vicerrectoría Académica (2020). 


\section{Población Estudiantil}

\section{GRI 102-6}

La calidad de estudiante en la Universidad Militar Nueva Granada se adquiere o renueva mediante el acto individual y voluntario de la matrícula, aceptando y comprometiéndose a cumplir los estatutos, reglamentos y demás disposiciones y normas establecidas por el Estado colombiano y la institución.

Total de estudiantes matriculados

El número de estudiantes matriculados en los cuatro últimos períodos académicos se muestra en la Figura 13.

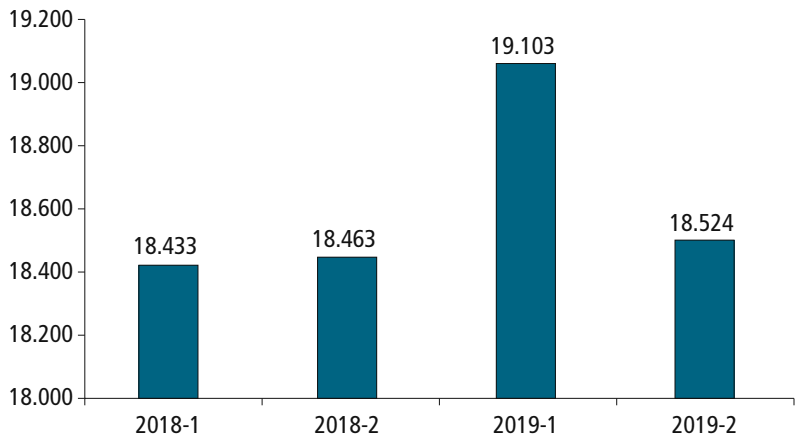

FIGURA 13. Gráfica Población estudiantil 2018-2019. Fuente: Vicerrectoría Académica (2020). 
Total de estudiantes matriculados por nivel de formación Según el nivel de formación, en la Tabla 34 se evidencia el número de estudiantes matriculados en la universidad durante la vigencia 2019.

TABLA 34. Estudiantes matriculados por nivel de formación 2019

\begin{tabular}{|l|c|c|}
\hline Nivel de formación & $\mathbf{2 0 1 9 - 1}$ & $\mathbf{2 0 1 9 - 2}$ \\
\hline Tecnología & 377 & 341 \\
\hline Pregrado & 16.016 & 15.595 \\
\hline Especialización & 1.898 & 1.905 \\
\hline Maestría & 766 & 659 \\
\hline Doctorado & 46 & 24 \\
\hline Total & 19.103 & 18.524 \\
\hline
\end{tabular}

Fuente: Vicerrectoría Académica (2020).

\section{Graduados}

Según los reglamentos estudiantiles de pregrado y posgrado, Acuerdos 02 de 2015 y 06 de 2012 respectivamente, el grado es el acto por el cual la universidad otorga al estudiante de pregrado o posgrado el título correspondiente, de acuerdo con las disposiciones legales vigentes y los procedimientos académicos, administrativos y económicos de la institución.

El acumulado con corte a diciembre de 2019 es de 50.330 graduados; en la Tabla 35 se evidencia el número de graduados en la presente vigencia por nivel de formación. 
TABLA 35. Estudiantes graduados 2019

\begin{tabular}{|l|c|c|c|}
\hline \multicolumn{1}{|c|}{ Nivel de formación } & $\begin{array}{c}\text { \# de } \\
\text { graduados } \\
2019-1\end{array}$ & $\begin{array}{c}\text { \# de } \\
\text { graduados } \\
2019-2\end{array}$ & $\begin{array}{c}\text { \# de } \\
\text { graduados } \\
\text { acumulado }\end{array}$ \\
\hline Tecnología & 55 & 40 & 502 \\
\hline Pregrado presencial & 876 & 406 & 22.470 \\
\hline Pregrado distancia & 229 & 129 & 3.338 \\
\hline Especialización no médica & 656 & 667 & 18.425 \\
\hline Especialización medico quirúrgica & 108 & 14 & 3.137 \\
\hline Especialización odontológica & 0 & 0 & 970 \\
\hline Maestría & 101 & 85 & 1.480 \\
\hline Doctorado & 0 & 0 & 8 \\
\hline Total & 2.025 & 1.341 & 50.330 \\
\hline
\end{tabular}

Fuente: Vicerrectoría Académica (2020).

\section{Bienestar Universitario}

A partir de la política específica de bienestar, contenida en el Acuerdo 09 de 2018, expedido por el Consejo Superior Universitario, se ejecutaron actividades para incrementar el potencial de las dimensiones que le son atinentes a las personas y que conllevan tres directrices concretas (Tabla 36). 
TABLA 36. Directrices

\begin{tabular}{|c|c|}
\hline \multirow{5}{*}{$\begin{array}{l}\text { 1. El desarrollo humano } \\
\text { en un contexto saludable, } \\
\text { vinculado a acciones de } \\
\text { prevención y promoción. }\end{array}$} & $\begin{array}{l}\text { Autoevaluación y habilitación de servicios en } \\
\text { medicina, odontología y psicología }\end{array}$ \\
\hline & $\begin{array}{l}\text { Realización de campañas y jornadas en medicina } \\
\text { y odontología }\end{array}$ \\
\hline & Atención en primeros auxilios \\
\hline & $\begin{array}{l}\text { Asesorías personalizadas en medicina y } \\
\text { psicología }\end{array}$ \\
\hline & $\begin{array}{l}\text { Ejecución de eventos de promoción de hábitos } \\
\text { saludables }\end{array}$ \\
\hline \multirow{4}{*}{$\begin{array}{l}\text { 2. El fomento del crecimiento } \\
\text { intelectual, a partir de } \\
\text { experiencias formativas que } \\
\text { permitan a cada ser humano } \\
\text { identificar, adoptar y aplicar } \\
\text { competencias para la vida. }\end{array}$} & $\begin{array}{l}\text { Orientación de asignaturas electivas en artes y } \\
\text { deportes. } 58 \text { cursos }\end{array}$ \\
\hline & Conversatorios sobre temas de interés \\
\hline & $\begin{array}{l}\text { Desarrollo de jornadas pedagógicas, de apoyo } \\
\text { a la gestión integrada de seguridad, ambiente, } \\
\text { calidad y salud. }\end{array}$ \\
\hline & $\begin{array}{l}\text { Integración cultural interinstitucional, mediante } \\
\text { encuentros y festivales artísticos. }\end{array}$ \\
\hline \multirow{3}{*}{$\begin{array}{l}\text { 3. La formación en valores, } \\
\text { como aspecto esencial para } \\
\text { actuar en sana convivencia, } \\
\text { con una identidad basada en } \\
\text { la equidad y la justicia, que } \\
\text { permitan a cada individuo } \\
\text { su reconocimiento social en } \\
\text { contextos inclusivos. }\end{array}$} & $\begin{array}{l}\text { Jornadas de inducción para pregrados } \\
\text { y posgrados en las que se reafirman los } \\
\text { fundamentos sagrados de la universidad. }\end{array}$ \\
\hline & $\begin{array}{l}\text { Mensajes diarios sobre valores, emitidos desde } \\
\text { la capellanía }\end{array}$ \\
\hline & $\begin{array}{l}\text { Realización de eventos de fomento de la } \\
\text { identidad, la convivencia y la paz }\end{array}$ \\
\hline
\end{tabular}

Fuente: División de Bienestar Universitario.

Lo anterior abre un escenario de compromiso con el desarrollo sostenible, al involucrar el accionar del bienestar universitario en algunos de los postulados contemplados en la Agenda 2030 para el Desarrollo Sostenible, mediante el análisis y puesta en marcha de estrategias 
pedagógicas que proporcionan herramientas asociadas a los objetivos propuestos, en pro de adherir a los actores que intervienen en esta iniciativa global.

Aporte de bienestar a los oDs en 2019

- Se estableció una estructura de seis políticas específicas que contribuyen a integrar la misión del bienestar de cara a los objetivos de desarrollo sostenible.

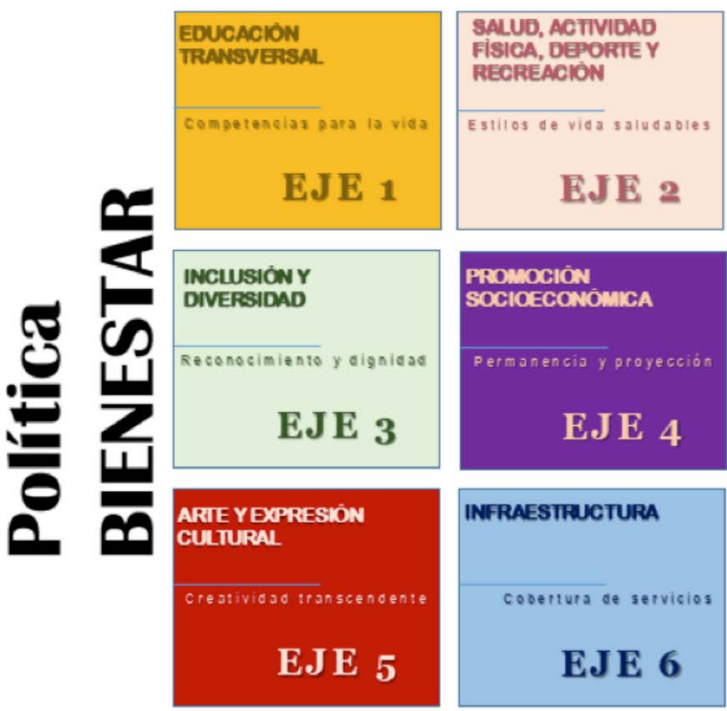

FIGURA 14. Política de bienestar. Fuente: División de Bienestar Universitario. Armando Lázaro Carvajalino - Jefe de División de Bienestar Universitario Universidad Militar Nueva Granada. 
- Ejecución de procesos de sensibilización docente sobre su compromiso de formar en habilidades transversales y competencias clave a los estudiantes. Cuatro jornadas (dos por semestre)

- Participación en la gobernanza de la universidad, mediante la representación de un estudiante de Administración de la Seguridad y Salud Ocupacional, un docente de Administración de Empresas, un Decano de Ingeniería y un egresado graduado, en el Consejo de Bienestar Institucional.

- Orientación de programas de formación vocacional: más de setenta espacios de electivas y talleres en artes y deportes.

- Soporte pedagógico para la realización de cuatro ejercicios comunitarios de convivencia, paz y trascendencia, en los que participan estudiantes, funcionarios administrativos y docentes.

- Asignación de recursos económicos para movilidad académica, a estudiantes interesados en fortalecer su intelecto y dar a conocer los resultados de sus experiencias académicas, de investigación, emprendimiento e innovación.

- Apoyo a estudiantes deportistas y artistas en condición de discapacidad que adelantan estudios en la institución. 


\section{GRI 102-15}

- Dos contribuciones didácticas con la estrategia "Pedalea la Mili" sobre impacto institucional en hechos trascendentes de movilidad sostenible, en atención a políticas públicas de defensa del medio ambiente.

FIGURA 15. Legalidad + Emprendimiento = Equidad. Presidencia de la República (s. f.).

- Impulso a las iniciativas gubernamentales de fomento de la cultura y economía naranja, alineado al Plan Nacional de Desarrollo 2018-2022 "Pacto por Colombia, pacto por la equidad", como aspecto esencial para nutrir el talento y la creatividad del personal residente en la institución, en procura de la gestación de espacios creativos de alcance regional y nacional.

1. Festivales de teatro.

2. Festival de danza.

3. Festival de la canción.

4. Festivales de música (Tunas, bandas urbanas).

5. Creación de dos nuevas bandas de música.

6. Participación en convocatorias distritales y departamentales de teatro y danza (Cundinamarca, Boyacá y Bogotá). 
- Formulación de una propuesta de "Universidad Militar distrito creativo y cultural", creada para facilitar el acercamiento a las comunidades, con propuestas alineadas con los oDs desde una perspectiva sensible y plural.

- Entrega de 142 apoyos para permanencia estudiantil por un valor de $\$ 350.000 .000$, en el segundo semestre de 2019.

\section{GRI 204 Prácticas de Adquisición}

GRI 406 No discriminación

Los objetivos en los cuales interviene directa e indirectamente Bienestar Universitario son (Figura 16):

- oDs 3 - Garantizar una vida sana y promover el bienestar para todos en todas las edades

- oDs 4 - Garantizar una educación incluyente, equitativa y de calidad y promover oportunidades de aprendizaje durante toda la vida para todos

- oDs 5 - Lograr la igualdad entre los géneros

- ods 16 - Promover sociedades justas, pacíficas e incluyentes 

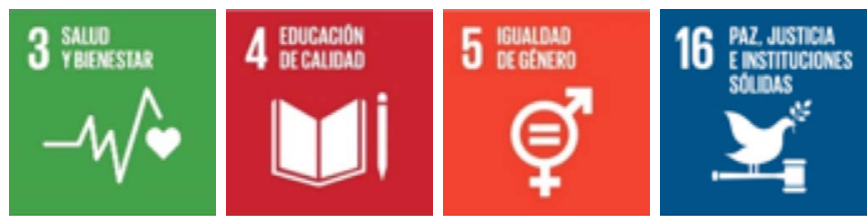

FIGURA 16. Objetivos en los cuales interviene Bienestar Universitario. Fuente: Organización de Naciones Unidas (2016). Propiedad Intelectual @

\section{Reconocimiento de la excelencia académica}

La excelencia académica nace de la necesidad de autotransformación y autorregulación, que es transversal al quehacer universitario institucional y que genera, como resultado, una sociedad más equitativa e igualitaria.

Desde la Universidad Militar Nueva Granada se tiene como premisa el diseño de currículos integrales y flexibles con las metodologías pertinentes a las particularidades de nuestra población estudiantil y a los contextos de la población de la Región Sabana - Centro y Bogotá, entre otros, que permitan la trayectoria completa por la educación superior con enfoques para el inscrito, estudiante, matriculado y graduado. 


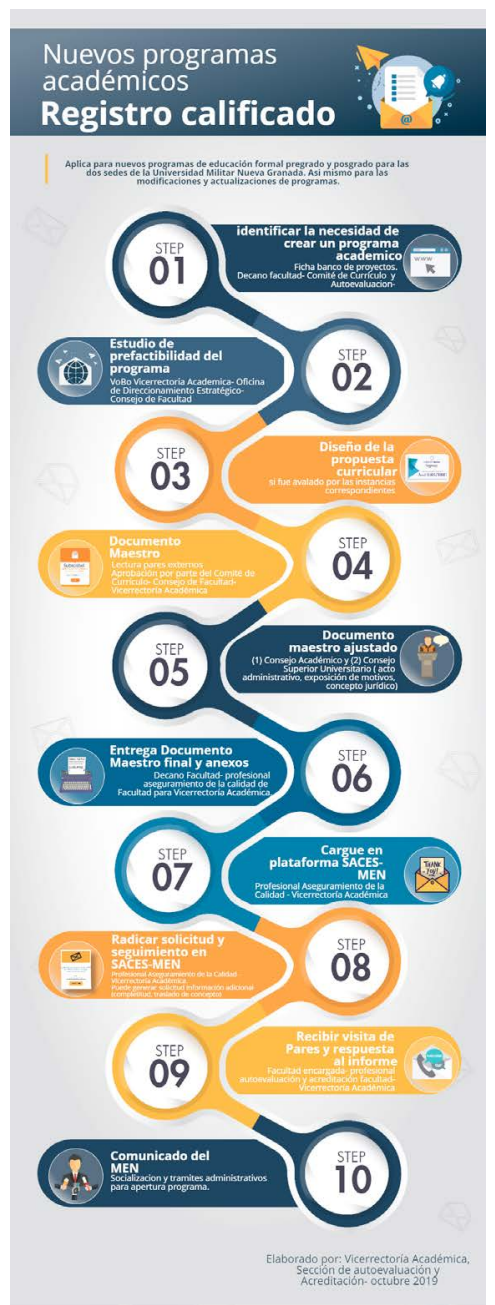

FIGURA 17. Obtención de Registro Calificado. Fuente: Sección de autoevaluación y acreditación de la Vicerrectoría Académica (Universidad Militar Nueva Granada, 2020). 


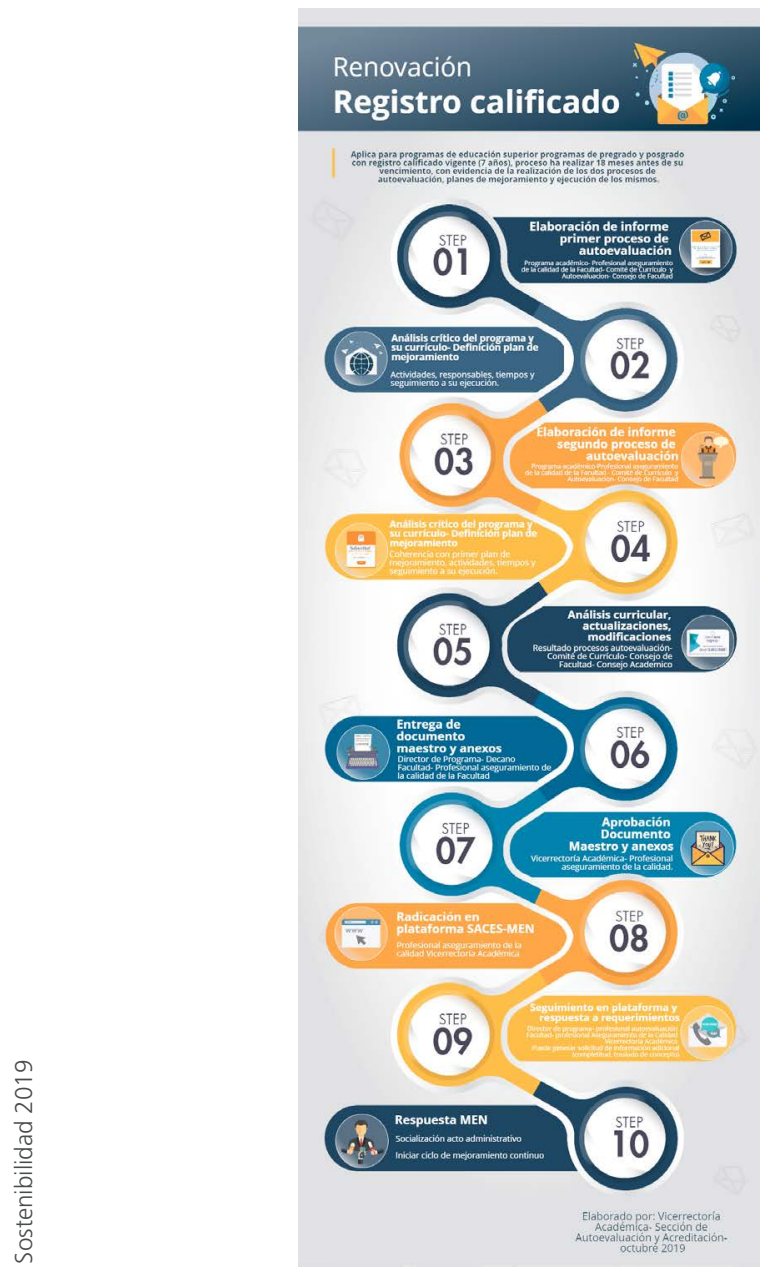

FIGURA 18. Renovación de Registro Calificado. Fuente: Sección de autoevaluación y acreditación de la Vicerrectoría Académica (Universidad Militar Nueva Granada, 2020). 


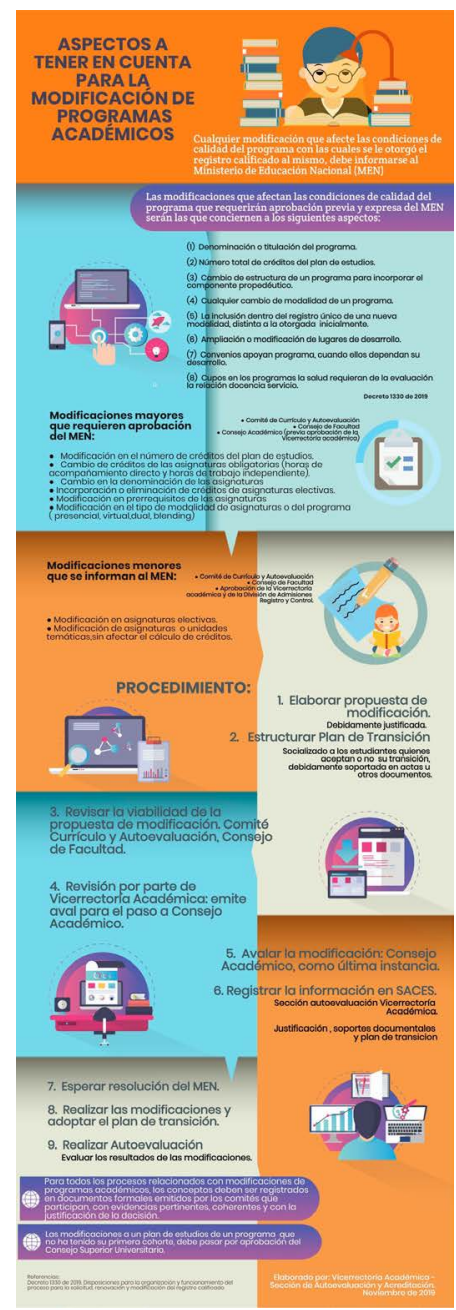

FIGURA 19. Modificaciones de programas académicos. Fuente: Sección de autoevaluación y acreditación de la Vicerrectoría Académica (Universidad Militar Nueva Granada, 2020). 

CALIDAD 



\section{CONTENIDO}

90 Calidad académica

100 Oferta académica

108 Procesos académicos en 2019

116 Nuevos programas académicos 2019

118 Proceso de renovación de la Acreditación Institucional Multicampus 


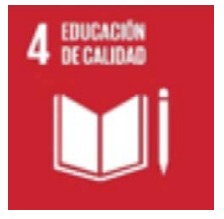

GRI 103-1

GRI 103-2

GRI 103-3

\section{Calidad académica}

En concordancia con el concepto de calidad académica, aplicado a la educación superior, se refiere a la síntesis de características que permiten, por un lado, reconocer un programa académico específico o una institución de determinado tipo y, por el otro, hacer un juicio sobre la distancia que media entre el modo en que esa institución o ese programa académico presta dicho servicio y el resultado óptimo que corresponde a su naturaleza. 


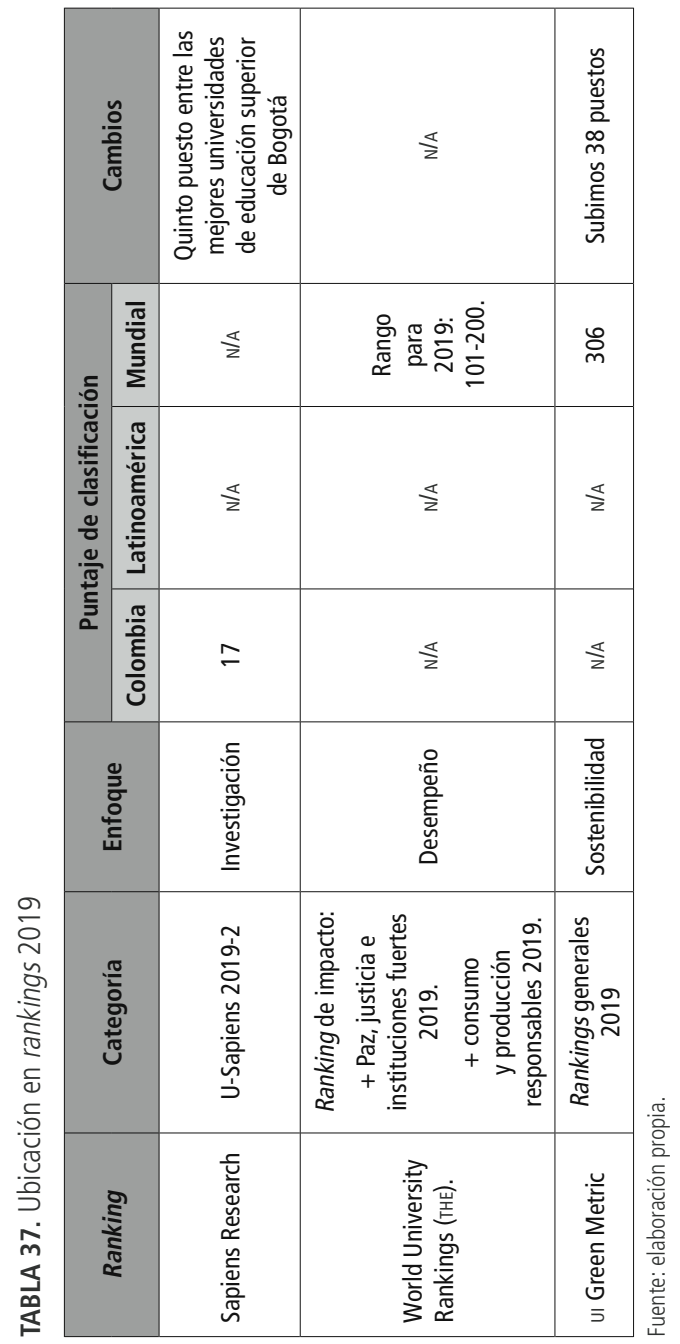




\section{Oferta académica}

GRI 102-6

GRI 102-7

Como se muestra en la Tabla 38, la oferta académica de la universidad con corte a noviembre de 2019, la componen 134 programas académicos aprobados por el Ministerio de Educación Nacional (MEN) y distribuidos en las dos sedes de la institución, así:

- Sede Bogotá: 93 programas

- Sede Campus Nueva Granada: 31 programas

- Modalidad distancia: ocho programas

- Otras ciudades: dos programas, uno en Cali y otro en Cartagena

TABLA 38. Oferta académica

\begin{tabular}{|c|c|c|c|c|c|}
\hline Nivel de formación & 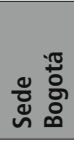 & 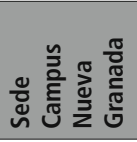 & 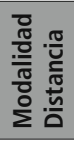 & 竞 & $\begin{array}{l}\overline{\widetilde{\sigma}} \\
\text { 음 }\end{array}$ \\
\hline Tecnología & 1 & 3 & 0 & 0 & 4 \\
\hline Pregrado & 12 & 13 & 7 & 0 & 32 \\
\hline Especialización no médica & 20 & 6 & 1 & 2 & 29 \\
\hline Especialización medico quirúrgica & 50 & 0 & 0 & 0 & 50 \\
\hline Maestría & 10 & 7 & 0 & 0 & 17 \\
\hline Doctorado & 0 & 2 & 0 & 0 & 2 \\
\hline Total & 93 & 31 & 8 & 2 & 134 \\
\hline
\end{tabular}

Fuente: Vicerrectoría Académica (2020).

La distribución de la oferta académica por nivel de formación en el 2019, se evidencia en las Figuras 20 y 21. 


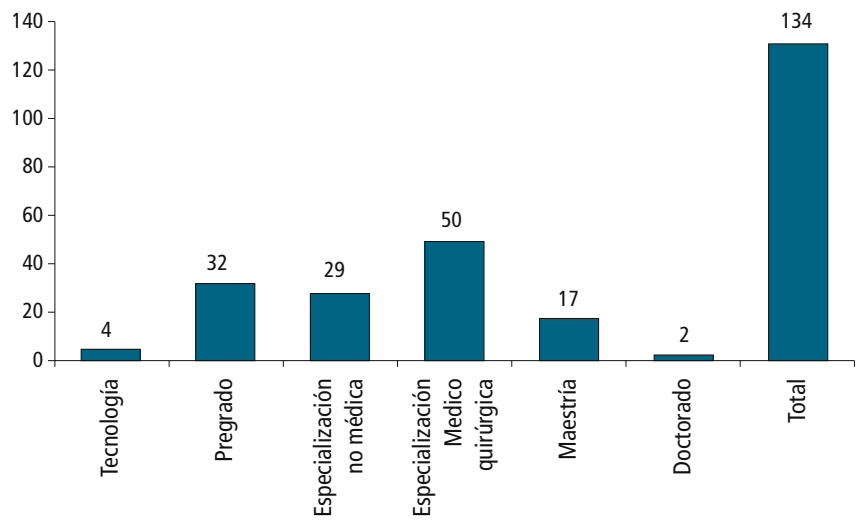

FIGURA 20. Programas académicos por nivel de formación. Fuente: Vicerrectoría Académica (2020).

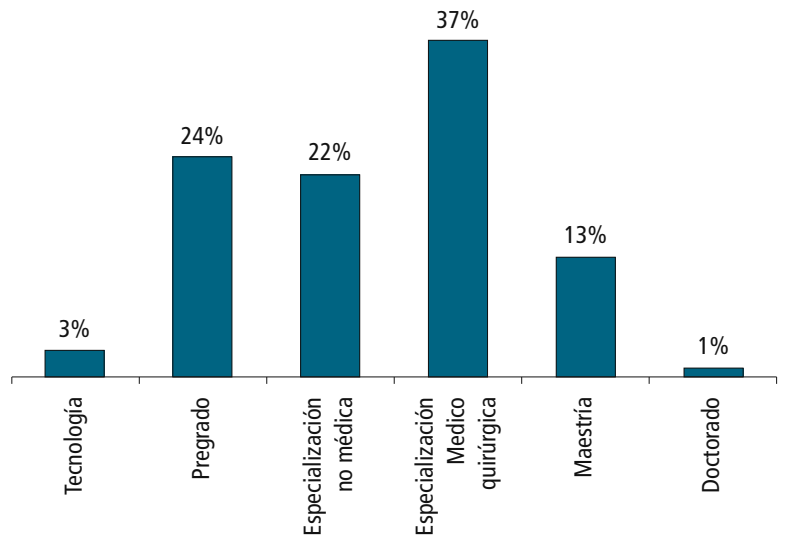

FIGURA 21. Distribución porcentual de programas académicos por nivel de formación. Fuente: Vicerrectoría Académica (2020). 
La universidad, con base en las necesidades de la sociedad y el sector productivo, dispone de su oferta académica en las dos sedes, Sede Bogotá, incluida la Facultad de Medicina y Ciencias de la Salud, y Sede Campus Nueva Granada.

La siguiente (Tabla 39) es la composición de la oferta académica durante el 2019 en cada una de las sedes de la universidad. En algunos casos, el mismo programa académico se ofrece en las dos sedes y por tanto se contabiliza dos veces para obtener el total de 134 programas académicos.

TABLA 39. Composición de la oferta académica (2019)

\begin{tabular}{|c|l|l|}
\hline $\begin{array}{c}\text { Nivel de } \\
\text { formación }\end{array}$ & \multicolumn{1}{|c|}{ Sede } & \multicolumn{1}{c|}{ Nombre del programa } \\
\hline \multirow{4}{*}{ Tecnología } & $\begin{array}{l}\text { Campus } \\
\text { Nueva } \\
\text { Granada }\end{array}$ & Tecnología en gestión y producción hortícola \\
\cline { 3 - 3 } & Tecnología en contabilidad y tributaria \\
\cline { 2 - 3 } & Bogotá & Tecnología en atención prehospitalaria \\
\hline
\end{tabular}

\begin{tabular}{|c|l|l|}
\hline $\begin{array}{c}\text { Nivel de } \\
\text { formación }\end{array}$ & \multicolumn{1}{c|}{ Sede } & \multicolumn{1}{c|}{ Nombre del programa } \\
\hline \multirow{4}{*}{ Pregrado } & \multirow{2}{*}{$\begin{array}{l}\text { Campus } \\
\text { Nueva } \\
\text { Granada }\end{array}$} & Ingeniería ambiental \\
\cline { 3 - 3 } & & Ingeniería biomédica \\
\cline { 3 - 3 } & & Biología aplicada \\
\cline { 3 - 3 } & & Derecho \\
\hline
\end{tabular}


CONTINUACIÓN TABLA 39. Composición de la oferta académica (2019)

\begin{tabular}{|c|c|c|}
\hline $\begin{array}{l}\text { Nivel de } \\
\text { formación }\end{array}$ & Sede & Nombre del programa \\
\hline \multirow{19}{*}{ Pregrado } & \multirow{7}{*}{$\begin{array}{l}\text { Campus } \\
\text { Nueva } \\
\text { Granada }\end{array}$} & Ingeniería informática (distancia) \\
\hline & & Administración de empresas (distancia) \\
\hline & & $\begin{array}{l}\text { Administración de la seguridad y salud ocupacional } \\
\text { (distancia) }\end{array}$ \\
\hline & & $\begin{array}{l}\text { Relaciones internacionales y estudios políticos } \\
\text { (distancia) }\end{array}$ \\
\hline & & Ingeniería civil (distancia) \\
\hline & & Ingeniería industrial (distancia) \\
\hline & & Contaduría pública (distancia) \\
\hline & \multirow{3}{*}{ Bogotá } & Derecho \\
\hline & & Ingeniería en telecomunicaciones \\
\hline & & Medicina \\
\hline & \multirow{9}{*}{$\begin{array}{l}\text { Bogotá y } \\
\text { Campus } \\
\text { Nueva } \\
\text { Granada }\end{array}$} & Ingeniería civil \\
\hline & & Ingeniería industrial \\
\hline & & Ingeniería en multimedia \\
\hline & & Ingeniería en mecatrónica \\
\hline & & Administración de empresas \\
\hline & & Contaduría pública \\
\hline & & Economía \\
\hline & & Relaciones internacionales y estudios políticos \\
\hline & & Administración de la seguridad y salud ocupacional \\
\hline
\end{tabular}


CONTINUACIÓN TABLA 39. Composición de la oferta académica (2019)

\begin{tabular}{|c|c|c|}
\hline $\begin{array}{l}\text { Nivel de } \\
\text { formación }\end{array}$ & Sede & Nombre del programa \\
\hline \multirow{17}{*}{ 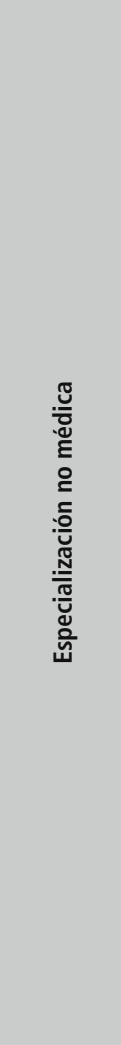 } & $\begin{array}{l}\text { Campus } \\
\text { Nueva } \\
\text { Granada }\end{array}$ & Especialización en Alta Gerencia (Distancia) \\
\hline & \multirow{16}{*}{ Bogotá } & Especialización en Geomática \\
\hline & & Especialización en Gerencia de la Calidad \\
\hline & & $\begin{array}{l}\text { Especialización en Planeación Ambiental y Manejo } \\
\text { Integral de los Recursos Naturales }\end{array}$ \\
\hline & & Especialización en Gerencia Logística Integral \\
\hline & & Especialización en Ingeniería de Pavimentos \\
\hline & & Especialización en Gerencia Integral de Proyectos \\
\hline & & Especialización en Control Interno \\
\hline & & $\begin{array}{l}\text { Especialización en Administración Aeronáutica y } \\
\text { Aeroespacial }\end{array}$ \\
\hline & & $\begin{array}{l}\text { Especialización en Gestión de Desarrollo } \\
\text { Administrativo }\end{array}$ \\
\hline & & $\begin{array}{l}\text { Especialización en Revisoría Fiscal y Auditoria } \\
\text { Internacional }\end{array}$ \\
\hline & & Especialización en Mercadeo de Servicios \\
\hline & & $\begin{array}{l}\text { Especialización en Gerencia de Comercio } \\
\text { Internacional }\end{array}$ \\
\hline & & Especialización en Derecho Administrativo \\
\hline & & Especialización en Administración de la Seguridad \\
\hline & & $\begin{array}{l}\text { Especialización en Alta Gerencia de Seguridad y } \\
\text { Defensa }\end{array}$ \\
\hline & & Especialización en Docencia Universitaria \\
\hline
\end{tabular}


CONTINUACIÓN TABLA 39. Composición de la oferta académica (2019)

\begin{tabular}{|c|c|c|}
\hline $\begin{array}{l}\text { Nivel de } \\
\text { formación }\end{array}$ & Sede & Nombre del programa \\
\hline \multirow{6}{*}{ 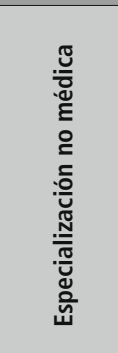 } & \multirow{5}{*}{$\begin{array}{c}\text { Bogotá y } \\
\text { Campus } \\
\text { Nueva } \\
\text { Granada }\end{array}$} & Especialización en Finanzas y Administración Pública \\
\hline & & Especialización en Alta Gerencia \\
\hline & & $\begin{array}{l}\text { Especialización en Derechos Humanos y Sistemas de } \\
\text { Protección }\end{array}$ \\
\hline & & Especialización en Derecho Sancionatorio \\
\hline & & $\begin{array}{l}\text { Especialización en Procedimiento Penal Constitucional } \\
\text { y Justicia Militar }\end{array}$ \\
\hline & $\begin{array}{c}\text { Cali y } \\
\text { Cartagena }\end{array}$ & Especialización en Administración de la Seguridad \\
\hline
\end{tabular}

\begin{tabular}{|c|c|c|}
\hline $\begin{array}{l}\text { Nivel de } \\
\text { formación }\end{array}$ & Sede & Nombre del programa \\
\hline \multirow{14}{*}{ 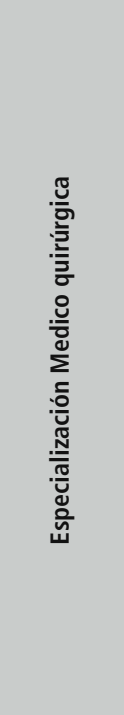 } & \multirow{14}{*}{ Bogotá } & Especialización en Anestesiología \\
\hline & & Especialización en Cardiología \\
\hline & & Especialización en Cirugía Cardiovascular \\
\hline & & Especialización en Cirugía de Columna \\
\hline & & $\begin{array}{l}\text { Especialización en Cirugía de la Mano y Miembro } \\
\text { Superior }\end{array}$ \\
\hline & & Especialización en Cirugía General \\
\hline & & Especialización en Cirugía Oral y Maxilofacial \\
\hline & & Especialización en Cirugía Pediátrica \\
\hline & & $\begin{array}{l}\text { Especialización en Cirugía Plástica Reconstructiva y } \\
\text { Estética }\end{array}$ \\
\hline & & $\begin{array}{l}\text { Especialización en Cirugía Reconstructiva y del } \\
\text { Reemplazo Articular de Cadera y Rodilla }\end{array}$ \\
\hline & & Especialización en Cirugía Vascular y Angiología \\
\hline & & Especialización en Coloproctología \\
\hline & & Especialización en Dermatología \\
\hline & & Especialización en Endocrinología \\
\hline
\end{tabular}


CONTINUACIÓN TABLA 39. Composición de la oferta académica (2019)

\begin{tabular}{|c|c|c|}
\hline $\begin{array}{l}\text { Nivel de } \\
\text { formación }\end{array}$ & Sede & Nombre del programa \\
\hline \multirow{24}{*}{ 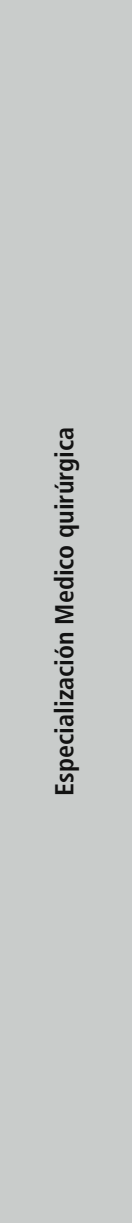 } & \multirow{24}{*}{ Bogotá } & Especialización en Gastroenterología \\
\hline & & Especialización en Ginecología y Obstetricia \\
\hline & & Especialización en Hematología y Oncología Clínica \\
\hline & & Especialización en Laringología y Vía Aérea Superior \\
\hline & & $\begin{array}{l}\text { Especialización en Medicina Crítica y Cuidados } \\
\text { Intensivos }\end{array}$ \\
\hline & & Especialización en Medicina Física y Rehabilitación \\
\hline & & Especialización en Medicina Interna \\
\hline & & Especialización en Nefrología \\
\hline & & Especialización en Neonatología \\
\hline & & Especialización en Neumología \\
\hline & & Especialización en Neurocirugía \\
\hline & & Especialización en Neurología \\
\hline & & Especialización en Neurología Pediátrica \\
\hline & & $\begin{array}{l}\text { Especialización en Neurología Pediátrica para } \\
\text { Especialistas en Pediatría }\end{array}$ \\
\hline & & Especialización en Cirugía Plástica Ocular \\
\hline & & Especialización en Oftalmología \\
\hline & & Especialización en Ortopedia y Traumatología \\
\hline & & Especialización en Otología \\
\hline & & Especialización en Otorrinolaringología \\
\hline & & Especialización en Patología \\
\hline & & Especialización en Pediatría \\
\hline & & Especialización en Psiquiatría \\
\hline & & $\begin{array}{l}\text { Especialización en Radiología e Imágenes } \\
\text { Diagnósticas }\end{array}$ \\
\hline & & Especialización en Reumatología \\
\hline
\end{tabular}


CONTINUACIÓN TABLA 39. Composición de la oferta académica (2019)

\begin{tabular}{|c|c|c|}
\hline $\begin{array}{l}\text { Nivel de } \\
\text { formación }\end{array}$ & Sede & Nombre del programa \\
\hline \multirow{12}{*}{ 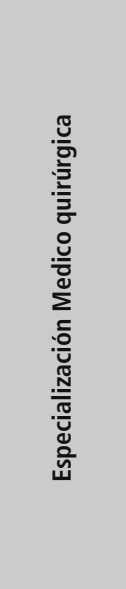 } & \multirow{12}{*}{ Bogotá } & Especialización en Urología \\
\hline & & Especialización en Cirugía de Pie y Tobillo \\
\hline & & Especialización en Cirugía Oncológica \\
\hline & & $\begin{array}{l}\text { Especialización en Medicina del Dolor y Cuidados } \\
\text { Paliativos }\end{array}$ \\
\hline & & Especialización en Oncología Radioterápica \\
\hline & & Especialización en Rehabilitación Oncológica \\
\hline & & Especialización en Cirugía de Cabeza y Cuello \\
\hline & & Especialización en Urología Oncológica \\
\hline & & Especialización en Ginecología Oncológica \\
\hline & & Especialización en Hemato-Oncología Pediátrica \\
\hline & & Especialización en Ortopedia Oncológica \\
\hline & & Especialización en Dermatología Oncológica \\
\hline
\end{tabular}

\begin{tabular}{|c|c|c|}
\hline $\begin{array}{l}\text { Nivel de } \\
\text { formación }\end{array}$ & Sede & Nombre del programa \\
\hline \multirow{5}{*}{ 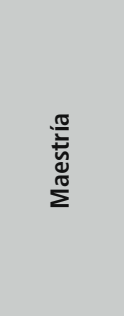 } & $\begin{array}{l}\text { Campus } \\
\text { Nueva } \\
\text { Granada }\end{array}$ & Maestría en Biología Aplicada \\
\hline & \multirow{4}{*}{ Bogotá } & Maestría en Ingeniería Mecatrónica \\
\hline & & Maestría en Derecho Administrativo \\
\hline & & $\begin{array}{l}\text { Maestría en Instituciones Jurídicas de la Fuerza } \\
\text { Pública }\end{array}$ \\
\hline & & Maestría en Derecho Procesal Penal \\
\hline
\end{tabular}


CONTINUACIÓN TABLA 39. Composición de la oferta académica (2019)

\begin{tabular}{|c|c|c|}
\hline $\begin{array}{l}\text { Nivel de } \\
\text { formación }\end{array}$ & Sede & Nombre del programa \\
\hline \multirow{6}{*}{ 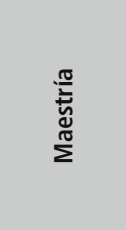 } & \multirow{6}{*}{$\begin{array}{l}\text { Bogotá y } \\
\text { Campus } \\
\text { Nueva } \\
\text { Granada }\end{array}$} & Maestría en Logística Integral \\
\hline & & Maestría en Gerencia de Proyectos \\
\hline & & Maestría en Ingeniería Civil \\
\hline & & Maestría en Gestión de Organizaciones \\
\hline & & Maestría en Relaciones y Negocios Internacionales \\
\hline & & Maestría en Educación \\
\hline
\end{tabular}

\begin{tabular}{|c|l|l|}
\hline $\begin{array}{c}\text { Nivel de } \\
\text { formación }\end{array}$ & \multicolumn{1}{|c|}{ Sede } & \multicolumn{1}{c|}{ Nombre del programa } \\
\hline \multirow{2}{*}{ Doctorado } & $\begin{array}{l}\text { Campus } \\
\text { Nueva } \\
\text { Granada }\end{array}$ & Doctorado en Ciencias Aplicadas \\
\cline { 3 - 3 } & & Doctorado en Bioética \\
\hline
\end{tabular}

Fuente: Vicerrectoría Académica (2020).

\section{Procesos académicos en 2019}

Con la entrada en vigencia del Decreto N. ${ }^{\circ} 1330$ del 25 de julio de 2019 que establece, entre otros aspectos, la extensión automática a la vigencia de los registros calificados, los procesos académicos en esta materia se vieron afectados durante la vigencia 2019.

Con lo anterior, los registros calificados que vencían entre el 1 de junio y el 31 de diciembre de 2020, extienden automáticamente su vigencia por dieciocho meses más, y para los programas de educación superior cuyos registros vencen entre el 1 de enero y el 30 de junio de 2021, su vigencia durará doce meses más. 
Sin embargo, siguiendo los lineamientos del Ministerio de Educación Nacional, los programas académicos de la Universidad Militar Nueva Granada adelantan sus procesos de autoevaluación identificando las brechas y oportunidades de mejora a nivel curricular y generando planes de acción encaminados a mantener la calidad académica que permita responder a las necesidades y expectativas del entorno.

En las Tablas 40 y 41, se amplía lo pertinente a la gestión adelantada respecto a los procesos académicos. Se evidencia la gestión de los procesos que tienen que ver con la solicitud o renovación de registros calificados, o con la acreditación o renovación de la acreditación de los programas académicos de la universidad.

TABLA 40. Renovación de Registros Calificados

\begin{tabular}{|c|c|c|c|}
\hline 뮴 & $\begin{array}{c}\text { Nombre del } \\
\text { programa }\end{array}$ & $\begin{array}{l}\text { Número y fecha de la } \\
\text { resolución del MEN }\end{array}$ & Vigencia \\
\hline 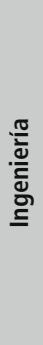 & $\begin{array}{l}\text { Ingeniería } \\
\text { Industrial } \\
\text { Bogotá y } \\
\text { Campus }\end{array}$ & $\begin{array}{l}\text { Res. } 005909 \text { del } 07 / 06 / 2019 \text { por } \\
\text { medio de la cual se corrige la } \\
\text { resolución } 309 \text { del16/01/2019 por } \\
\text { medio de la cual se Renueva de } \\
\text { Oficio el Registro Calificado por } \\
7 \text { años, contados a partir de la } \\
\text { expedición de la Resolución } 11595 \\
\text { del } 17 / 07 / 2018 \text {, corregida por la } \\
\text { Resolución 017745 del 15/11/2018 } \\
\text { de Acreditación Alta Calidad. }\end{array}$ & $\begin{array}{c}7 \text { años } \\
\text { contados } \\
\text { a partir de } \\
\text { la fecha de } \\
\text { Acreditación } \\
\text { de Alta } \\
\text { Calidad del } \\
\text { Programa. } \\
\text { Vencimiento } \\
\text { del Registro } \\
\text { 16/07/2025 }\end{array}$ \\
\hline
\end{tabular}


CONTINUACIÓN TABLA 40. Renovación de Registros Calificados

\begin{tabular}{|c|c|c|c|}
\hline 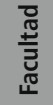 & $\begin{array}{l}\text { Nombre del } \\
\text { programa }\end{array}$ & $\begin{array}{l}\text { Número y fecha de la } \\
\text { resolución del MEN }\end{array}$ & Vigencia \\
\hline 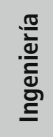 & $\begin{array}{l}\text { Ingeniería } \\
\text { Multimedia } \\
\text { Bogotá y } \\
\text { Campus }\end{array}$ & $\begin{array}{l}\text { Res. } 009977 \text { del } 19 / 09 / 2019 \text {. Por } \\
\text { medio de la cual se renueva por } 7 \\
\text { años y aprueba modificación del } \\
\text { registro calificado. }\end{array}$ & $\begin{array}{l}7 \text { años. } \\
\text { 18/09/2026 }\end{array}$ \\
\hline \multirow[t]{2}{*}{ 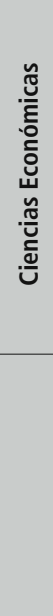 } & $\begin{array}{l}\text { Administración } \\
\text { de Empresas } \\
\text { Bogotá y } \\
\text { Campus }\end{array}$ & $\begin{array}{l}\text { Res. } 005735 \text { del } 06 / 06 / 2019 \text { por } \\
\text { medio de la cual se corrige la } \\
\text { Resol. } 000306 \text { del } 16 / 01 / 2019 \\
\text { por medio de la cual se renueva } \\
\text { de oficio el registro calificado por } \\
7 \text { años, contados a partir de la } \\
\text { expedición de la Resolución } 11558 \\
\text { del } 17 / 07 / 2018 \text {, corregida por la } \\
\text { Resolución } 017438 \text { del } 31 / 10 / 2018 \\
\text { de Acreditación Alta Calidad. }\end{array}$ & $\begin{array}{l}7 \text { años } \\
\text { contados } \\
\text { a partir de } \\
\text { la fecha de } \\
\text { Acreditación } \\
\text { de Alta } \\
\text { Calidad del } \\
\text { Programa. } \\
\text { Vencimiento } \\
\text { del Registro } \\
\text { 16/07/2025 }\end{array}$ \\
\hline & $\begin{array}{l}\text { Economía } \\
\text { Bogotá y } \\
\text { Campus }\end{array}$ & $\begin{array}{l}\text { Res. } 002728 \text { del } 18 / 03 / 2019 \text { por } \\
\text { medio de la cual se renueva el } \\
\text { registro calificado por } 7 \text { años, } \\
\text { Resolución } 004447 \text { del } 8 \text { de } \\
\text { mayo de } 2019 \text { donde se otorga } \\
\text { la acreditación de alta calidad y } \\
\text { en la que se corrige el lugar de } \\
\text { desarrollo. }\end{array}$ & $\begin{array}{l}7 \text { años. } \\
17 / 03 / 2026\end{array}$ \\
\hline & $\begin{array}{l}\text { Especialización } \\
\text { en Finanzas y } \\
\text { Administración } \\
\text { Pública Bogotá } \\
\text { y Campus }\end{array}$ & $\begin{array}{l}\text { Res. } 016067 \text { del 18/12/2019 Por } \\
\text { medio de la cual se resuelve } \\
\text { la renovación y ampliación de } \\
\text { cobertura del registro calificado. }\end{array}$ & $\begin{array}{l}7 \text { años. } \\
\text { 17/12/2026 }\end{array}$ \\
\hline & $\begin{array}{l}\text { Especialización } \\
\text { en Alta Gerencia } \\
\text { Bogotá y } \\
\text { Campus }\end{array}$ & $\begin{array}{l}\text { Res. } 016069 \text { del } 18 / 12 / 2019 \text { Por } \\
\text { medio de la cual se resuelve la } \\
\text { renovación y modificación del } \\
\text { registro calificado. }\end{array}$ & $\begin{array}{l}7 \text { años. } \\
\text { 17/12/2026 }\end{array}$ \\
\hline & $\begin{array}{l}\text { Especialización } \\
\text { en Control } \\
\text { Interno Bogotá }\end{array}$ & $\begin{array}{l}\text { Res. } 016191 \text { del } 18 / 12 / 2019 \text { Por } \\
\text { medio de la cual se resuelve la } \\
\text { renovación del registro calificado. }\end{array}$ & $\begin{array}{c}7 \text { años. } \\
17 / 12 / 2026\end{array}$ \\
\hline
\end{tabular}


CONTINUACIÓN TABLA 40. Renovación de Registros Calificados

\begin{tabular}{|c|c|c|c|}
\hline 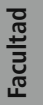 & $\begin{array}{l}\text { Nombre del } \\
\text { programa }\end{array}$ & $\begin{array}{l}\text { Número y fecha de la } \\
\text { resolución del MEN }\end{array}$ & Vigencia \\
\hline \multirow{4}{*}{ 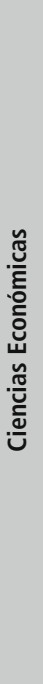 } & $\begin{array}{l}\text { Especialización } \\
\text { en Gestión } \\
\text { de Desarrollo } \\
\text { Administrativo } \\
\text { Bogotá }\end{array}$ & $\begin{array}{l}\text { Res. } 016068 \text { del } 18 / 12 / 2019 \text { Por } \\
\text { medio de la cual se resuelve la } \\
\text { renovación y modificación del } \\
\text { registro calificado. }\end{array}$ & $\begin{array}{l}7 \text { años. } \\
17 / 12 / 2026\end{array}$ \\
\hline & $\begin{array}{l}\text { Especialización } \\
\text { en Revisoría } \\
\text { Fiscal y } \\
\text { Auditoria } \\
\text { Internacional } \\
\text { Bogotá }\end{array}$ & $\begin{array}{l}\text { Res. } 016044 \text { del 18/12/2019 Por } \\
\text { medio de la cual se resuelve la } \\
\text { renovación y modificación del } \\
\text { registro calificado. }\end{array}$ & $\begin{array}{l}7 \text { años. } \\
17 / 12 / 2026\end{array}$ \\
\hline & $\begin{array}{l}\text { Especialización } \\
\text { en Mercadeo de } \\
\text { Servicios Bogotá }\end{array}$ & $\begin{array}{l}\text { Res. } 016040 \text { del } 18 / 12 / 2019 \text { Por } \\
\text { medio de la cual se resuelve la } \\
\text { renovación y modificación del } \\
\text { registro calificado. }\end{array}$ & $\begin{array}{l}7 \text { años. } \\
17 / 12 / 2026\end{array}$ \\
\hline & $\begin{array}{l}\text { Especialización } \\
\text { en Gerencia } \\
\text { de Comercio } \\
\text { Internacional } \\
\text { Bogotá }\end{array}$ & $\begin{array}{l}\text { Res. } 016046 \text { del 18/12/2019 Por } \\
\text { medio de la cual se resuelve la } \\
\text { renovación del registro calificado. }\end{array}$ & $\begin{array}{c}7 \text { años. } \\
17 / 12 / 2026\end{array}$ \\
\hline \multirow{2}{*}{ 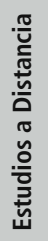 } & $\begin{array}{l}\text { Contaduría } \\
\text { Pública }\end{array}$ & $\begin{array}{l}\text { Res. } 005908 \text { del } 07 / 06 / 2019 \text { por } \\
7 \text { años }\end{array}$ & $\begin{array}{l}7 \text { años. } \\
\text { 06/06/2026 }\end{array}$ \\
\hline & $\begin{array}{l}\text { Relaciones } \\
\text { Internacionales } \\
\text { y Estudios } \\
\text { Políticos }\end{array}$ & $\begin{array}{l}\text { Res. } 015474 \text { del 18/12/2019 Por } \\
\text { medio de la cual se resuelve la } \\
\text { renovación del registro calificado. }\end{array}$ & $\begin{array}{c}7 \text { años. } \\
17 / 12 / 2026\end{array}$ \\
\hline
\end{tabular}


CONTINUACIÓN TABLA 40. Renovación de Registros Calificados

\begin{tabular}{|c|c|c|c|}
\hline 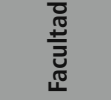 & $\begin{array}{l}\text { Nombre del } \\
\text { programa }\end{array}$ & $\begin{array}{l}\text { Número y fecha de la } \\
\text { resolución del MEN }\end{array}$ & Vigencia \\
\hline \multirow{2}{*}{ 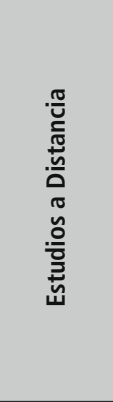 } & $\begin{array}{l}\text { Administración } \\
\text { de la Seguridad } \\
\text { y Salud } \\
\text { Ocupacional }\end{array}$ & $\begin{array}{l}\text { Res. } 008165 \text { del } 05 / 08 / 2019 \text { por } \\
\text { medio de la cual se resuelve } \\
\text { la Renovación por } 7 \text { años y } \\
\text { la modificación del Registro } \\
\text { Calificado. Se aprueba la Nueva } \\
\text { Denominación, Administración de } \\
\text { Riesgos, Seguridad y Salud en el } \\
\text { Trabajo. }\end{array}$ & $\begin{array}{c}7 \text { años. } \\
\text { 04/08/2026 }\end{array}$ \\
\hline & $\begin{array}{l}\text { Administración } \\
\text { de Empresas }\end{array}$ & $\begin{array}{l}\text { Res. } 015607 \text { del } 18 / 12 / 2019 \text { Por } \\
\text { medio de la cual se resuelve la } \\
\text { solicitud de renovación del registro } \\
\text { calificado. }\end{array}$ & $\begin{array}{c}7 \text { años. } \\
\text { 17/12/2026 }\end{array}$ \\
\hline \multirow[b]{2}{*}{ 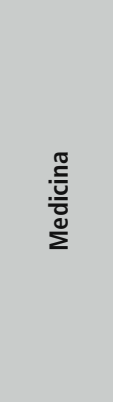 } & $\begin{array}{l}\text { Especialización } \\
\text { en Cardiología }\end{array}$ & $\begin{array}{l}\text { Res. } 003316 \text { del 2/04/2019, por } \\
\text { medio de la cual se modifica el } \\
\text { Registro Calificado }\end{array}$ & $\mathrm{N} / \mathrm{A}$ \\
\hline & $\begin{array}{l}\text { Tecnología } \\
\text { en Atención } \\
\text { Prehospitalaria }\end{array}$ & $\begin{array}{l}\text { Res. } 006866 \text { del 28/06/2019 Por } \\
\text { medio de la cual se decide no } \\
\text { renovar el Registro Calificado. } \\
\text { Res. } 015763 \text { del 18/12/2019 Por } \\
\text { medio de la cual se resuelve el } \\
\text { recurso de reposición interpuesto } \\
\text { por la UMNG, contra la Resolución } \\
006866 \text { del 28/06/2019. }\end{array}$ & $\begin{array}{c}7 \text { años. } \\
\text { 17/12/2026 }\end{array}$ \\
\hline 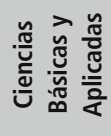 & Biología Aplicada & $\begin{array}{l}\text { Res. } 014757 \text { del } 17 / 12 / 2019 \text { Por } \\
\text { medio de la cual se resuelve la } \\
\text { modificación del registro calificado. }\end{array}$ & $\begin{array}{c}7 \text { años. } \\
\text { 25/12/2024 }\end{array}$ \\
\hline 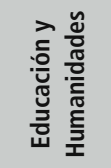 & $\begin{array}{l}\text { Doctorado en } \\
\text { Bioética }\end{array}$ & $\begin{array}{l}\text { Res. } 009086 \text { del 28/08/2019, por } \\
\text { medio de la cual se renueva el } \\
\text { registro calificado por } 7 \text { años. }\end{array}$ & $\begin{array}{c}7 \text { años. } \\
27 / 08 / 2026\end{array}$ \\
\hline
\end{tabular}


CONTINUACIÓN TABLA 40. Renovación de Registros Calificados

\begin{tabular}{|c|c|c|c|}
\hline 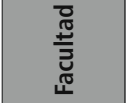 & $\begin{array}{l}\text { Nombre del } \\
\text { programa }\end{array}$ & $\begin{array}{l}\text { Número y fecha de la } \\
\text { resolución del MEN }\end{array}$ & Vigencia \\
\hline \multirow{3}{*}{ 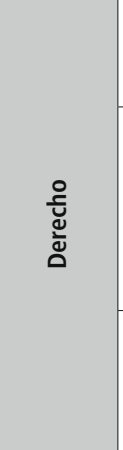 } & Derecho Bogotá & $\begin{array}{l}\text { Res. } 016166 \text { del 18/12/2019 Por } \\
\text { medio de la cual se resuelve la } \\
\text { renovación del registro calificado. }\end{array}$ & $\begin{array}{c}7 \text { años. } \\
\text { 17/12/2026 }\end{array}$ \\
\hline & $\begin{array}{l}\text { Especialización } \\
\text { en Procedimiento } \\
\text { Penal } \\
\text { Constitucional y } \\
\text { Justicia Militar } \\
\text { Bogotá y Campus }\end{array}$ & $\begin{array}{l}\text { Res. } 011716 \text { del } 07 / 11 / 2019 \text { Por } \\
\text { medio de la cual se resuelve } \\
\text { la solicitud de renovación y } \\
\text { modificación del registro calificado. }\end{array}$ & $\begin{array}{c}7 \text { años. } \\
\text { 06/11/2026 }\end{array}$ \\
\hline & $\begin{array}{l}\text { Especialización } \\
\text { en Derecho } \\
\text { Sancionatorio } \\
\text { Bogotá y Campus }\end{array}$ & $\begin{array}{l}\text { Res. } 015363 \text { del 18/12/2019 Por } \\
\text { medio de la cual se resuelve la } \\
\text { renovación del registro calificado. }\end{array}$ & $\begin{array}{c}7 \text { años. } \\
\text { 17/12/2026 }\end{array}$ \\
\hline \multirow{3}{*}{ 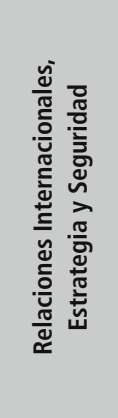 } & $\begin{array}{l}\text { Relaciones } \\
\text { Internacionales y } \\
\text { Estudios Políticos } \\
\text { Bogotá y Campus }\end{array}$ & $\begin{array}{l}\text { Res. } 015814 \text { del } 18 / 12 / 2019 \text { Por } \\
\text { medio de la cual se resuelve la } \\
\text { renovación del registro calificado. }\end{array}$ & $\begin{array}{c}7 \text { años. } \\
\text { 17/12/2026 }\end{array}$ \\
\hline & $\begin{array}{l}\text { Especialización } \\
\text { en Administración } \\
\text { de la Seguridad } \\
\text { Bogotá }\end{array}$ & $\begin{array}{l}\text { Res. } 015648 \text { del 18/12/2019 Por } \\
\text { medio de la cual se resuelve la } \\
\text { renovación del registro calificado. }\end{array}$ & $\begin{array}{c}7 \text { años. } \\
\text { 17/12/2026 }\end{array}$ \\
\hline & $\begin{array}{l}\text { Especialización } \\
\text { en Administración } \\
\text { de la Seguridad } \\
\text { Cali }\end{array}$ & $\begin{array}{l}\text { Res. } 016058 \text { del } 18 / 12 / 2019 \text { Por } \\
\text { medio de la cual se resuelve la } \\
\text { renovación del registro calificado. }\end{array}$ & $\begin{array}{c}7 \text { años. } \\
\text { 17/12/2026 }\end{array}$ \\
\hline 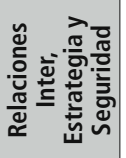 & $\begin{array}{l}\text { Especialización } \\
\text { en } \\
\text { Administración } \\
\text { de la Seguridad } \\
\text { Cartagena }\end{array}$ & $\begin{array}{l}\text { Res. } 016019 \text { del } 18 / 12 / 2019 \text { Por } \\
\text { medio de la cual se resuelve la } \\
\text { renovación del registro calificado. }\end{array}$ & $\begin{array}{c}7 \text { años. } \\
\text { 17/12/2026 }\end{array}$ \\
\hline
\end{tabular}

continúa 
CONTINUACIÓN TABLA 40. Renovación de Registros Calificados

\begin{tabular}{|c|c|c|c|}
\hline$\frac{7}{\frac{7}{5}}$ & $\begin{array}{l}\text { Nombre del } \\
\text { programa }\end{array}$ & $\begin{array}{l}\text { Número y fecha de la } \\
\text { resolución del MEN }\end{array}$ & Vigencia \\
\hline \multirow{5}{*}{ 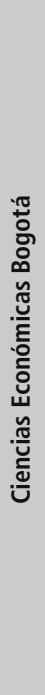 } & $\begin{array}{l}\text { Especialización } \\
\text { en Control } \\
\text { Interno }\end{array}$ & $\begin{array}{l}\text { Res. } 016191 \text { del 18/12/2019 Por } \\
\text { medio de la cual se resuelve la } \\
\text { renovación del registro calificado. }\end{array}$ & $\begin{array}{c}7 \text { años. } \\
\text { 17/12/2026 }\end{array}$ \\
\hline & $\begin{array}{l}\text { Especialización } \\
\text { en Gestión } \\
\text { de Desarrollo } \\
\text { Administrativo }\end{array}$ & $\begin{array}{l}\text { Res. } 016068 \text { del } 18 / 12 / 2019 \text { Por } \\
\text { medio de la cual se resuelve la } \\
\text { renovación y modificación del } \\
\text { registro calificado. }\end{array}$ & $\begin{array}{c}7 \text { años. } \\
\text { 17/12/2026 }\end{array}$ \\
\hline & $\begin{array}{l}\text { Especialización } \\
\text { en Revisoría } \\
\text { Fiscal y } \\
\text { Auditoria } \\
\text { Internacional }\end{array}$ & $\begin{array}{l}\text { Res. } 016044 \text { del } 18 / 12 / 2019 \text { Por } \\
\text { medio de la cual se resuelve la } \\
\text { renovación y modificación del } \\
\text { registro calificado. }\end{array}$ & $\begin{array}{c}7 \text { años. } \\
\text { 17/12/2026 }\end{array}$ \\
\hline & $\begin{array}{l}\text { Especialización } \\
\text { en Mercadeo de } \\
\text { Servicios }\end{array}$ & $\begin{array}{l}\text { Res. } 016040 \text { del } 18 / 12 / 2019 \text { Por } \\
\text { medio de la cual se resuelve la } \\
\text { renovación y modificación del } \\
\text { registro calificado. }\end{array}$ & $\begin{array}{c}7 \text { años. } \\
\text { 17/12/2026 }\end{array}$ \\
\hline & $\begin{array}{l}\text { Especialización } \\
\text { en Gerencia } \\
\text { de Comercio } \\
\text { Internacional }\end{array}$ & $\begin{array}{l}\text { Res. } 016046 \text { del 18/12/2019 Por } \\
\text { medio de la cual se resuelve la } \\
\text { renovación del registro calificado. }\end{array}$ & $\begin{array}{c}7 \text { años. } \\
\text { 17/12/2026 }\end{array}$ \\
\hline
\end{tabular}

Fuente: Vicerrectoría Académica (2020).

TABLA 41. Registros calificados en proceso de evaluación en Sistema de Aseguramiento de la Calidad en Educación (Saces)

\begin{tabular}{|l|c|l|}
\hline \multicolumn{1}{|c|}{ Nombre del programa } & $\begin{array}{c}\text { Fecha } \\
\text { radicación } \\
\text { documentos }\end{array}$ & \multicolumn{1}{|c|}{ Estado } \\
\hline Esp. En Medicina Interna & $14 / 06 / 2019$ & Completitud \\
\hline $\begin{array}{l}\text { Esp. en Administración Aeronáutica y } \\
\text { Aeroespacial }\end{array}$ & $22 / 07 / 2019$ & Recurso de Reposición \\
\hline
\end{tabular}


CONTINUACIÓN TABLA 41. Registros calificados en proceso de evaluación en Sistema de Aseguramiento de la Calidad en Educación (Saces)

\begin{tabular}{|l|c|l|}
\hline \multicolumn{1}{|c|}{ Nombre del programa } & $\begin{array}{c}\text { Fecha } \\
\text { radicación } \\
\text { documentos }\end{array}$ & \multicolumn{1}{|c|}{ Estado } \\
\hline $\begin{array}{l}\text { Especialización en Gerencia de la } \\
\text { Calidad }\end{array}$ & $30 / 07 / 2019$ & Completitud \\
\hline $\begin{array}{l}\text { Especialización en Planeación } \\
\text { Ambiental y Manejo Integral de los } \\
\text { Recursos Naturales }\end{array}$ & $30 / 07 / 2019$ & Completitud \\
\hline $\begin{array}{l}\text { Administración de la Seguridad y Salud } \\
\text { Ocupacional Bogotá y Campus }\end{array}$ & $23 / 10 / 2018$ & Recurso de Reposición \\
\hline Doctorado en Ingeniería & $29 / 07 / 2019$ & $\begin{array}{l}\text { Proyección y Generación } \\
\text { de Resolución }\end{array}$ \\
\hline
\end{tabular}

Fuente: Vicerrectoría Académica (2020).

TABLA 42. Programas Académicos Acreditados

\begin{tabular}{|l|l|l|}
\hline \multicolumn{1}{|c|}{$\begin{array}{c}\text { Nombre del } \\
\text { programa }\end{array}$} & \multicolumn{1}{|c|}{$\begin{array}{c}\text { Número y fecha de la } \\
\text { resolución del MEN }\end{array}$} & \multicolumn{1}{c|}{ Vigencia } \\
\hline Derecho & $\begin{array}{l}\text { Resol. 13933 del 08 de octubre de } \\
\text { 2013. Renovación }\end{array}$ & $\begin{array}{l}\text { Vencido. La visita se } \\
\text { recibió en Octubre. } \\
\text { En espera de Informe }\end{array}$ \\
\hline $\begin{array}{l}\text { Tecnología en } \\
\text { Electrónica y } \\
\text { Comunicaciones }\end{array}$ & $\begin{array}{l}\text { Resol. 17274 del } 29 \text { de noviembre } \\
\text { de 2013. Renovación }\end{array}$ & $\begin{array}{l}\text { 6 años. } \\
\text { La visita se realizó en } \\
\text { mayo de 2019. }\end{array}$ \\
\hline $\begin{array}{l}\text { Ingeniería } \\
\text { Mecatrónica }\end{array}$ & $\begin{array}{l}\text { Resol. 20269 del 27 de noviembre } \\
\text { de 2014. Otorgamiento }\end{array}$ & $\begin{array}{l}\text { 6 años. Vence en } \\
\text { noviembre de 2020 }\end{array}$ \\
\hline Medicina & $\begin{array}{l}\text { Resol. 21086 del 24 de diciembre } \\
\text { de 2015. Renovación }\end{array}$ & $\begin{array}{l}\text { 6 años. Vence en } \\
\text { diciembre de 2021 }\end{array}$ \\
\hline Contaduría Pública & $\begin{array}{l}\text { Resol. 1447 del 3 de febrero de } \\
\text { 2017. Otorgamiento }\end{array}$ & $\begin{array}{l}\text { 4 años. Vence en } \\
\text { febrero de 2021 }\end{array}$ \\
\hline Biología Aplicada & $\begin{array}{l}\text { Resol. 29162 del } 26 \text { de diciembre } \\
\text { de 2017. Renovación }\end{array}$ & $\begin{array}{l}\text { 4 años. Vence en } \\
\text { diciembre de 2021 }\end{array}$ \\
\hline
\end{tabular}


CONTINUACIÓN TABLA 42. Programas Académicos Acreditados

\begin{tabular}{|l|l|l|}
\hline \multicolumn{1}{|c|}{$\begin{array}{c}\text { Nombre del } \\
\text { programa }\end{array}$} & \multicolumn{1}{|c|}{$\begin{array}{c}\text { Número y fecha de la } \\
\text { resolución del MEN }\end{array}$} & \multicolumn{1}{c|}{ Vigencia } \\
\hline $\begin{array}{l}\text { Administración de } \\
\text { Empresas }\end{array}$ & $\begin{array}{l}\text { Resol. 11558 del 17 de julio de } \\
\text { 2018. Renovación }\end{array}$ & $\begin{array}{l}\text { 4 años. Vence en julio } \\
\text { de 2022 }\end{array}$ \\
\hline Ingeniería Civil & $\begin{array}{l}\text { Resol.4261 del 7 de marzo de } \\
\text { 2016. Renovación }\end{array}$ & $\begin{array}{l}6 \text { años. Vence en } \\
\text { marzo de 2022. }\end{array}$ \\
\hline Ingeniería Industrial & $\begin{array}{l}\text { Resol. 11595 del 17 de julio de } \\
\text { 2018. Renovación }\end{array}$ & $\begin{array}{l}\text { 4 años. Vence en julio } \\
\text { de 2022 }\end{array}$ \\
\hline $\begin{array}{l}\text { Ingeniería en } \\
\text { Telecomunicaciones }\end{array}$ & $\begin{array}{l}\text { Resol. 03990 del 12 de abril de } \\
\text { 2019. Otorgamiento }\end{array}$ & $\begin{array}{l}\text { 4 años. Vence en abril } \\
\text { de 2023 }\end{array}$ \\
\hline Economía & $\begin{array}{l}\text { Resol. 04447 del 8 de mayo de } \\
\text { 2019. Otorgamiento }\end{array}$ & $\begin{array}{l}\text { 4 años. Vence en } \\
\text { mayo de 2023 }\end{array}$ \\
\hline $\begin{array}{l}\text { Relaciones } \\
\text { Internacionales y } \\
\text { Estudios Políticos }\end{array}$ & $\begin{array}{l}\text { Resol. 007583 del 24 de julio de } \\
\text { 2019. Otorgamiento }\end{array}$ & $\begin{array}{l}\text { 4 años. Vence en julio } \\
\text { de 2023 }\end{array}$ \\
\hline $\begin{array}{l}\text { Ingeniería } \\
\text { Multimedia }\end{array}$ & $\begin{array}{l}\text { Resol. 009742 del 11 de } \\
\text { septiembre de 2019. Otorgamiento }\end{array}$ & $\begin{array}{l}\text { 4 años. Vence en } \\
\text { septiembre de 2023 }\end{array}$ \\
\hline
\end{tabular}

Fuente: Vicerrectoría Académica (2020).

\section{Nuevos programas académicos en 2019}

La universidad, durante el 2019, gestionó lo pertinente para realizar lectura de los documentos maestros por pares externos; esto con el fin de garantizar la pertinencia de los contenidos y documentación de los nuevos programas académicos.

En la Tabla 43, se relacionan los nuevos programas, ocho en total: tres pregrados, cuatro maestrías y un doctorado, este último en compleción con toda la documentación radicada en Sistema de Aseguramiento de la Calidad de la Educación Superior (Saces). 
TABLA 43. Nuevos programas académicos

\begin{tabular}{|c|c|c|c|c|}
\hline \multicolumn{5}{|c|}{ Vigencia 2019} \\
\hline Facultad & Sede & $\begin{array}{c}\text { Nombre del } \\
\text { programa }\end{array}$ & $\begin{array}{l}\text { Nivel de } \\
\text { formación }\end{array}$ & Situación Actual \\
\hline Ingeniería & $\begin{array}{l}\text { Campus } \\
\text { Nueva } \\
\text { Granada }\end{array}$ & $\begin{array}{l}\text { Ingeniería } \\
\text { Química }\end{array}$ & Pregrado & $\begin{array}{l}\text { Documento maestro } \\
\text { listo con decreto } \\
1075 \text {, se debe } \\
\text { ajustar al } 1330 .\end{array}$ \\
\hline Ingeniería & $\begin{array}{l}\text { Campus } \\
\text { Nueva } \\
\text { Granada }\end{array}$ & $\begin{array}{l}\text { Ingeniería } \\
\text { de Recursos } \\
\text { Energéticos }\end{array}$ & Pregrado & $\begin{array}{l}\text { Documento maestro } \\
\text { listo con decreto } \\
1075 \text {, se debe } \\
\text { ajustar al } 1330 .\end{array}$ \\
\hline $\begin{array}{l}\text { Ciencias } \\
\text { Básicas y } \\
\text { Aplicadas }\end{array}$ & $\begin{array}{l}\text { Campus } \\
\text { Nueva } \\
\text { Granada }\end{array}$ & $\begin{array}{l}\text { Matemáticas } \\
\text { Aplicadas }\end{array}$ & Pregrado & $\begin{array}{l}\text { Documento maestro } \\
\text { listo con decreto } \\
1075 \text {, se debe } \\
\text { ajustar al } 1330 .\end{array}$ \\
\hline $\begin{array}{l}\text { Relaciones } \\
\text { Internacionales, } \\
\text { Estrategia y } \\
\text { Seguridad }\end{array}$ & Bogotá & $\begin{array}{l}\text { Maestría en } \\
\text { Seguridad y } \\
\text { Gestión del } \\
\text { Riesgo }\end{array}$ & Posgrado & $\begin{array}{l}\text { Documento maestro } \\
\text { listo con decreto } \\
1075, \text { se debe } \\
\text { ajustar al } 1330 .\end{array}$ \\
\hline $\begin{array}{l}\text { Ciencias } \\
\text { Económicas }\end{array}$ & Bogotá & $\begin{array}{l}\text { Maestría en } \\
\text { Contabilidad y } \\
\text { Aseguramiento } \\
\text { de la } \\
\text { Información }\end{array}$ & Posgrado & $\begin{array}{l}\text { Documento maestro } \\
\text { listo con decreto } \\
1075, \text { se debe } \\
\text { ajustar al } 1330 .\end{array}$ \\
\hline Ingeniería & Bogotá & $\begin{array}{l}\text { Maestría en } \\
\text { Ciencias de la } \\
\text { Información } \\
\text { Geoespacial }\end{array}$ & Posgrado & $\begin{array}{l}\text { Documento maestro } \\
\text { listo con decreto } \\
1075, \text { se debe } \\
\text { ajustar al } 1330 .\end{array}$ \\
\hline Ingeniería & $\begin{array}{l}\text { Campus } \\
\text { Nueva } \\
\text { Granada }\end{array}$ & $\begin{array}{l}\text { Maestría en } \\
\text { Tecnologías } \\
\text { y Procesos } \\
\text { Sostenibles } \\
\end{array}$ & Posgrado & $\begin{array}{l}\text { Documento maestro } \\
\text { listo con decreto } \\
1075 \text {, se debe } \\
\text { ajustar al } 1330 .\end{array}$ \\
\hline Ingeniería & Bogotá & $\begin{array}{l}\text { Doctorado en } \\
\text { Ingeniería }\end{array}$ & Posgrado & En completitud \\
\hline
\end{tabular}

Fuente: Vicerrectoría Académica (2020). 


\section{Proceso de renovación de la Acreditación Institucional Multicampus}

Dentro de la ruta de la excelencia planteada como guía de los procesos de autoevaluación con fines de renovación de la acreditación institucional multicampus, basada en los lineamientos del Consejo Nacional de Acreditación CNA 2014 (institucional), 2010 (maestrías), 2013 (programas pregrado) y 2017 (especialidades médico quirúrgicas) de la Universidad Militar Nueva Granada, se continúa por las fases de mantenimiento, alistamiento, presentación y tránsito, para cumplir con los requerimientos para la entrega del informe de autovaluación el 15 de julio de 2020.

En 2019 se recibieron visitas de evaluación externa con fines de renovación de la acreditación de los programas de Tecnología en electrónica y comunicaciones, y Derecho de la sede Bogotá; y por primera vez de los programas de Contaduría Pública de la Facultad de Estudios a distancia, y de las especialidades médico quirúrgicas de Medicina Física y Rehabilitación y Neurocirugía, de la Facultad de Medicina y Ciencias de la Salud.

Durante la vigencia 2019 se contaba con los programas acreditados por sede visibles en la Figura 22. 


\section{Programas acreditados 2019}

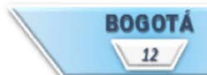

CAMPUS NUEVA GRANADA

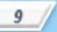

\begin{tabular}{|l|l|}
\hline Administración de empresas \\
Contaduria pública \\
\hline Derecho \\
\hline Economia \\
\hline Ingenieria civil \\
\hline Ingenieria en multimedia \\
\hline Ingenieria en telecomunicaciones \\
\hline Ingenieria industrial \\
\hline Relaciones internacionales y estudios politicos \\
\hline Ingenieria mecatrónica \\
\hline Medicina \\
\hline Tecnologia en electrónica y comunicaciones
\end{tabular}

FIGURA 22. Programas Acreditados en 2019 vistos por sede. Fuente: Oficina de Acreditación Institucional (2019).

Dentro del sistema Institucional de Autoevaluación de la Universidad Militar Nueva Granada, y como parte del proceso de autoevaluación con fines de renovación de la Acreditación Institucional Multicampus, el 31 de diciembre de 2019 se dio cierre al Plan de mejoramiento 20172019, originado en el ejercicio evaluativo 2016-2017; el cierre se llevó a cabo con los lineamientos del cNA para tal fin en el 2014. Esta actividad fue un trabajo colaborativo desarrollado por los grupos de apoyo por factor por sede, en el que se establecieron 130 acciones de mejoramiento, sujetas a análisis y seguimiento, logrando cerrar la vigencia con un cumplimiento del 83\%. 
El 17\% que al cierre de la vigencia aún no han sido finalizadas, fueron retomadas por la Autoevaluación Institucional 2019 - 2020 que será entregada al cNA a mediados del año y tendrá como producto el plan de mejoramiento 2020-2022, Para el 31 de diciembre se cerró el plan de mejoramiento institucional 2017-2019 como se muestra en la Figura 23.

\section{Plan de mejoramiento 2017 - 2019}

Características

35

Asuectos a evaluar

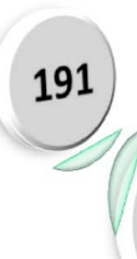

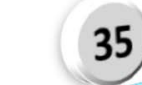

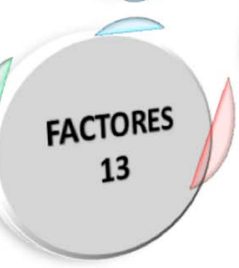

130 ageiones

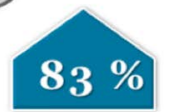

FIGURA 23. Plan de Mejoramiento 2017-2019. Fuente: Oficina de Acreditación Institucional (2019). 


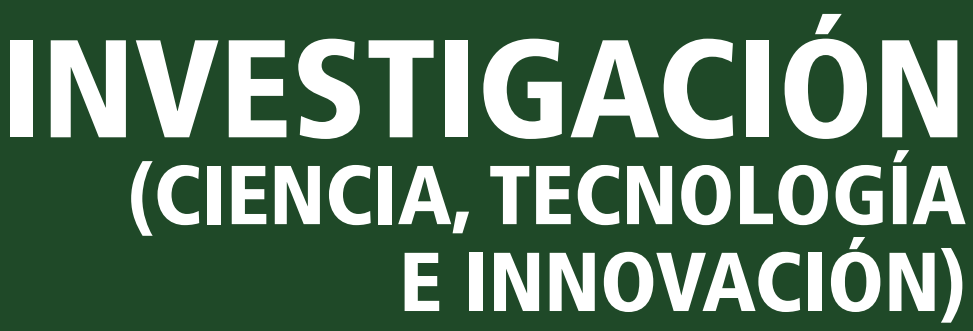





\section{CONTENIDO}

127 Investigación científica

131 Desarrollo tecnológico e innovación

134 Editorial Neogranadina

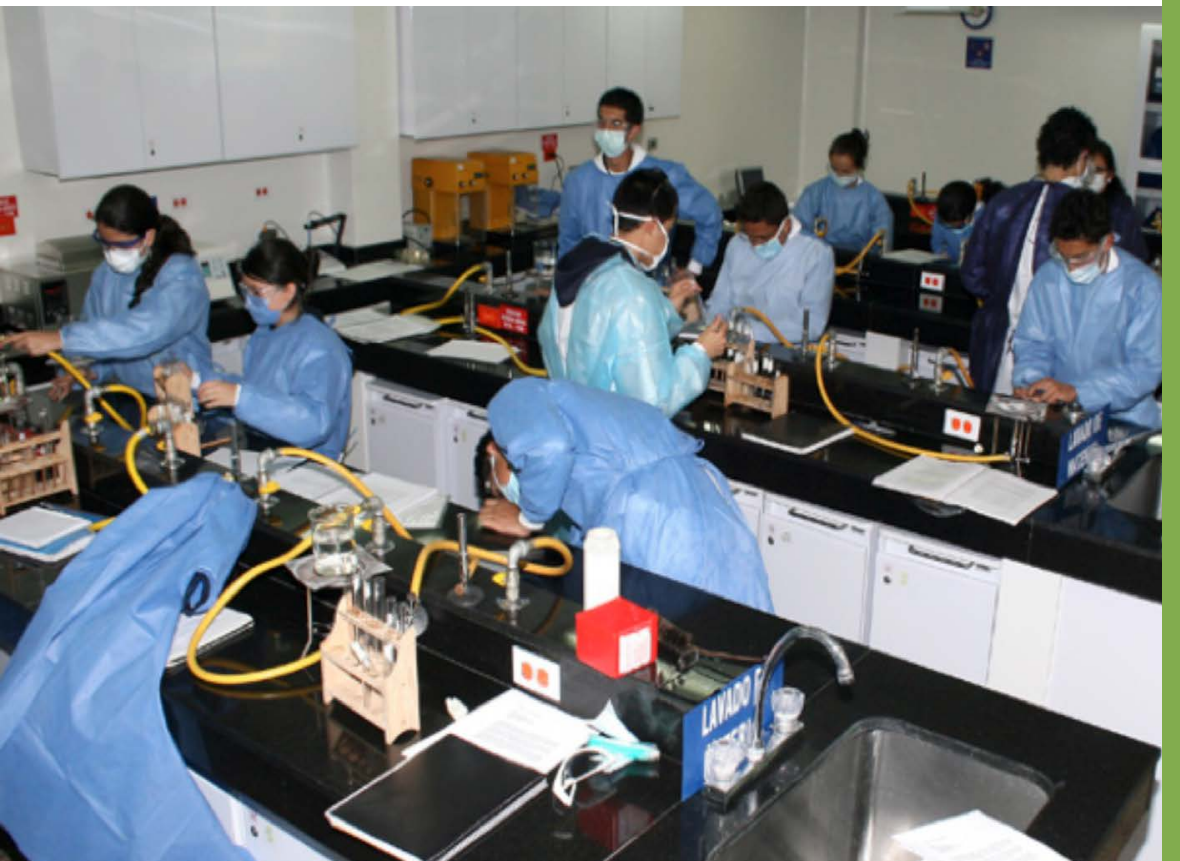


Enucteilw

of CEUIOL

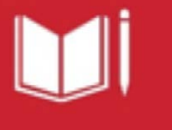

Para alcanzar la excelencia académica, desde Vicerrectoría de Investigaciones de la unng se forjó la Política de Formación para la Investigación, la Innovación y el Emprendimiento (PFIE), con el fin de fortalecer los procesos de formación para la investigación, la innovación y el emprendimiento en la UMNG. La idea es promover el desarrollo de las competencias y habilidades necesarias en la formación de profesionales autónomos, reflexivos, críticos, éticos y socialmente responsables, con capacidades para la argumentación, la rigurosidad científica y el trabajo colectivo.

\section{GRI 103-1}

TABLA 44. Importancia de la Política fiie

\begin{tabular}{|c|l|}
\hline F & $\begin{array}{l}\text { Formación. La umNG tiene como objetivo ser un referente en investigación } \\
\text { científica con repercusión en el triángulo universidad-empresa-Estado. La } \\
\text { política FllE surge para fortalecer la relación existente entre formación e } \\
\text { investigación. }\end{array}$ \\
\hline I & $\begin{array}{l}\text { Investigación. Permite la inmersión en la lógica y las prácticas de la } \\
\text { investigación científica, de modo que el nuevo conocimiento que se } \\
\text { genere, se apropie, y se aplique en diferentes contextos }\end{array}$ \\
\hline I & $\begin{array}{l}\text { Innovación. Da las herramientas para buscar, descubrir y desarrollar nuevas } \\
\text { oportunidades, a través de modelos de implementación. }\end{array}$ \\
\hline E & $\begin{array}{l}\text { Emprendimiento. Asume las iniciativas de cambio desde la perspectiva del } \\
\text { líder, que busca el logro de objetivos determinados, gestiona riesgos y genera } \\
\text { prácticas sistemáticas para innovar. }\end{array}$ \\
\hline
\end{tabular}

Fuente: Vicerrectoría de Investigaciones. 


\section{GRI 103-2}

Cultura de la investigación, la innovación y el emprendimiento importancia de la Política FIIE

Con la política fiie se busca crear una cultura. Es decir, un conjunto de prácticas, acciones, significados, disposiciones y directrices que se interiorizan, reproducen y manifiestan de forma colectiva, y que determinan el comportamiento institucional hacia la investigación, para desarrollar la producción de conocimiento científico y académico, y para formar investigadores y profesionales que promuevan la innovación y el emprendimiento.

\section{Objetivos específicos}

- Promover la cultura investigativa a través del uso de metodologías y estrategias pedagógicas, orientadas al desarrollo de competencias y habilidades relacionadas con la investigación formativa.

- Potenciar la capacidad investigativa, innovadora y emprendedora de los estudiantes de la UMNG.

- Fomentar entre los profesores de la UMNG la formación para la investigación, la innovación y el emprendimiento, así como la investigación formativa.

- Articular espacios, actividades y estrategias de fomento de la formación para la investigación, la innovación y el emprendimiento con el currículo actual de la uMNG. 
- Impulsar la formación de profesionales con la capacidad, la habilidad y la iniciativa de trabajar en equipos multidisciplinares e interdisciplinares.

- Incentivar la población docente para que implemente estrategias de aprendizaje por descubrimiento y construcción en la elaboración de sus programas de cursos o syllabus.

- Establecer las estrategias necesarias para alimentar la formación de profesionales con un sentido de la responsabilidad ética, social y ambiental.

\section{Presupuesto de investigación para 2019}

En este orden de ideas, el presupuesto aprobado para la vigencia 2019, se estableció como se enuncia en la Tabla 45.

\section{GRI 102-15}

TABLA 45. Presupuesto de investigación para 2019

\begin{tabular}{|c|c|c|}
\hline Programa o línea de acción & Proyectos & Valor asignado \\
\hline Proyectos de investigación científica & 67 & $\$ 4.190 .388 .439$ \\
\hline Proyectos de alto impacto año 1 & 15 & $\$ 1.936 .165 .934$ \\
\hline Proyectos de alto impacto año 2 & 10 & $\$ 1.513 .277 .189$ \\
\hline Proyectos de iniciación científica 1er. semestre & 34 & $\$ 13.991 .230$ \\
\hline Proyectos de iniciación científica 20. semestre & 32 & $\$ 16.984 .910$ \\
\hline Proyectos de innovación & 8 & $\$ 229.943 .470$ \\
\hline Total & 166 & $\$ 7.900 .751 .172$ \\
\hline
\end{tabular}

Fuente: Vicerrectoría de Investigaciones. 

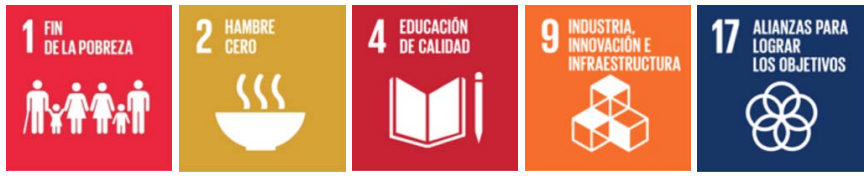

FIGURA 24. Objetivos de desarrollo sostenible relacionados. Fuente: Organización de Naciones Unidas (2016). Propiedad Intelectual @

\section{Investigación científica}

Los recursos asignados al fondo de investigación nos permiten mostrar la siguiente gestión en términos de investigación (Tabla 46, Figura 25).

TABLA 46. Grupos de investigación clasificados por Colciencias

\begin{tabular}{|c|c|c|}
\hline Clasificación & 2018 & 2019 \\
\hline A1 & 3 & 4 \\
\hline A & 7 & 7 \\
\hline B & 6 & 12 \\
\hline C & 42 & 35 \\
\hline Reconocido & 0 & 1 \\
\hline No Reconocido & 9 & 11 \\
\hline
\end{tabular}

Fuente: Vicerrectoría de Investigaciones. 


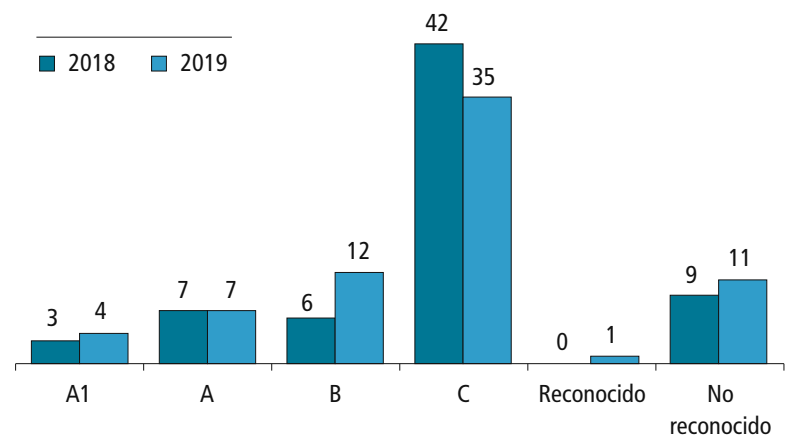

FIGURA 25. Grupos de investigación clasificados por Colciencias. Fuente: Vicerrectoría de Investigaciones.

\section{GRI 103-3}

Los docentes de las facultades participaron en proyectos de investigación durante la vigencia 2019 dedicando en total 6.717 horas a investigación (Tabla 47 y Figura 26).

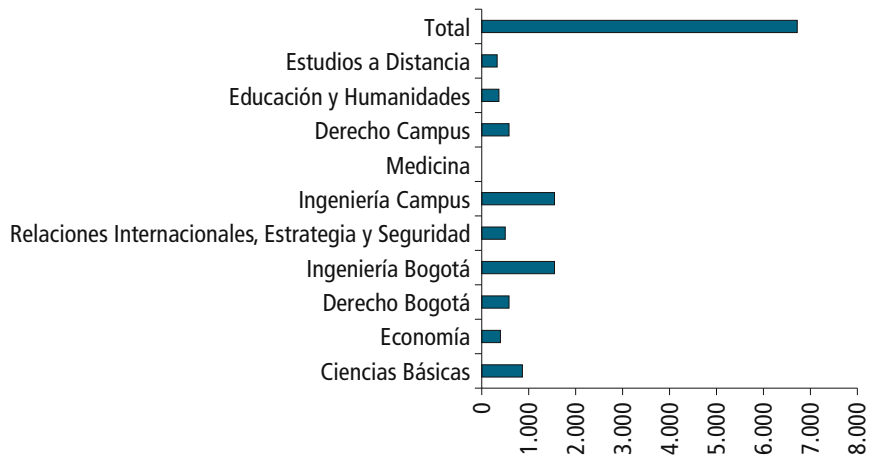

FIGURA 26. Número de horas dedicadas 2019. Fuente: Vicerrectoría de Investigaciones. 


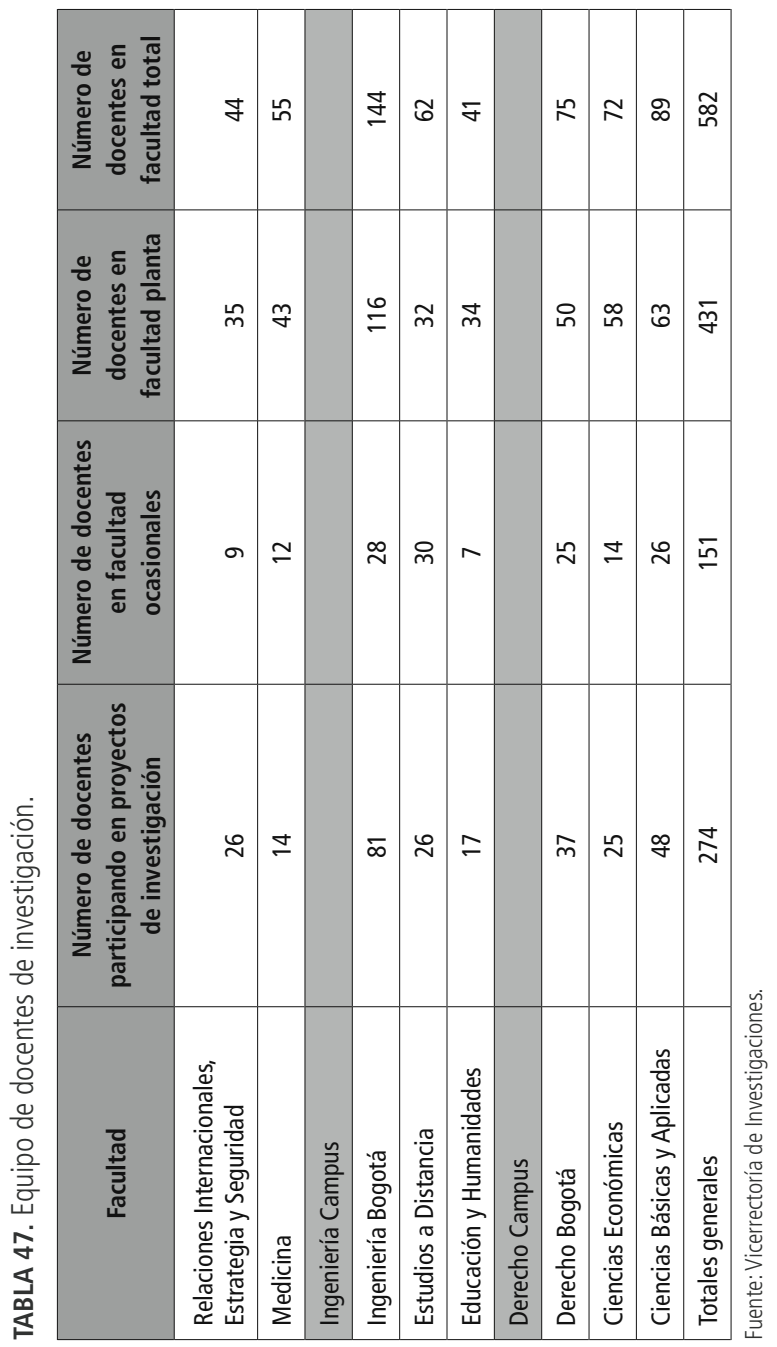

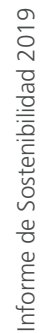


TABLA 48. Convocatorias Internas

\begin{tabular}{|l|c|c|}
\hline \multicolumn{1}{|c|}{ Nombre convocatoria } & $\begin{array}{c}\text { Número de proyectos } \\
\text { presentados }\end{array}$ & $\begin{array}{c}\text { Total } \\
\text { aprobados }\end{array}$ \\
\hline Convocatoria de alto impacto & 16 & 14 \\
\hline Convocatoria de investigación científica & 177 & 72 \\
\hline Convocatoria de iniciación científica 2019-1 & 105 & 92 \\
\hline Convocatoria de iniciación científica 2019-2 & 76 & 0 \\
\hline Total de proyectos & 374 & 178 \\
\hline
\end{tabular}

Fuente: Vicerrectoría de Investigaciones.

Programa de movilidad de docentes investigadores

El programa de movilidad de docentes investigadores financia la participación de docentes investigadores en eventos científicos nacionales e internacionales, con el fin de divulgar los resultados parciales y finales de los proyectos de investigación. Un total de 34 movilidades se aprobaron en el 2019 (Figura 27).

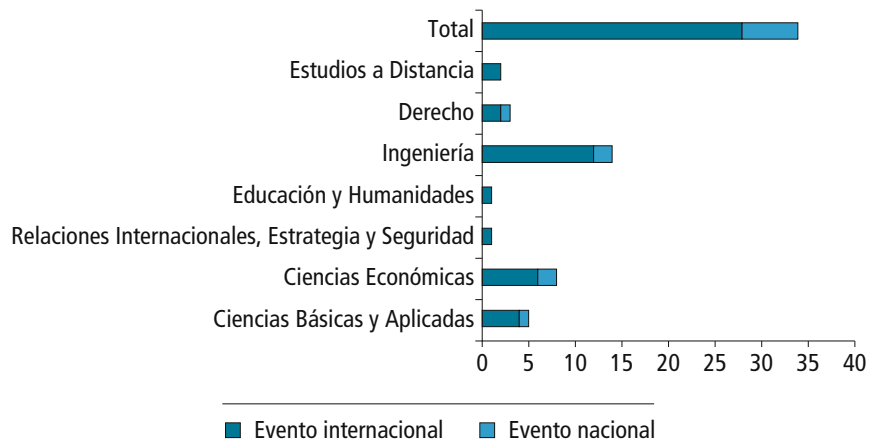

FIGURA 27. Programa de movilidad de docentes investigadores. Fuente: Vicerrectoría de Investigaciones. 

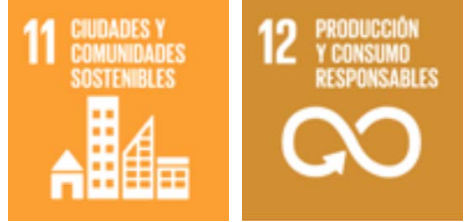

FIGURA 28. Objetivos de desarrollo sostenible relacionados. Fuente: Organización de Naciones Unidas (2016). Propiedad Intelectual $®$

\section{Desarrollo tecnológico e innovación}

\section{Convocatorias de innovación}

De las convocatorias desarrolladas en 2019 se distinguen las señaladas en la Tabla 49.

TABLA 49. Las convocatorias desarrolladas en 2019

\begin{tabular}{|l|c|c|c|}
\hline \multicolumn{1}{|c|}{ Convocatoria } & Postulados & Aprobados & Facultad \\
\hline $\begin{array}{l}\text { Convocatoria interna para conformar } \\
\text { un banco de proyectos de desarrollo } \\
\text { tecnológico e innovación financiables, } \\
\text { vigencia 2019. }\end{array}$ & 1 & 1 & Ingeniería \\
\hline $\begin{array}{l}\text { Convocatoria extraordinaria para el } \\
\text { fortalecimiento y apoyo de invenciones } \\
\text { con potencial de protección, } \\
\text { transferencia o comercialización, } \\
\text { vigencia 2019. }\end{array}$ & 6 & 4 & $\begin{array}{l}\text { Ingeniería } \\
\text { Ciencias } \\
\text { Básicas }\end{array}$ \\
\hline $\begin{array}{l}\text { Convocatoria para el fortalecimiento y } \\
\text { apoyo de innovaciones con potencial } \\
\text { de protección, transferencia o } \\
\text { comercialización, vigencia segundo } \\
\text { semestre de 2019. }\end{array}$ & 6 & 2 & Ingeniería \\
\hline
\end{tabular}

Fuente: Vicerrectoría de Investigaciones. 


\section{Creaciones}

Relación histórica de patentes concedidas y solicitadas con corte a 2019 (Tabla 50).

TABLA 50. Relación histórica de patentes concedidas y solicitadas con corte a 2019

\begin{tabular}{|l|c|}
\hline \multicolumn{1}{|c|}{ Tipo de proceso } & Cantidad \\
\hline Patentes de invención concedidas & 30 \\
\hline Patentes de modelo de utilidad concedidas & 14 \\
\hline Patentes internacionales & 7 \\
\hline Radicadas en Colombia (examen de forma) & 1 \\
\hline Radicadas internacionalmente (PCT) & 0 \\
\hline Procesos de búsqueda autorizados & 2 \\
\hline En proceso de autorización & 8 \\
\hline
\end{tabular}

Fuente: Vicerrectoría de Investigaciones.

Entre los registros concedidos por la Dirección de Derechos de Autor se observó lo consignado en la Tabla 51.

TABLA 51. Registros concedidos de la Dirección de Derechos de Autor

\begin{tabular}{|l|l|}
\hline$\#$ & \multicolumn{1}{|c|}{ SOFTWARE } \\
\hline 1 & Canalización de acceso venoso central en dispositivo móvil \\
\hline 2 & Software Cadvi \\
\hline 3 & Software miтı \\
\hline 4 & Software para la plataforma robótica móvil terrestre para exploración minera \\
\hline 5 & Acceso venoso central yugular inmersivo \\
\hline 6 & Plataforma de tsp en diseño de bodegas \\
\hline 7 & Análisis de la radiación solar sobre el Campus Nueva Granada \\
\hline 8 & Diseño para dimensión de monobrazo para vehículos de ruedas \\
\hline 9 & VoinVo \\
\hline
\end{tabular}

Fuente: Vicerrectoría de Investigaciones. 


\section{Emprendimiento}

Opción de grado de innovación para el emprendimiento y Club de Emprendedores Neogranadinos.

TABLA 52. Actividades de innovación y emprendimiento

\begin{tabular}{|l|}
\hline Hub de innovación y conocimiento \\
\hline Centro de apoyo a las tecnologías y la información - CATI \\
\hline Mapeo tecnológico \\
\hline Red de oficinas de transferencia tecnológica \\
\hline Taller de comercialización de tecnologías \\
\hline $\begin{array}{l}\text { Impulso al Parque Científico y Tecnológico como proyecto bandera de la División } \\
\text { de Desarrollo Tecnológico e Innovación, por medio de dos programas: la Unidad de } \\
\text { Emprendimiento y la Incubadora Neogranadina de Empresas de Base Tecnológica } \\
\text { (Inebatec) }\end{array}$ \\
\hline Campus de emprendimiento \\
\hline
\end{tabular}

Fuente: Vicerrectoría de Investigaciones.
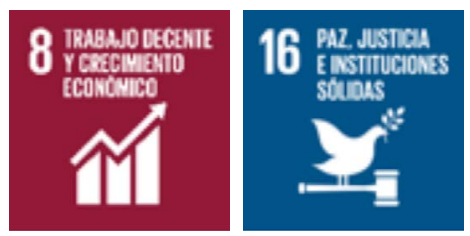

FIGURA 29. Objetivos de desarrollo sostenible relacionados. Fuente: Organización de Naciones Unidas (2016). Propiedad Intelectual @ 


\section{Editorial Neogranadina}

Las ventas que se han dado en el transcurso de la vigencia 2019 se presentan en la Tabla 53.

TABLA 53. Venta de libros.

\begin{tabular}{|c|c|c|}
\hline \multicolumn{2}{|r|}{ Ventas de libros } & Total \\
\hline \multirow{8}{*}{$\begin{array}{c}\text { Colección } \\
\text { bicentenario }\end{array}$} & $\begin{array}{l}\text { La educación en Colombia. Una perspectiva } \\
\text { histórica }\end{array}$ & 80 \\
\hline & $\begin{array}{l}\text { Historia de libertad. Un viaje mimético hacia el } \\
\text { sentido de la independencia de Colombia }\end{array}$ & 91 \\
\hline & Geopolítica e infraestructura de Colombia & 74 \\
\hline & $\begin{array}{l}\text { Desarrollo histórico del orden político en } \\
\text { Colombia }\end{array}$ & 78 \\
\hline & Historia de la ciencia en Colombia & 76 \\
\hline & Historia económica de Colombia & 79 \\
\hline & $\begin{array}{l}\text { Política y relaciones internacionales en la } \\
\text { infancia republicana de Colombia }\end{array}$ & 80 \\
\hline & Colección completa bicentenario & 47 \\
\hline \multirow{2}{*}{$\begin{array}{l}\text { Difusión } \\
\text { científica }\end{array}$} & $\begin{array}{l}\text { Historia y geografía de algunas enfermedades } \\
\text { de Colombia }\end{array}$ & 113 \\
\hline & $\begin{array}{l}\text { Toxicología para administradores de la } \\
\text { seguridad y salud en el trabajo }\end{array}$ & 144 \\
\hline $\begin{array}{l}\text { Colección } \\
\text { derecho público }\end{array}$ & $\begin{array}{l}\text { Entre la guerra y la paz: un estudio crítico sobre } \\
\text { la cultura jurídica colombiana y española }\end{array}$ & 192 \\
\hline $\begin{array}{c}\text { Diálogos de } \\
\text { innovación }\end{array}$ & $\begin{array}{l}\text { Innovación en organizaciones colombianas. } \\
\text { Casos de estudio }\end{array}$ & 38 \\
\hline \multirow{2}{*}{$\begin{array}{l}\text { Difusión } \\
\text { científica }\end{array}$} & Introducción al cálculo fraccional & 37 \\
\hline & Políticas públicas de la educación & 10 \\
\hline \multicolumn{2}{|r|}{ Total } & 1139 \\
\hline
\end{tabular}




\section{Producción editorial}

\section{GRI 102-17}

En la Figura 30 se muestra la cantidad de libros, revistas y textos de literatura gris en proceso de producción y la colección en la cual serán incluidas en la Tabla 54.

TABLA 54. Enfoque de las obras recibidas.

\begin{tabular}{|l|c|}
\hline \multicolumn{1}{|c|}{ Enfoque } & Cantidad \\
\hline Colección investigación & 18 \\
\hline Colección docencia & 5 \\
\hline Colección divulgación & 4 \\
\hline Colección derecho público & 2 \\
\hline Colección literatura gris & 5 \\
\hline Revistas umng & 17 \\
\hline
\end{tabular}

Fuente: Vicerrectoría de Investigaciones.

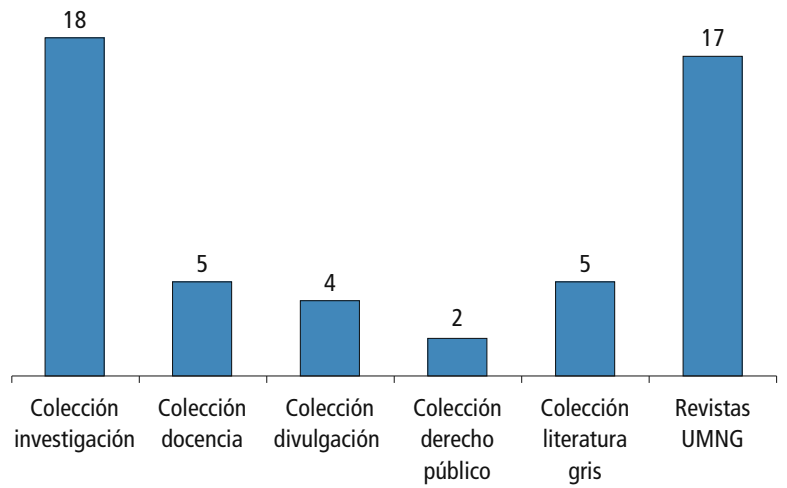

FIGURA 30. Enfoque de obras recibidas. Fuente: Vicerrectoría de Investigaciones. 
Respecto a las revistas de la UMNG, el crecimiento en nuevos visitantes entre los años 2018 y 2019 fue del 233\%, siendo las revistas Prolegómenos con 55.680 y Educación y Desarrollo social con 33.092, las de mayor número de visitantes nuevos (Tabla 55).

TABLA 5. Pospublicaciones

\begin{tabular}{|l|c|c|c|c|}
\hline \multirow{2}{*}{\multicolumn{1}{|c|}{ Revista }} & \multicolumn{2}{c|}{2018} & \multicolumn{2}{c|}{2019} \\
\cline { 2 - 6 } & $\begin{array}{c}\text { Nuevos } \\
\text { visitantes } \\
\text { (2018) }\end{array}$ & $\begin{array}{c}\text { Visitantes } \\
\text { regulares } \\
\text { (2018) }\end{array}$ & $\begin{array}{c}\text { Nuevos } \\
\text { visitantes } \\
\text { (2019) }\end{array}$ & $\begin{array}{c}\text { Visitantes } \\
\text { regulares } \\
\text { (2019) }\end{array}$ \\
\hline Facultad de Ciencias básicas & 12.261 & 1.950 & 19.227 & 3.091 \\
\hline Med & 9.073 & 1.102 & 19.666 & 2.150 \\
\hline $\begin{array}{l}\text { Relaciones Internacionales, } \\
\text { estrategia y seguridad }\end{array}$ & 9.178 & 1.321 & 25.622 & 3.379 \\
\hline $\begin{array}{l}\text { Latinoamericana } \\
\text { de bioética }\end{array}$ & 13.847 & 1.838 & 25.730 & 3.143 \\
\hline Academia y Virtualidad & 1.752 & 12.777 & 26.314 & 3.244 \\
\hline Educación y desarrollo social & 16.929 & 1.910 & 33.092 & 3.273 \\
\hline $\begin{array}{l}\text { Facultad de Ciencias } \\
\text { económicas }\end{array}$ & 36 & 2 & 2.312 & 283 \\
\hline Prolegómenos & 21.342 & 1.990 & 54.680 & 5.280 \\
\hline \multirow{2}{*}{$\underset{\sim}{\text { Ciencias e ingeniería }}$} & 32.876 & 3.834 & 76.607 & 8.061 \\
\hline neogranadina & & & & \\
\hline
\end{tabular}

Fuente: Vicerrectoría de Investigaciones. 


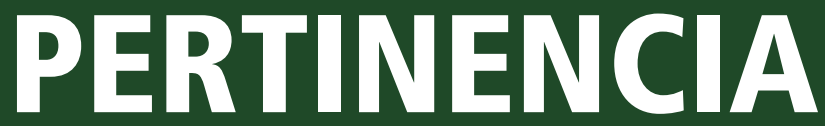





\section{CONTENIDO}

140 Permanencia estudiantil

140 Extensión y proyección social

150 Tecnologías de la información y comunicaciones

151 Gestión de calidad

153 Comunicaciones, publicaciones y mercadeo

155 Instituto nacional e Internacional de posgrados (Inip)

159 Instituto de Estudios Geoestratégicos y Asuntos Políticos (legap) 


\section{GRI 103-3}

\section{Permanencia estudiantil}

Durante el 2019 se logró fortalecer el equipo de trabajo del Centro de Acompañamiento y Seguimiento Estudiantil con la vinculación de profesionales que hacen parte del Plan Fomento a la Calidad de la Educación Superior y quienes están a cargo de siete proyectos transversales a la formación académico-profesional de los estudiantes. Con ellos se beneficia a la comunidad neogranadina y a otros grupos de interés, impactando de forma positiva en el desempeño académico y calidad de vida de los estudiantes, lo que aporta a la permanencia y graduación estudiantil en aras de generar cambios a nivel social, formando ciudadanos íntegros y socialmente responsables en su ejercicio profesional.

\section{Extensión y proyección social}

\section{GRI 102-19}

La extensión como función misional de la Universidad Militar fortalece la interacción con el entorno mediante la actualización del conocimiento y el desarrollo de 
actividades en articulación con las unidades académicas, como respuesta a las necesidades de la sociedad en general y del sector defensa. Así mismo, se establece una interacción privilegiada y recíproca entre el conocimiento sistemático de la academia y los saberes y necesidades de la sociedad y de las organizaciones e instituciones que hacen parte de ella.

Esta relación se debe reflejar en la ampliación del espacio de liberación democrática y en el bienestar de las comunidades. Con la extensión se cualifican la ciencia, la tecnología, el arte y la cultura, con el fin de que se promueva el intercambio recíproco del conocimiento entre la Universidad Militar y la sociedad y así contribuir de manera permanente en el marco del desarrollo de la misma sociedad.

La Universidad Militar Nueva Granada, comprometida con su entorno, está orientando su concepción de proyección social dentro del marco general de su misión, la cual está articulada con procesos de desarrollo social, económico y cultural, en el contexto institucional y en los contextos locales y regionales.

El conjunto de acciones que se desprenden de la proyección social como función sustantiva, hace que se responda a los interrogantes de un mundo en constante transformación, para lo cual la comunidad educativa debe generar resultados a tiempo y consecuentes con 
las necesidades del medio; partiendo del hecho de que la educación constituye un elemento fundamental para el desarrollo de las potencialidades individuales y sociales que enmarcan el proceso que conduce al desarrollo y obtención de los resultados proyectados, las funciones sustantivas y, en especial la proyección social, suponen que el futuro egresado se apropie de un perfil que abarca no solo el conocimiento sino las habilidades, destrezas y actitudes que de él se desprenden y lo hacen un sujeto capaz de transformarse y de transformar el medio que lo rodea.

Como resultado de la gestión realizada por la División de Extensión y Proyección Social de la Universidad Militar Nueva Granada en la vigencia 2019 se obtuvo un margen de utilidad de mil seiscientos sesenta millones de pesos $(\$ 1.660 .000 .000)$. 


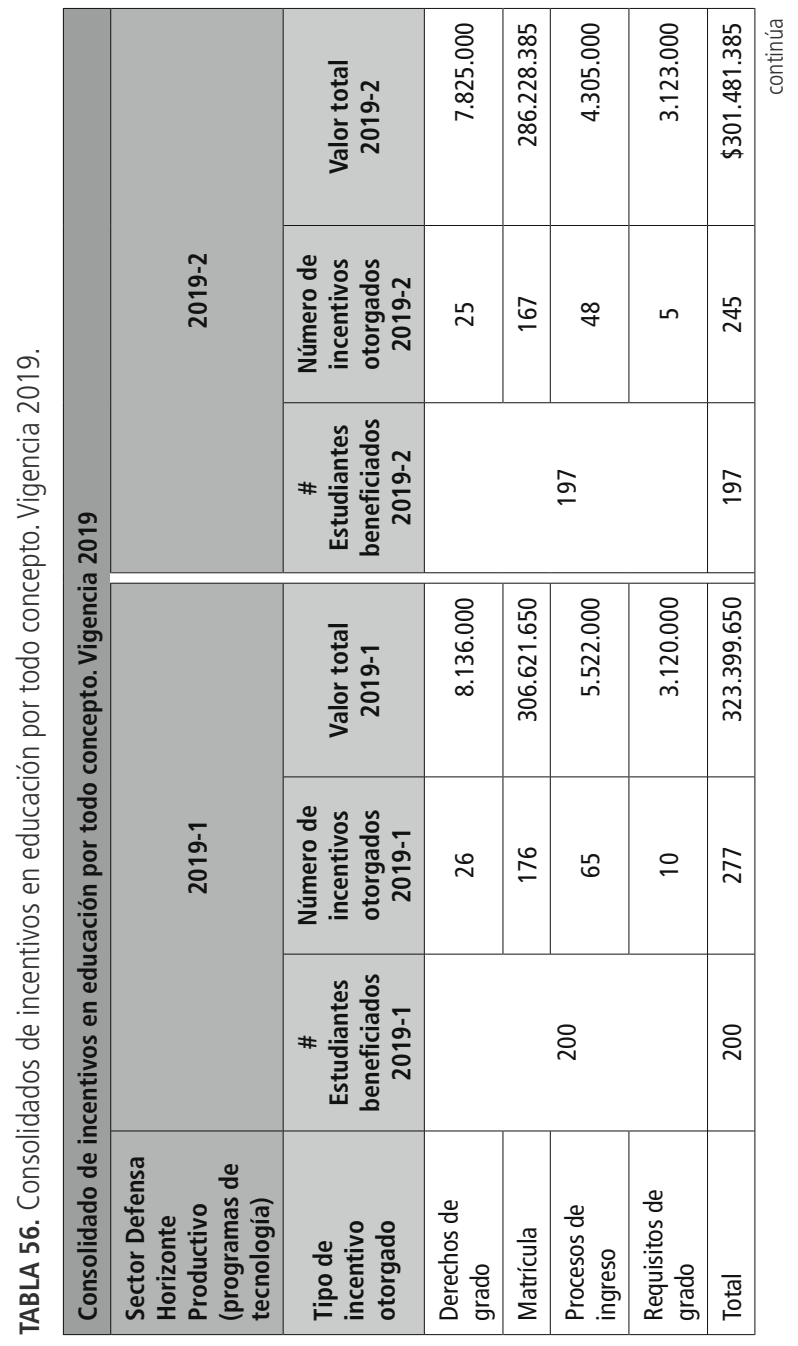




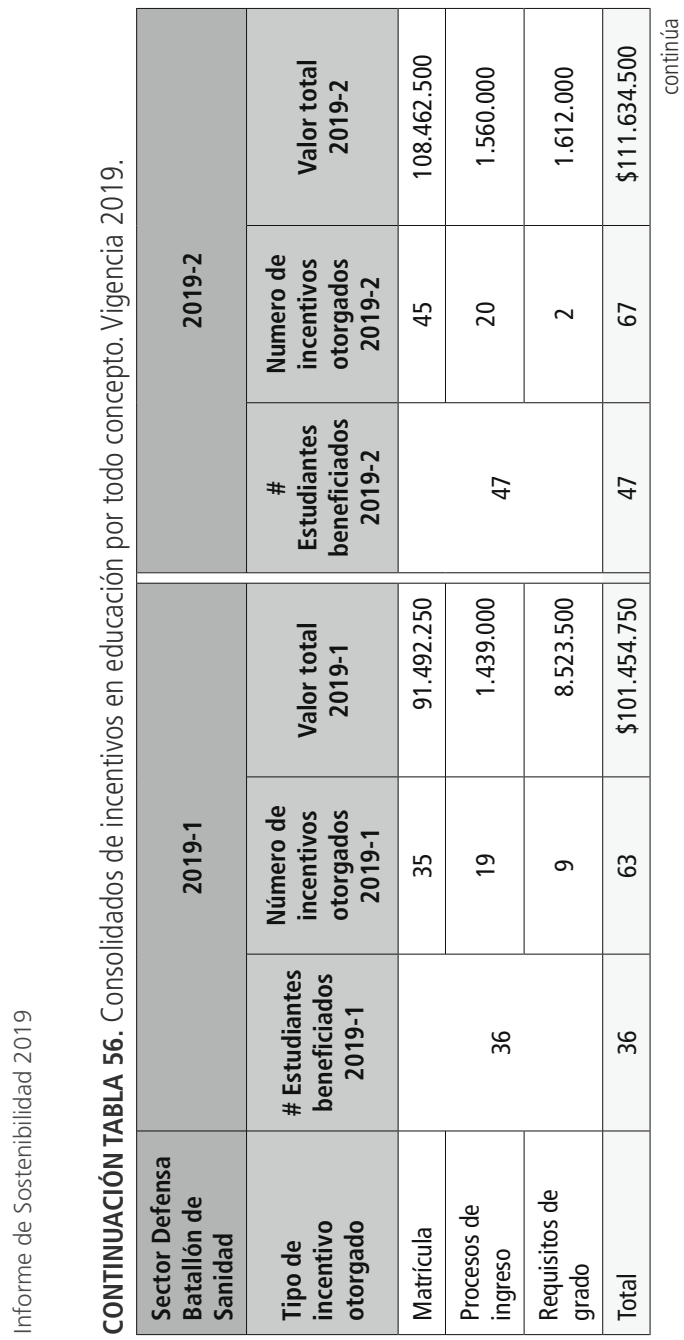




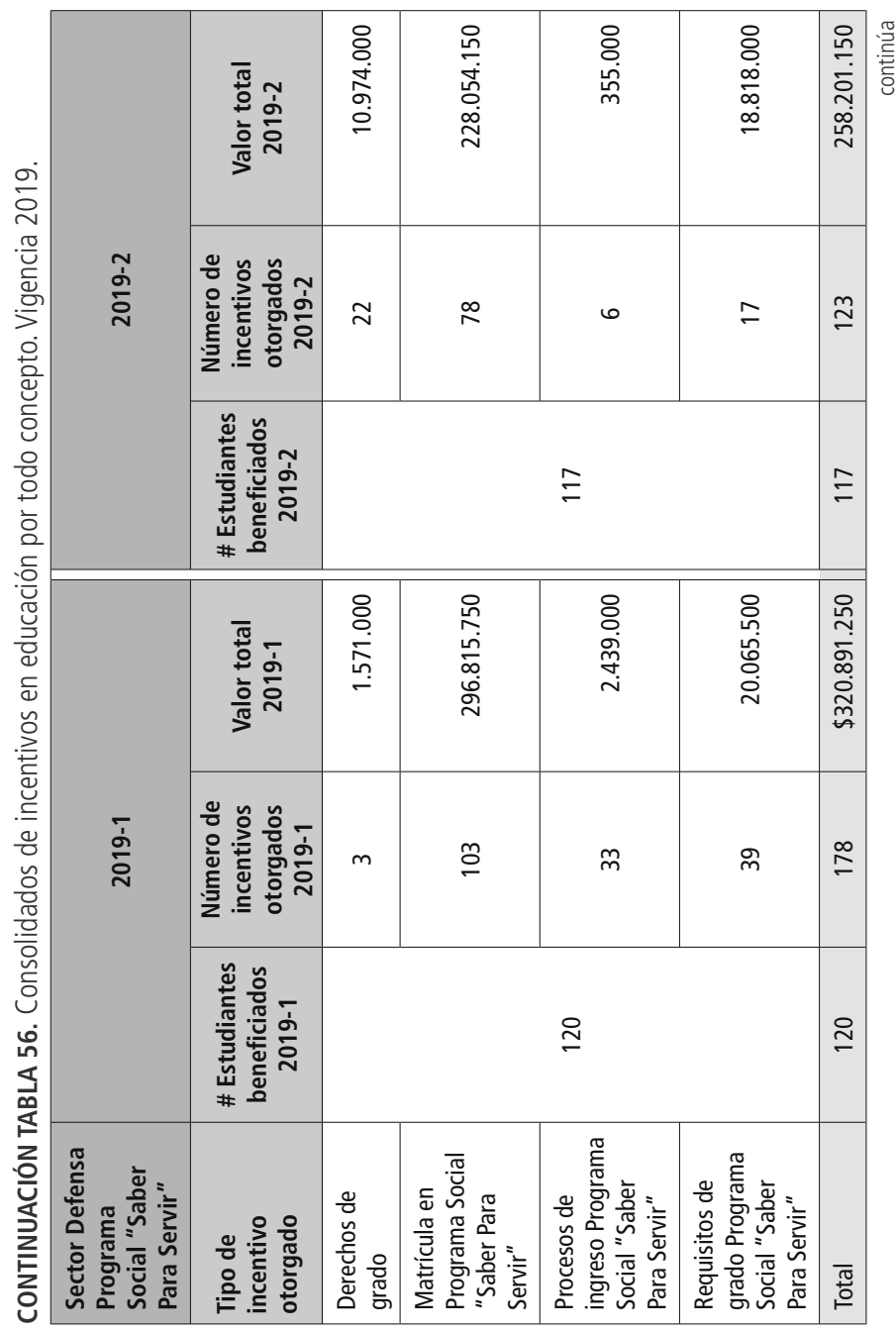

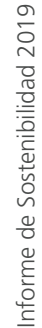




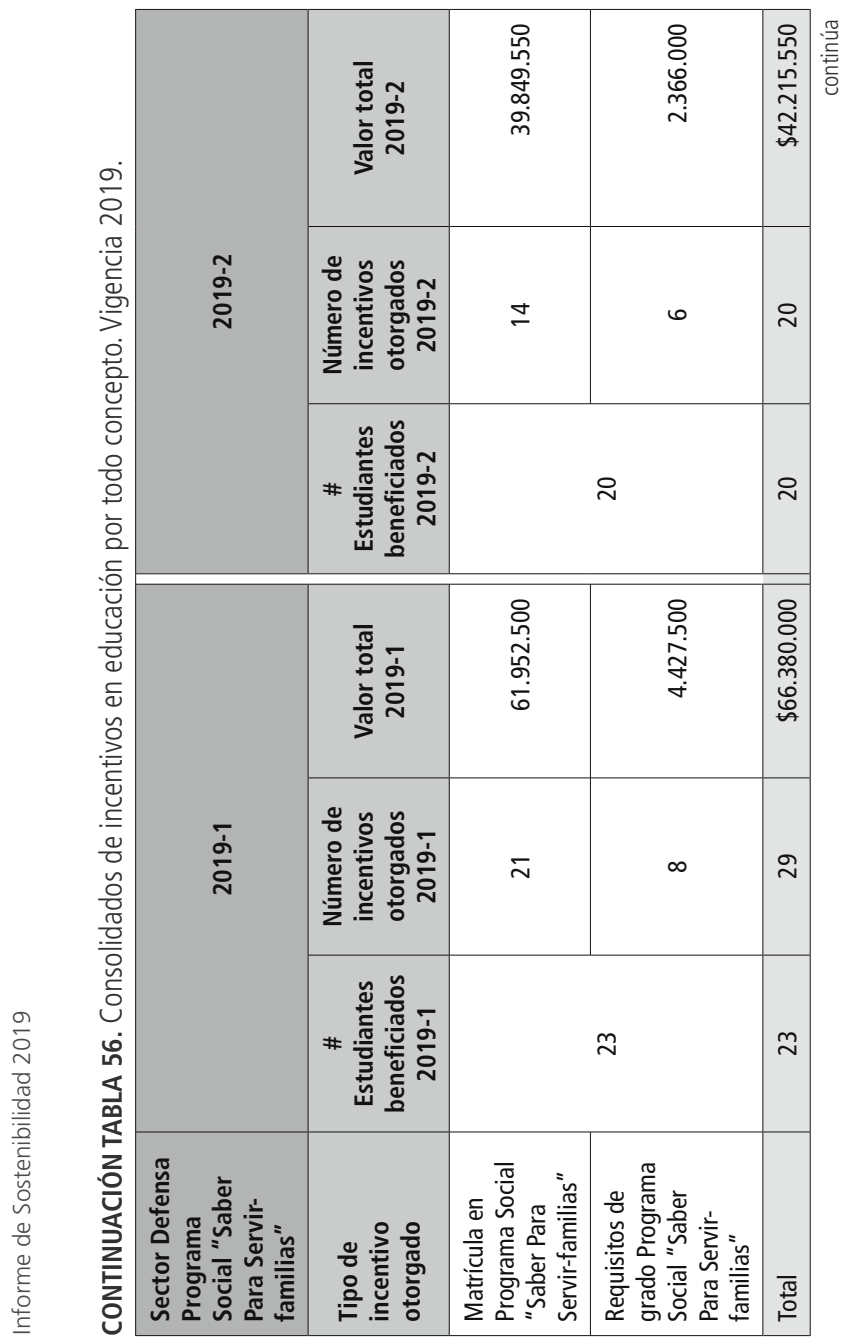




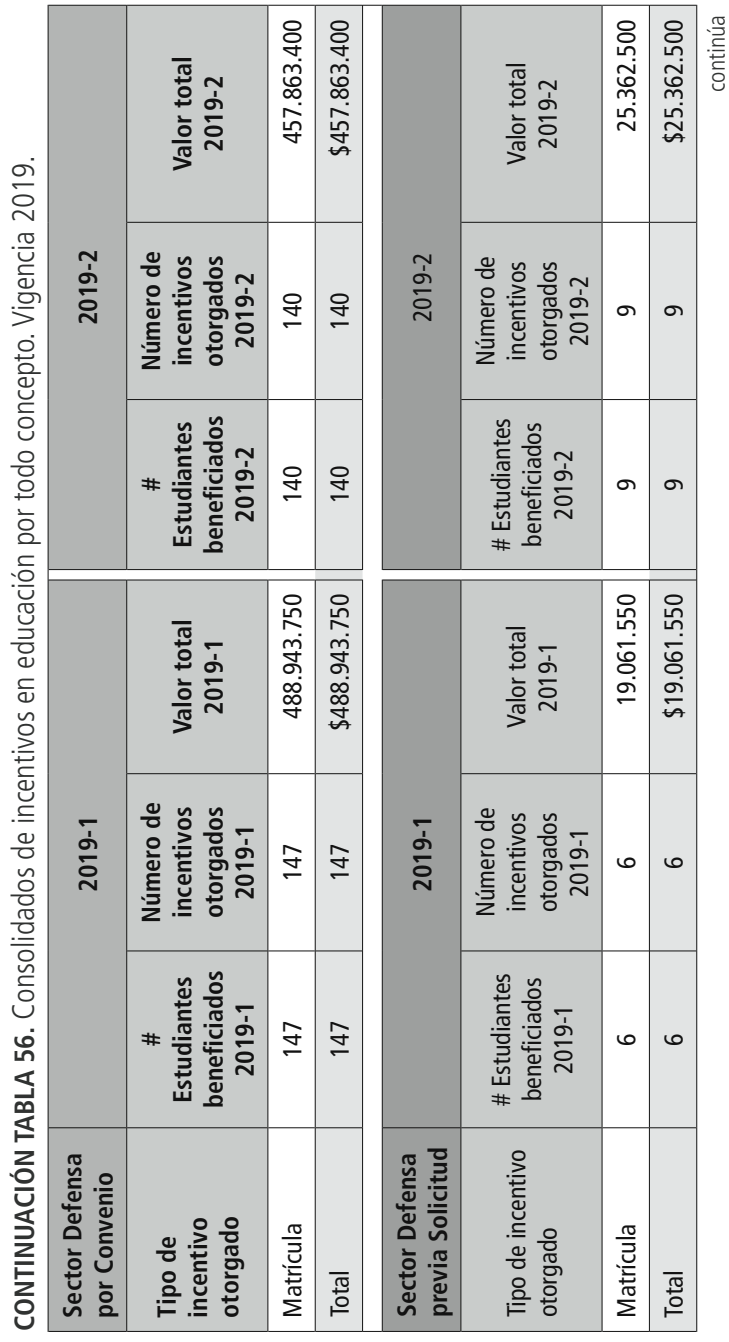




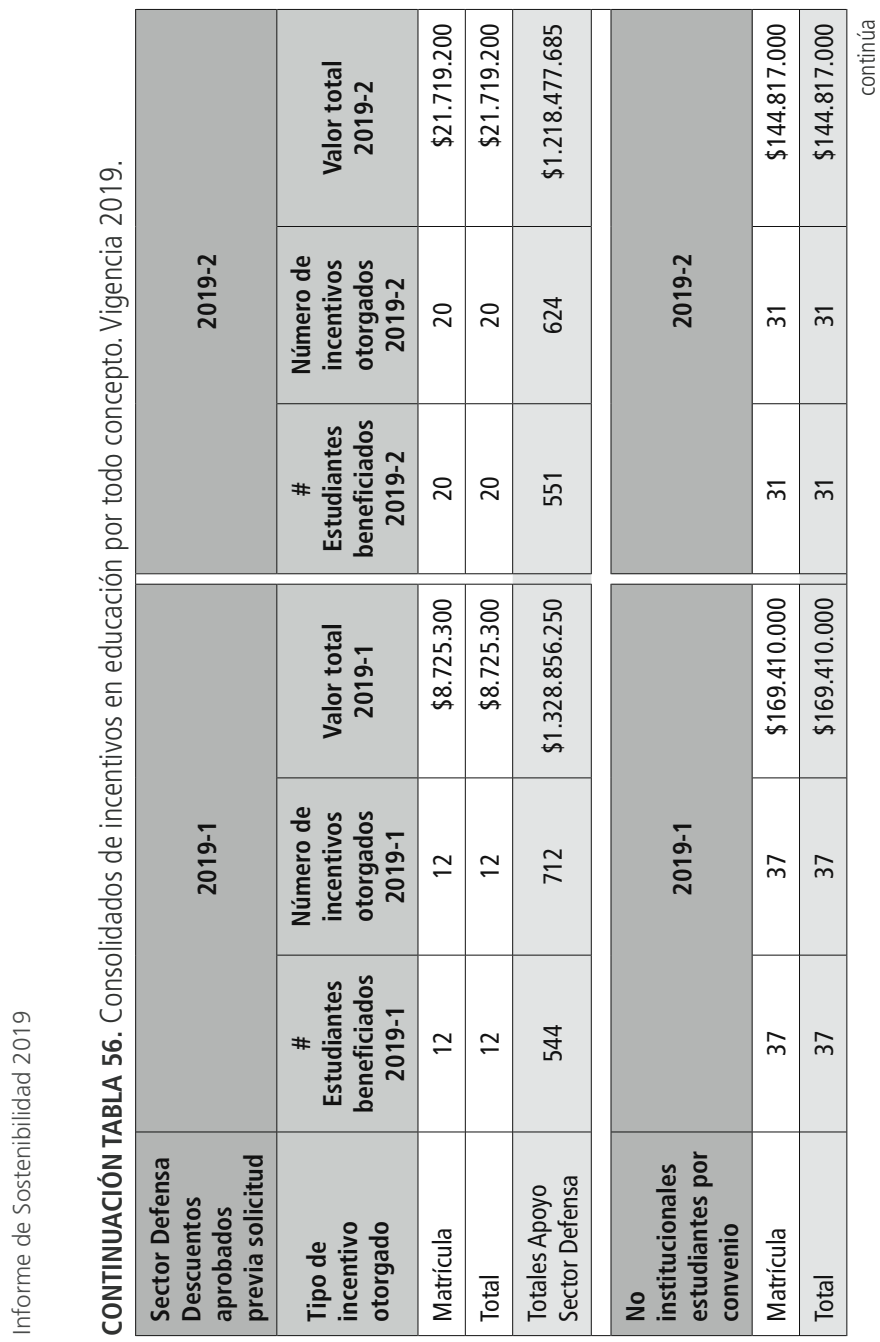




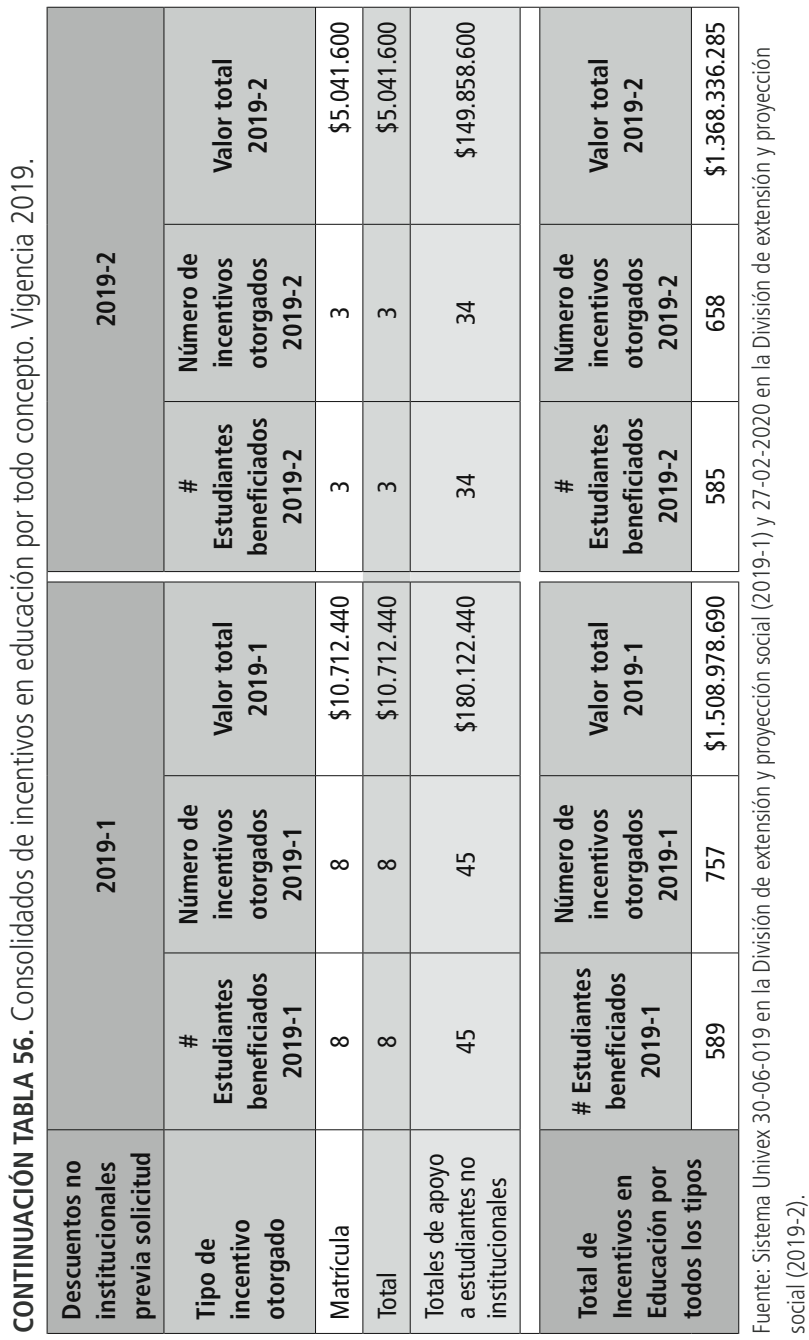




\section{Tecnologías de la información y comunicaciones}

\section{GRI 103-2}

Uno de los aspectos importantes para alcanzar la excelencia académica de la educación superior en Colombia consiste en promover el uso de las tecnologías de la información y las comunicaciones en las funciones de docencia, investigación y extensión. Este acercamiento se vio reflejado en la implementación de las aulas Scale up en el Campus Nueva Granada durante la vigencia 2019.

Las aulas Scale up o aula ampliada son entornos de aprendizaje activo centrados en el estudiante; el término proviene del inglés Student Centred Active Learning Environment with Upside-down Pedagogies; estas aulas sustituyen el modelo educativo tradicional y dan paso a una forma de trabajo más efectiva y colaborativa. Este modelo de aulas promueve el mejoramiento de las habilidades de resolución de problemas, puesto que a los estudiantes se les brindan las herramientas tecnológicas con las que pueden generar un pensamiento crítico por cuenta propia, guiados por el docente, el cual por la disposición de las aulas no es visto como una figura de autoridad sino como un par. El resultado del aprendizaje en estas aulas es una mejora tanto en la calidad del aprendizaje como en los conjuntos de habilidades individuales. 


\section{Gestión de calidad}

\section{GRI 102-11}

GRI 403-1

GRI 403-2

Se tienen en cuenta los lineamientos del Plan Nacional de Desarrollo (PND) del Gobierno nacional, "Pacto por Colombia, pacto por la equidad", que establecen, en el desarrollo de la temática de equidad, que se debe tener una educación de calidad para un futuro con oportunidades para todos; y dentro de sus objetivos se propone impulsar una educación superior incluyente y de calidad. Consecuentemente con lo anterior es necesario que las instituciones de educación superior, y en este caso la Universidad Militar Nueva Granada, desarrollen en forma permanente estrategias tendientes al cumplimiento de estos objetivos mediante el sostenimiento y mejoramiento del Sistema Integrado de Gestión. Con ellas se apoya a los líderes de proceso para el desarrollo, medición y mejoramiento continuo de su gestión con base en los requisitos de las normas que lo integran.

La UMNG, en cumplimiento de las políticas institucionales, requisitos del Sistema Integrado de Gestión, análisis de las necesidades y expectativas de los grupos de interés y otros requisitos, desarrolló una detallada planificación. En ella se definieron estrategias claras, medibles 
y efectivas para lograr el mantenimiento y la mejora del Sistema Integrado de Gestión como herramienta fundamental de apoyo a todos los líderes de proceso de la universidad; se logró mediante ese trabajo coordinado la certificación de la norma de calidad iso 9001/2015 y la renovación de los certificados de las normas Iso 14001/2015 Medio ambiente y Ohsas 18001 Seguridad y salud en el trabajo en el lapso 2019-2020.

La UMNG en cumplimiento de la normativa legal medioambiental, los requisitos de la Norma Iso14001 V 2015 y la Política Integral, desarrolla actividades planificadas para la protección del medio ambiente, orientadas al control de aspectos e impactos ambientales; lo hace mediante la implementación de seis programas ambientales que contienen actividades específicas a desarrollar por los grupos de interés que interactúan en las sedes en las que se desarrolla la actividad académica; por ejemplo, la de Villa Académica, que incluye la facultad de medicina y el Campus Nueva Granada, reduciendo así los riesgos ambientales identificados y logrando un equilibrio que satisfaga las necesidades y expectativas de los grupos de interés institucionales y haga posible el cumplimento de la misión institucional. 

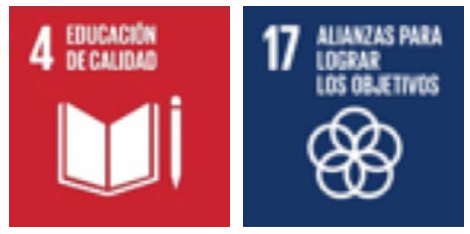

FIGURA 31. Objetivos de desarrollo sostenible relacionados. Fuente: Organización de Naciones Unidas (2016). Propiedad Intelectual $®$

\section{Comunicaciones, publicaciones y mercadeo}

\section{GRI 103}

GRI 202

La División de Comunicaciones, Publicaciones y Mercadeo, es un área de carácter funcional y transversal para desarrollar estrategias relacionadas con la aplicabilidad de las comunicaciones de la universidad, acompañadas de un plan de comunicación, que permita brindar coherencia comunicacional y de impacto para los diferentes grupos de interés; y que, además, soporta las acciones inherentes a las publicaciones de orden académico y al mercadeo estructural de la entidad, con el propósito de ofrecer los programas académicos y demás servicios.

En este sentido, se proyecta un marco de acciones que permitan dar valor al uso de los diferentes medios de comunicación definidos por la institución, priorizando temas de mayor importancia, tanto para la organización como 
para sus usuarios; divulgar las victorias, éxitos y cumplimiento de metas, así como proyectar la imagen corporativa en diferentes escenarios.

Por la naturaleza de la misión que cumple, la Universidad Militar Nueva Granada debe garantizar procesos ágiles de comunicaciones para la difusión interna y externa del quehacer institucional, la promoción de la oferta académica, la difusión del pensamiento y la investigación. En ese orden de ideas para el 2019 se logró la implementación del portal Web, que permite fomentar los resultados estratégicos de cada área académica y administrativa. Adicionalmente, se proyectó la propuesta de creación de Emisora de Interés Público en Frecuencia Modulada y se realizaron las acciones pertinentes para consecución de recursos y radicación de solicitud ante el Ministerio de Tecnologías de la Información y las Comunicaciones (Mintic).

Desde la División de Comunicaciones, Publicaciones y Mercadeo se abre una gran posibilidad, que, a manera de compromiso, incorpora en la Agenda 2030 para el Desarrollo Sostenible, la posibilidad de mediar en forma activa en los procesos de socialización de las actividades y acciones que se realicen en este tema. En suma, la puesta en marcha de planes de divulgación y reconocimiento ante la opinión pública de hechos y quehaceres propios de la academia, en beneficio del desarrollo sostenible. En 
el Objetivo 17, se indica la necesidad de fortalecer los medios de ejecución y revitalizar la Alianza Mundial para el Desarrollo Sostenible.

\section{Instituto Nacional e Internacional de Posgrados (INIP)}

GRI 103-1

GRI 103-2
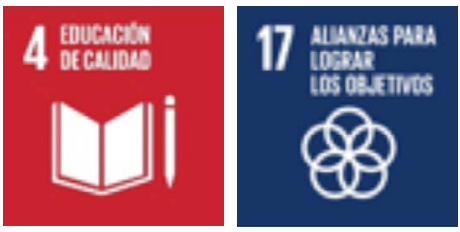

FIGURA 32. Objetivos de desarrollo sostenible relacionados. Fuente: Organización de Naciones Unidas (2016). Propiedad Intelectual $®$

Con el fin de apoyar las actividades académicas de los posgrados, el INIP apoyó la contratación de los docentes de cátedra y ops de los posgrados no médicos. Estas contrataciones se rigieron por las resoluciones 5233 de 2018, 2909 de 2018, 3111 de 2018 y la directiva 06 del 6 de febrero de 2019, que regulan la contratación de docentes por ops o por hora cátedra, en el caso de los funcionarios públicos. En total, en el rubro de honorarios por ops se contrataron 32.855 horas por valor de $\$ 3.235 .762 .200$ para satisfacer las necesidades de los dos doctorados, 14 maestrías y 26 especializaciones. En cuanto a horas cátedra, se apoyó la 
contratación de 4.020 horas para funcionarios públicos externos a la universidad y 2.276 horas para funcionarios públicos de la UMNG, para un total de $\$ 437.448 .118$ solicitados por 12 maestrías y 16 especializaciones.

Además, los programas fueron apoyados por profesores de planta de la universidad en 33.952 horas de docencia y gestión académica como parte de su plan de trabajo. Por otro lado, para apoyar la gestión y docencia de los programas de posgrado, se contrataron 21 docentes ocasionales que apoyaron la gestión y actividades académicas de los programas. Además de los estudiantes, otros grupos de interés para el INIP son por una parte los gestores y coordinadores de posgrado, y por otro, los docentes, directores y evaluadores de los trabajos de grado y tesis; por lo que el INIP trabajó activamente en el mejoramiento de la planeación de la contratación y en los procesos de contratación y pagos, haciéndolos más eficientes y organizados, con el fin de apoyar tanto la gestión para los programas como los profesores.

También trabajó en la actualización del reglamento estudiantil de posgrados, contando actualmente con una propuesta consolidada para ser discutida ante diferentes instancias a nivel institucional y en la Mesa de Trabajo del Sistema de Evaluación Profesoral; ello con el fin de que se incluyan las particularidades de los profesores de posgrado, tanto de planta como externos, en los diferentes 
niveles de formación y disciplinas; este sistema que está relacionado con el plan de trabajo profesoral, también está en proceso de reestructuración.

Hasta el año 2019, se ha recopilado la información de 1.069 trabajos de maestría y 40 tesis de doctorado. De estos trabajos, el 64,39\% fueron dirigidos por profesores de la UMNG y el 35,61\% restante por directores externos; y de estos 1.109 trabajos entre trabajos y tesis de grado, solamente el 44\% están asociados a grupos y líneas de investigación de la UMNG.

Con el objetivo de aumentar la tasa de retención estudiantil, el INIP apoyó en la gestión de los Planes de Articulación Formativa en tres facultades de la UMNG y hasta el momento se han firmado ocho resoluciones que permiten que los estudiantes de pregrado y posgrado puedan continuar sus estudios de posgrado en un menor tiempo y con menos recursos. Actualmente se están gestionando tres resoluciones más que beneficiarán a más estudiantes de pregrado y posgrado y se cuenta aproximadamente con 32 estudiantes activos en los diferentes programas.

En cuanto a la gestión con el sector externo, el INIP lideró la participación de la UMNG en el programa de excelencia doctoral del Ministerio de Ciencias del Bicentenario mediante la socialización y alistamiento de seis propuestas de tesis doctoral en su primer corte, en cooperación 
con la sección de Cooperación Científica de la Vicerrectoría de Investigaciones.

Como resultado de la participación en esta convocatoria, se elaboró un proyecto de inversión denominado "Formación de Capital Humano de Alto Nivel Universidad Militar Nueva Granada Nacional", con un costo total de \$294.375.000, el cual será financiado por el departamento de Cundinamarca. Estará asociado al foco estratégico de salud establecido en el plan y acuerdo estratégico departamental de стеI, y estará dirigido a la formación de un estudiante del Doctorado en Ciencias Aplicadas quien desarrollará la tesis "Desarrollo de un sistema de generación de imágenes de tomografía por impedancia eléctrica para detección temprana de cáncer gástrico de forma no invasiva".

Es importante mencionar que es la primera vez que la Universidad Militar Nueva Granada se presenta como ejecutora de un proyecto de inversión financiado por el Sistema General de Regalías, lo cual abre camino a una nueva hoja de ruta, que permita fortalecer la estructuración de este tipo de proyectos que permitan la financiación en стег. Además, se gestionó la suscripción de tres acuerdos específicos para la supervisión conjunta de tesis doctorales con el Institut National des Sciences Appliquées de Lyon (INSA) (Francia), Université libre de Bruxelles (Bélgica), y La Universitat Politècnica de Catalunya (UPC) 
(España), de tres estudiantes del Doctorado en Ciencias Aplicadas. Se creó el programa y se emitió la Resolución 2156 del 2019 para la realización de pasantías doctorales en el exterior.

Adicionalmente, se manejó la convocatoria de movilidades internacionales para estudiantes de doctorado, que permitió la movilidad de nueve estudiantes del Doctorado en Ciencias Aplicadas a congresos en E.U.A., Alemania, Brasil, México y Panamá, con el objetivo de presentar avances de sus investigaciones desarrolladas bajo sus tesis de grado. Por otro lado, se comenzó el apoyo a las actividades de divulgación de los posgrados mediante la mediación de la oficina de Comunicaciones y por ejemplo, mediante la actividad de divulgación y promoción realizada en Tolemaida.

\section{Instituto de Estudios Geoestratégicos y Asuntos Políticos (legap)}

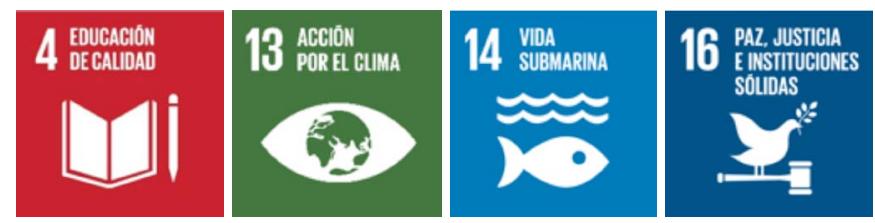

FIGURA 33. Objetivos de desarrollo sostenible relacionados. Fuente: Organización de Naciones Unidas (2016). Propiedad Intelectual $®$ 


\section{GRI 103}

\section{GRI 415}

Durante la vigencia 2019 y como producto de un nuevo conocimiento, el Iegap planteó investigaciones, generó documentos de análisis, realizó asesorías, ponencias y eventos académicos internacionales en conjunto con el sector Defensa; gestionó convenios para fortalecer alianzas estratégicas interinstitucionales, asesoró las líneas de investigación del doctorado que se proyecta realizar en convenio con la Escuela superior de Guerra y participó en el Comité Técnico Nacional de Asuntos Antárticos. Estas actividades de investigación, extensión y docencia desarrolladas por el Iegap, se enmarcan en el informe GRI 103 - 415 y Objetivos de Desarrollo Sostenible a fin de promover una educación incluyente, equitativa y de calidad; además, adoptar medidas para combatir el cambio climático, conservar y utilizar de forma sostenible los recursos marinos y propender por sociedades justas, pacíficas e incluyentes. Estos ods son el cuatro, Educación de calidad, el trece, Acción por el Clima, el catorce, Vida Submarina y el dieciséis, Paz, justicia e instituciones sólidas.

Los principales logros obtenidos en esta vigencia se sintetizan a continuación.

- En términos de asesorías, el Instituto asesoró a la Escuela de Guerra (Esdegue) en el desarrollo del 
proyecto de ley de Seguridad y Defensa Nacional. Adicionalmente hizo parte del grupo que asesoró la planeación y el desarrollo de las líneas de investigación del doctorado en defensa, seguridad y relaciones internacionales proyectado por la Esdegue y la UMNG.

- En términos de eventos académicos, se realizaron el Foro Internacional "Contexto y Prospectiva de Colombia en la оTAN"; la conferencia internacional, "La Defensa ante la Corte Penal Internacional - Los abogados ante la cPI, la defensa y las víctimas"; la ponencia "Colombia llega a la Antártida: una mirada al hemisferio austral desde las estaciones científicas Latinoamericanas"; la ponencia "Gestión Estratégica del Talento Humano desde La Gestión Pública" en el marco del V Congreso Internacional de Liderazgo Estratégico y Gestión del Talento Humano en la Escuela Militar de Cadetes.

- En términos de nuevas alianzas estratégicas, estas se encaminaron a fortalecer los lazos con el sector Defensa, para lo cual se llevaron a cabo reuniones de acercamiento desde el Instituto con los directivos de las siguientes instituciones: Comando de Educación y Doctrina (Cedoc); Centro de Misiones Internacionales y Acción Integral (Cemai); Escuela Superior de Guerra; Defensoría Militar (Demil); Centro de Memoria Histórica de la Escuela de Guerra; Centro de Memoria 
Histórica Armada; Memoria histórica, víctimas y derechos humanos de la fuerza aérea; director para la zona norte de Colombia de la comisión de la verdad (CEP); Centro Nacional de Memoria Histórica; Centro de Investigaciones y Altos Estudios Legislativos del Congreso de Colombia. 


\section{SOSTENIBILIDAD}





\section{CONTENIDO}

166 Sostenibilidad ecosistémica

175 Sostenibilidad financiera 


\section{Sostenibilidad ecosistémica}

La Universidad Militar Nueva Granada, consciente de su responsabilidad con el desarrollo sostenible y comprometida con la protección del ambiente, tiene inmerso dentro de sus objetivos integrales el componente ambiental; este está orientado a prevenir y mitigar la materialización de impactos ambientales por medio del fomento de una cultura para la protección del ambiente. El Sistema de Gestión Ambiental a través de sus ocho programas permite garantizar el cumplimiento normativo legal ambiental vigente y comprometerse con la responsabilidad socioambiental.

\section{GRI 102-12 \\ GRI 103-1 \\ GRI-304}
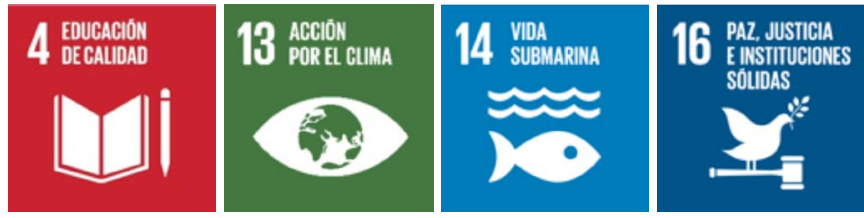

FIGURA 34. Objetivos de desarrollo sostenible relacionados. Fuente: Organización de Naciones Unidas (2016). Propiedad Intelectual ${ }^{\circledR}$

A continuación se presentan cada uno de los Programas del Sistema de Gestión ambiental y los logros obtenidos. 
Uso eficiente de los recursos renovables

\section{GRI 302-1}

\section{GRI 302-4}

- En cuanto al consumo de energía en la vigencia 2019 de las dos sedes de la universidad, se tuvo un ahorro significativo de más de un 5\% en comparación con el consumo anual del año 2018.

- En la siguiente gráfica, Figura 35, se puede evidenciar que el consumo de agua comparado con la vigencia 2018 disminuyó en más de un 30\%.

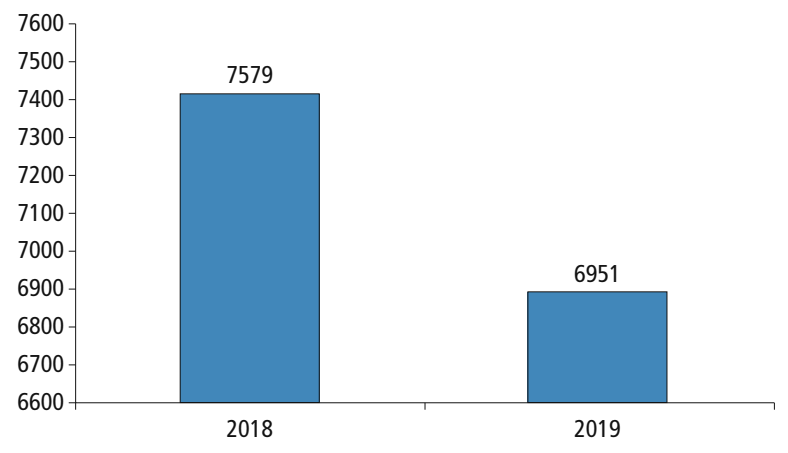

FIGURA 35. Consumo de agua. Fuente: Sección gestión ambiental de la Oficina de protección al patrimonio.

La Universidad Militar Nueva Granada, en cumplimiento de la Ley 373 de 1997 y el Decreto 1090 de 2017, cuenta con la aprobación del documento Programa de ahorro y uso eficiente del agua - Pueaa; este se desarrolla 
mediante la formulación de ocho proyectos enfocados principalmente a la optimización del recurso hídrico, contribuyendo de manera responsable a la sostenibilidad del recurso. Los proyectos que se encuentran en ejecución se muestran a continuación (Figura 36).

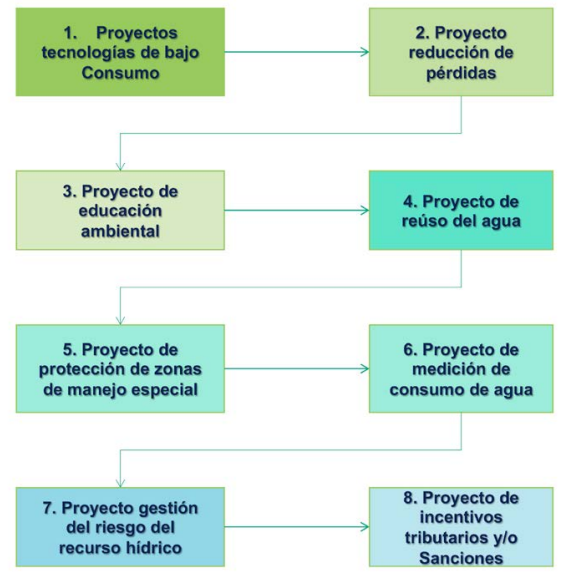

FIGURA 36. Proyectos Programas de Uso Eficiente y Ahorro de Agua (PUEAA). Fuente: Sección gestión ambiental de la Oficina de protección al patrimonio.

Por otra parte, la universidad ha realizado diferentes actividades para sensibilizar a la Comunidad en general acerca de la conservación de los ecosistemas estratégicos identificados como humedales, ronda hídrica del río Bogotá, y reservorios, entre otros. A través de los bicirrecorridos la universidad incentiva el cuidado del ambiente y la 
conservación de la biodiversidad que en él se encuentra, haciendo su aporte como responsable socioambiental.

En la Figura 37 se muestran algunas de las actividades realizadas en la vigencia 2019.
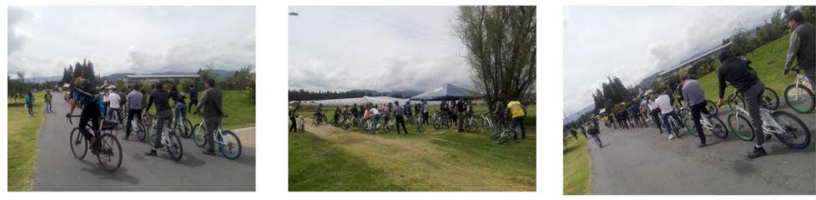

La Universidad Militar Nueva Granada ha realizado recorridos en bicicleta por el Gampus Nueva Granada, sensibilizando la Comunidad en la conservación de ecosistemas estratégicos.
Actores involucrados: Secretaria Distrital de ambiente - SDA,

Secretaria de Cundinamarca, Corporación Autónoma regional de Cundinamarca - CAR, grupo Nueva Granada. estudiantil de la Universidad Militar

FIGURA 37. Bicirrecorrido Campus Nueva Granada. Fuente: Sección gestión ambiental de la Oficina de protección al patrimonio.
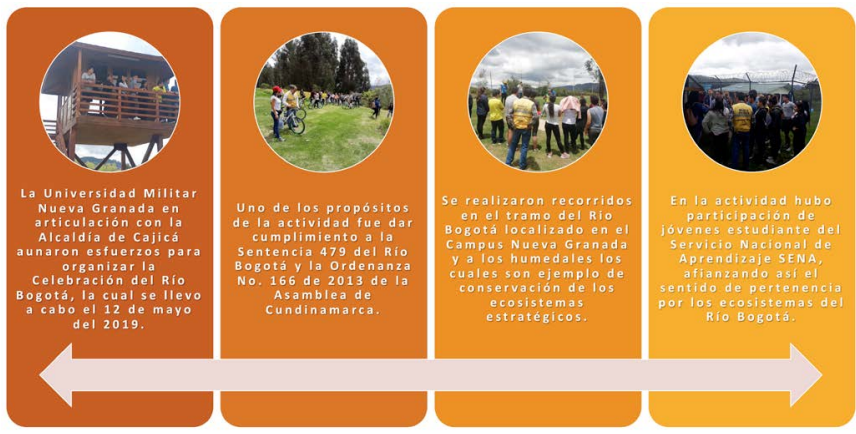

FIGURA 38. Actividad de conservación de los ecosistemas estratégicos. Fuente: Sección gestión ambiental de la Oficina de protección al patrimonio. 
Estrategia multidimensional para la sostenibilidad ambiental del campus de la Universidad Militar Nueva Granada y la conservación de recursos naturales en la Sabana de Bogotá.

Con el presente proyecto se busca implementar estrategias para la sostenibilidad ambiental del campus de la Universidad Militar Nueva Granada y la conservación de recursos naturales en la Sabana de Bogotá. Para lo anterior se consideran las siguientes tareas:

- Establecimiento del Jardín Botánico UMNG

- Análisis de factores ecosistémicos para sostenibilidad en el Campus Nueva Granada.
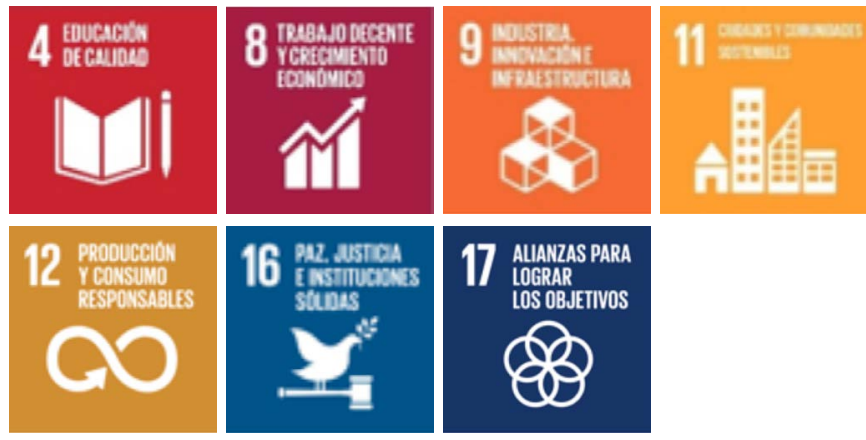

FIGURA 39. Objetivos de desarrollo sostenible relacionados. Fuente: Organización de Naciones Unidas (2016). Propiedad Intelectual $®$

Silvicultura y biodiversidad

La Sede Campus Nueva Granada cuenta con un observatorio de aves que permite identificar y observar la 
diversidad de especies que allí se albergan; su finalidad es generar convivencia armónica entre la comunidad y el medio físico en el que habitan las especies de avifauna.

Así mismo se cuenta aproximadamente con 53 especies de aves identificadas, las cuales ha sido posible registrar gracias a las jornadas programadas de avistamientos en las que existen diferentes actores involucrados y especialistas. A continuación (Figura 40) se muestran algunas de las aves identificadas y registradas.
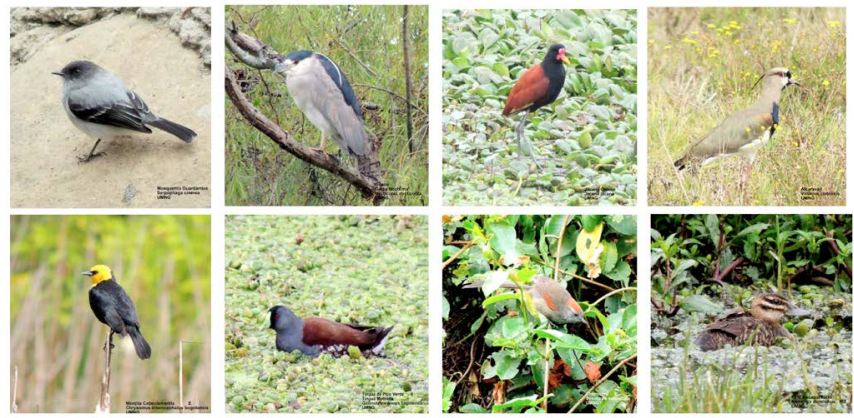

FIGURA 40. Especies de aves identificadas en el Campus Nueva Granada. Fuente: Sección gestión ambiental de la Oficina de protección al patrimonio.

En cuanto al Programa de silvicultura, la Universidad Militar Nueva Granada ha realizado la identificación y marcación de las especies arbóreas que allí se encuentran; son alrededor de

- 4.617 individuos arbóreos en la Sede Campus Nueva Granada. 
- 358 individuos arbóreos en la Sede Villa Académica.

- 25 individuos arbóreos en la Sede Facultad de Medicina y Ciencias de la salud.

Se han realizado varias jornadas de siembra de árboles nativos promoviendo ambientes sanos con un aporte significativo de oxígeno, mejorando así las condiciones ambientales y beneficios para la comunidad.
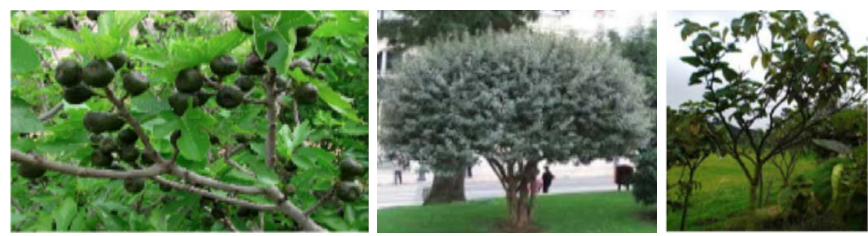

FIGURA 41. Muestra de árboles nativos sembrados. Fuente: Sección gestión ambiental de la Oficina de protección al patrimonio.

En ese mismo sentido, como forma de celebración, el día 30 de mayo de 2019 se hizo la siembra del árbol de la séptima cohorte del programa de Derecho Campus por parte de los futuros abogados neogranadinos.

El día 11 de octubre de 2019 hubo una jornada de siembra de los árboles del Bosque de la Primera Piedra ubicado en la Sede Campus Nueva Granada en Cajicá, que simboliza el compromiso de nuestra institución con el medio ambiente. 


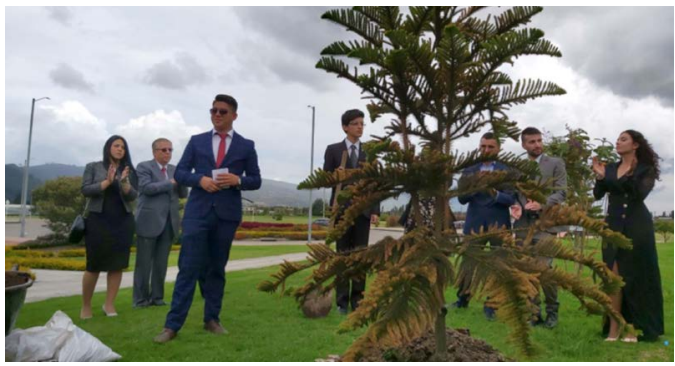

FIGURA 42. Evidencia compromiso institucional con medioambiente. Universidad Militar Nueva Granada (2019, 30 de mayo).
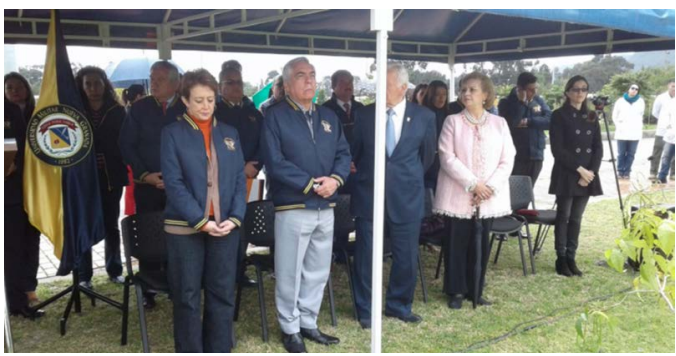

FIGURA 43. Evidencia compromiso institucional con medio ambiente. Fuente: Universidad Militar Nueva Granada (2019, 11 de octubre).

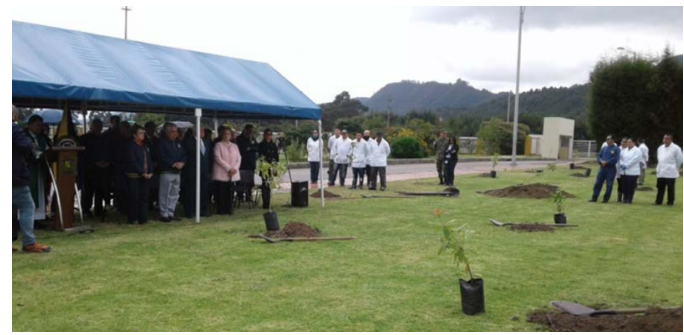

FIGURA 44. Evidencia compromiso institucional con medio ambiente. Fuente: Universidad Militar Nueva Granada (2019, 11 de octubre). 


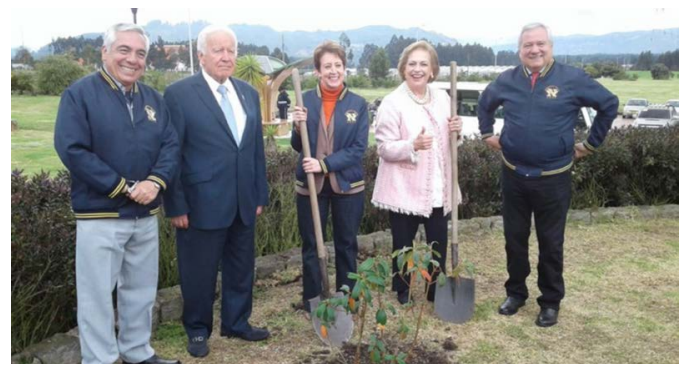

FIGURA 45. Evidencia compromiso institucional con medio ambiente. Fuente: Universidad Militar Nueva Granada (2019, 11 de octubre, Facebook).

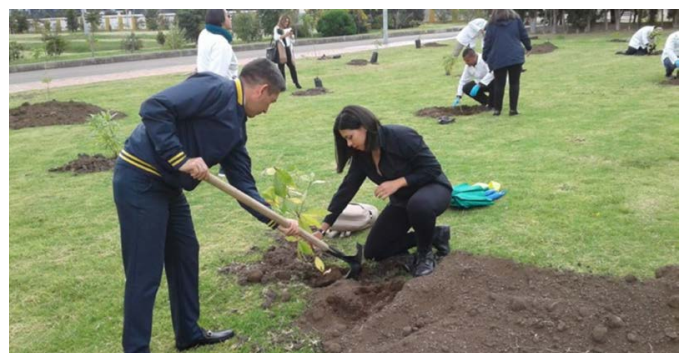

FIGURA 46. Evidencia compromiso institucional con medio ambiente. Fuente: Universidad Militar Nueva Granada (2019, 11 de octubre, Facebook).

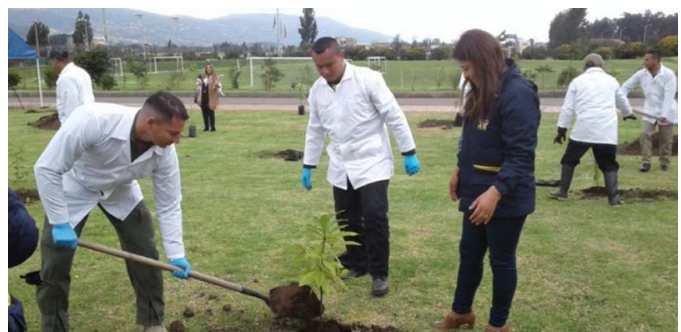

FIGURA 47. Evidencia compromiso institucional con medio ambiente. Fuente: Universidad Militar Nueva Granada (2019, 11 de octubre, Facebook). 


\section{Sostenibilidad financiera}

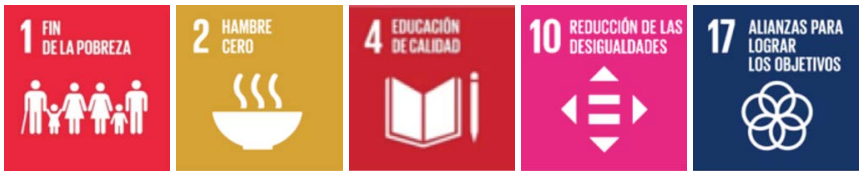

FIGURA 48. Objetivos de desarrollo sostenible relacionados. Fuente: Organización de Naciones Unidas (2016). Propiedad Intelectual @

\section{GRI 419}

La Vicerrectoría Administrativa, como estructura soporte y proceso de apoyo, es responsable de la ejecución del presupuesto, de los procesos de recaudo, del mantenimiento y control de los servicios y de los procesos de gestión del recurso humano, entre otros. Apoya el cumplimiento de los objetivos estratégicos de la Universidad Militar Nueva Granada y concretamente el cumplimiento del objetivo número 2, "Mejorar la gestión académica y administrativa efectiva para ofrecer servicios educativos de calidad". Es parte integral del grupo estratégico que trabaja por el cumplimiento de los resultados de los diferentes factores y específicamente del factor 10, "Recursos Físicos y Financieros".

Actividad financiera

Para la vigencia 2019, el Consejo Superior Universitario aprobó un presupuesto de ingresos inicial de $\$ 257.937$ 
millones; el monto total de ingresos a 31 de diciembre de 2019 fue de $\$ 301.702$ millones, equivalente al 111,01\% del presupuesto total aprobado de ( $\$ 271.776$ millones), incluidas las adiciones aprobadas durante la vigencia. Respecto a los ingresos de la vigencia 2018, que fueron $\$ 276.586$ millones, se presenta un incremento de 9,08\%.

En lo referente a la ejecución realizada por la UMNG en la vigencia 2019, se evidencia a nivel general lo que presenta la Tabla 57.

TABLA 57. Ejecución Presupuestal, Vigencia Actual (con corte en 31-dic2019)

\begin{tabular}{|l|r|r|c|}
\hline \multicolumn{4}{|c|}{ INGRESOS 2019} \\
\hline $\begin{array}{c}\text { CONCEPTO DEL } \\
\text { INGRESO }\end{array}$ & $\begin{array}{c}\text { VALOR } \\
\text { PRESUPUESTADO } \\
\text { (millones de pesos) }\end{array}$ & $\begin{array}{c}\text { VALOR RECAUDADO } \\
\text { (millones de pesos) }\end{array}$ & $\begin{array}{c}\text { PORCENTAJE } \\
\text { DEL RECAUDO }\end{array}$ \\
\hline Aportes de la nación. & $\$ 37.469$ & $\$ 37.469$ & $100 \%$ \\
\hline Recursos propios. & $\$ 138.644$ & $\$ 159.175$ & $115 \%$ \\
\hline Recursos de capital & $\$ 95.663$ & $\$ 105.058$ & $109 \%$ \\
\hline TOTAL INGRESOS & $\$ 271.776$ & $\$ 301.702$ & $111 \%$ \\
\hline
\end{tabular}

\begin{tabular}{|l|r|r|c|}
\hline \multicolumn{4}{|c|}{ GASTOS 2019} \\
\hline CONCEPTO & $\begin{array}{c}\text { VALOR } \\
\text { PRESUPUESTO } \\
\text { DEFINITIVO } \\
\text { (Millones de Pesos) }\end{array}$ & $\begin{array}{c}\text { VALOR EJECUTADO } \\
\text { (Millones de Pesos) }\end{array}$ & $\begin{array}{c}\text { PORCENTAJE } \\
\text { DE LA } \\
\text { EJECUCION }\end{array}$ \\
\hline Funcionamiento. & $\$ 229.294$ & $\$ 180.544$ & $78,74 \%$ \\
\hline Inversión. & $\$ 42.482$ & $\$ 34.062$ & $80,18 \%$ \\
\hline TOTAL GASTOS & $\$ 271.776$ & $\$ 214.606$ & $78,92 \%$ \\
\hline
\end{tabular}

Fuente: División Financiera. 
A 31 de diciembre de 2019 la Universidad Militar Nueva Granada constituyó cuentas por pagar por valor de $\$ 9.885$ millones (Tabla 58) que representan el 3,64\% de la apropiación definitiva de la vigencia.

TABLA 58. Constitución de las cuentas por pagar

\begin{tabular}{|c|c|}
\hline Concepto Gastos & VALOR CONSTITUIDO (Millones de pesos) \\
\hline Gastos Personal & 6.857 \\
\hline Gastos Generales & 811 \\
\hline Transferencias & 125 \\
\hline Inversión & 2.092 \\
\hline Total & 9.885 \\
\hline
\end{tabular}

Fuente: División financiera.

Y en reserva se constituyó el valor de $\$ 21.658$ millones (Tabla 59) que representan el 7,97\% de la apropiación definitiva.

TABLA 59. Constitución de la reserva

\begin{tabular}{|c|c|}
\hline Concepto Gastos & VALOR CONSTITUIDO (Millones de pesos) \\
\hline Gastos Personal & 839 \\
\hline Gastos Generales & 10.544 \\
\hline Transferencias & 1.119 \\
\hline Inversión & 9.156 \\
\hline Total & 21.658 \\
\hline
\end{tabular}

Fuente: División financiera. 
Las cifras que reflejan la situación financiera de la universidad a 31 de diciembre de 2019 se presentan en los estados financieros, destacándose el monto total de los activos por $\$ 634.353$ millones, mientras los pasivos presentan la cifra de $\$ 43.713$ millones y un patrimonio neto de $\$ 590.640$ millones.

\section{GRI 102-45}

La situación de los recursos con corte a 31 de diciembre de 2019 es la presentada en la Tabla 60.

TABLA 60. Resumen en cifras del Estado de Situación Financiera 2018 - 2019 (en millones de \$ COP).

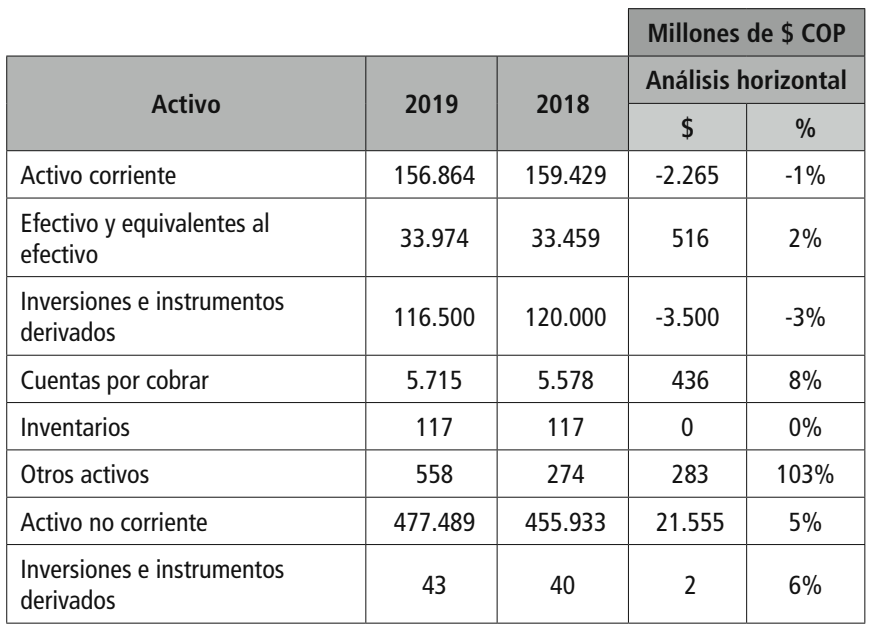


CONTINUACIÓN TABLA 60. Resumen en cifras del Estado de Situación Financiera 2018 - 2019 (en millones de \$ COP).

\begin{tabular}{|c|c|c|c|c|}
\hline \multirow{4}{*}{ Activo } & & & \multirow{3}{*}{\multicolumn{2}{|c|}{$\begin{array}{l}\text { Millones de \$ COP } \\
\text { Análisis horizontal }\end{array}$}} \\
\hline & \multirow{3}{*}{2019} & \multirow{3}{*}{2018} & & \\
\hline & & & & \\
\hline & & & $\$$ & $\%$ \\
\hline Cuentas por cobrar & 268 & 267 & 0 & $0 \%$ \\
\hline Propiedad, planta y equipo & 474.360 & 452761 & 21.599 & $5 \%$ \\
\hline Otros activos & 2.818 & 2865 & -47 & $-2 \%$ \\
\hline Total activo & 634.353 & 615.362 & 19.291 & $3 \%$ \\
\hline & & & \multicolumn{2}{|c|}{ Millones de \$ COP } \\
\hline \multirow{2}{*}{ Pasivo y patrimonio } & \multirow{2}{*}{2019} & \multirow{2}{*}{2018} & \multicolumn{2}{|c|}{ Análisis horizontal } \\
\hline & & & $\$$ & $\%$ \\
\hline Pasivo corriente & 35.962 & 36.936 & -975 & $-3 \%$ \\
\hline Cuentas por pagar & 6.473 & 8.133 & -1.660 & $-20 \%$ \\
\hline $\begin{array}{l}\text { Beneficios a los empleados a } \\
\text { corto plazo }\end{array}$ & 11.277 & 8.296 & 2.981 & $36 \%$ \\
\hline Otros pasivos & 18.212 & 20.507 & -2.296 & $-11 \%$ \\
\hline Pasivo no corriente & 7.751 & 4.681 & 3.070 & $66 \%$ \\
\hline $\begin{array}{l}\text { Beneficios a los empleados a } \\
\text { largo plazo }\end{array}$ & 1.338 & 1.676 & -338 & $-20 \%$ \\
\hline Beneficios posempleo & 562 & 562 & 0 & $0 \%$ \\
\hline Provisión por litigios y demandas & 5.852 & 2.444 & 3.408 & $139 \%$ \\
\hline Total pasivo & 43.713 & 41.618 & 2.095 & $5 \%$ \\
\hline Patrimonio & 590.640 & 573.444 & 17.195 & $3 \%$ \\
\hline Total pasivo y patrimonio & 634.353 & 615.062 & 19.291 & $3 \%$ \\
\hline
\end{tabular}

Fuente: División financiera. 
El excedente del ejercicio con corte al 31 de diciembre de 2019 (Tabla 60) es de $\$ 17.195$ millones.

TABLA 61. Resumen Estado de Resultados 2018-2019 (en millones de \$ (OP).

\begin{tabular}{|l|r|r|r|r|}
\cline { 5 - 6 } \multicolumn{2}{c|}{ Estado de Resultados } & 2019 & 2018 & \multicolumn{1}{c|}{ Millones de \$ COP } \\
\cline { 5 - 6 } & & & \multicolumn{1}{c|}{$\$$} & \multicolumn{1}{c|}{$\%$} \\
\hline $\begin{array}{l}\text { INGRESOS CON } \\
\text { CONTRAPRESTACIÓN }\end{array}$ & 168.146 & 159.896 & 8.250 & $5 \%$ \\
\hline Educación formal - Tecnología & 1.430 & 1.283 & 147 & $11 \%$ \\
\hline Educación formal - Pregrado & 129.681 & 118.675 & 11.006 & $9 \%$ \\
\hline Educación formal - Posgrado & 26.907 & 31.045 & -4.137 & $-13 \%$ \\
\hline Educación formal - Extensión & 10.128 & 8.894 & 1.234 & $14 \%$ \\
\hline $\begin{array}{l}\text { INGRESOS SIN } \\
\text { CONTRAPRESTACIÓN }\end{array}$ & 37.594 & 28.317 & 9.278 & $33 \%$ \\
\hline TOTAL INGRESOS OPERACIONALES & 205.740 & 188.213 & 17.528 & $9 \%$ \\
\hline Costo de ventas & 121.413 & 140.498 & -19.085 & $-14 \%$ \\
\hline Gastos de administración & 69.509 & 41.047 & 28.461 & $69 \%$ \\
\hline $\begin{array}{l}\text { Deterioro, depreciaciones, } \\
\text { amortizaciones y provisiones }\end{array}$ & 4.665 & 3.101 & 1.563 & $50 \%$ \\
\hline TOTAL COSTOS Y GASTOS & 195.587 & 184.647 & 10.940 & $6 \%$ \\
\hline
\end{tabular}

\begin{tabular}{|l|r|r|r|r|}
\hline EXCEDENTE OPERACIONAL & 10.153 & 3.566 & 6.588 & $185 \%$ \\
\hline Otros ingresos & 8.175 & 8.564 & -389 & $-5 \%$ \\
\hline Otros gastos & 1.133 & 1.089 & 44 & $4 \%$ \\
\hline EXCEDENTE DEL EJERCICIO & 17.195 & 11.040 & 6.155 & $56 \%$ \\
\hline
\end{tabular}

Fuente: División financiera. 
Los ingresos de la universidad se originan principalmente por recursos propios; el total de los ingresos netos para la vigencia 2019 ascendió a $\$ 213.915$ millones frente a unos ingresos netos de la vigencia 2018 que fueron de $\$ 196.777$ millones y estuvieron conformados como se aprecia en la Tabla 62.

TABLA 62. Ingresos 2018 - 2019 (en millones de \$ COP).

\begin{tabular}{|l|r|r|r|}
\hline CONCEPTO & \multicolumn{1}{|c|}{2019} & \multicolumn{1}{c|}{2018} & \multicolumn{1}{c|}{ VARIACIÓN } \\
\hline $\begin{array}{l}\text { Ingresos de transacciones con } \\
\text { contraprestación }\end{array}$ & 168.146 & 159.896 & $5,16 \%$ \\
\hline $\begin{array}{l}\text { Ingresos de transacciones sin } \\
\text { contraprestación }\end{array}$ & 37.594 & 28.317 & $32,76 \%$ \\
\hline Otros ingresos & 8.175 & 8.564 & $-4,54 \%$ \\
\hline TOTALES & 213.915 & 196.777 & $8,71 \%$ \\
\hline
\end{tabular}

Fuente: División financiera.

Los gastos de la universidad son originados, bien sea por salidas o disminuciones del valor de los activos, o bien por la generación o aumento de los pasivos que dan como resultado decrementos en el patrimonio y no están asociados con la adquisición o producción de bienes y la prestación de servicios vendidos, ni con la distribución de excedentes.

El total de los gastos netos para la vigencia 2019 ascendió a $\$ 75.307$ millones frente a unos gastos netos de la vigencia 2018 que fueron de $\$ 45.238$ millones. Su conformación se muestra en la Tabla 63. 
TABLA 63. Gastos 2018 - 2019 (en millones de \$ COP).

\begin{tabular}{|l|r|r|r|}
\hline \multicolumn{1}{|c|}{ CONCEPTO } & \multicolumn{1}{c|}{2019} & \multicolumn{1}{c|}{2018} & \multicolumn{1}{c|}{ VARIACIÓN } \\
\hline Gastos de administración & 69.509 & 41.047 & $69,34 \%$ \\
\hline $\begin{array}{l}\text { Deterioro, depreciaciones, } \\
\text { amortizaciones y provisiones }\end{array}$ & 4.665 & 3.101 & $50,41 \%$ \\
\hline Otros gastos & 1.133 & 1.089 & $4,06 \%$ \\
\hline TOTALES & 75.307 & 45.238 & $66,47 \%$ \\
\hline
\end{tabular}

Fuente: División financiera.

Los costos de la universidad están conformados por las erogaciones asociadas a gastos del personal por las diferentes modalidades de contratación como lo son docentes de medio tiempo y tiempo completo, hora cátedra y docentes ocasionales.

El total de los costos netos (Tabla 64) para la vigencia 2019 ascendió a $\$ 121.413$ millones frente a unos costos netos de la vigencia 2018 que fueron de $\$ 140.498$ millones. Se presentan en esa tabla.

TABLA 64. Comparación costos netos 2018 - 2019 (en millones de \$ COP).

\begin{tabular}{|l|r|r|r|}
\hline \multicolumn{1}{|c|}{ CONCEPTO } & \multicolumn{1}{c|}{2019} & \multicolumn{1}{c|}{2018} & \multicolumn{1}{c|}{ VARIACIÓN } \\
\hline Servicios personales & 91.481 & 92.388 & $-0,98 \%$ \\
\hline $\begin{array}{l}\text { Deterioro, depreciaciones, } \\
\text { amortizaciones y } \\
\text { provisiones }\end{array}$ & 29.902 & 41.548 & $-28,03 \%$ \\
\hline Otros gastos & 30 & 6.562 & $-99,54 \%$ \\
\hline TOTALES & 121.413 & 140.498 & $-13,58 \%$ \\
\hline
\end{tabular}

Fuente: División financiera. 
Gestiones adelantadas

Preparación y presentación de información financiera de 2019

- Aprobación de los estados financieros con corte al 31 de diciembre de 2019 por el Consejo Superior en febrero de 2020 .

- Transmisión trimestral a la Contaduría General de la Nación (CGN) de la información financiera comparativa conforme a las condiciones y plazos definidos por dicho organismo de regulación, en cumplimiento de los lineamientos definidos en la Resolución 533 de 2015 y sus modificatorias, y aplicación del Marco Normativo para Entidades de Gobierno.

- Transmisión trimestral a la CGN de las operaciones recíprocas y las variaciones trimestrales conforme a las condiciones y plazos definidos por dicho organismo de regulación.

- Transmisión semestral a la CGN del Boletín de Deudores Morosos del Estado (BDME)

- Transmisión trimestral al Ministerio de Educación Nacional de la información financiera conforme a las condiciones y plazos definidos por dicho organismo de supervisión y control.

- Participación activa en las mesas de trabajo desarrolladas con la División de Impuestos y Aduanas Nacionales (DIAN) y la Asociación Colombiana de Universidades 
(Ascun) para efectos de la implementación y aplicación de la facturación electrónica.

- Aplicación de las políticas contables definidas por la universidad mediante la Resolución Rectoral No. 5030 de diciembre de 2017 para el reconocimiento, medición, presentación y revelación de los hechos económicos.

- Presentación de información financiera atendiendo lineamientos de la Comisión Legal de Cuentas de la Contraloría General de la República para la vigencia 2018.

La calidad tributaria de la Universidad Militar Nueva Granada corresponde a lo indicado a continuación, sin perjuicio de las obligaciones contenidas en el registro único tributario (RUT).

\section{GRI 207}

\section{Impuestos nacionales}

- No contribuyente del impuesto sobre la renta - art. 23 del Estatuto Tributario.

- No contribuyente del impuesto de industria y comercio - literal D del numeral 2 del artículo 39 de la Ley 14 de 1983.

- No responsable del Impuesto de Valor Agregado (IVA)art. 92 de la Ley 30 de 1992. 
- No se encuentra obligada a contar con Resolución de Facturación - art. 04 de la Resolución 055 de 2016.

- Actividades económicas: 8544 - 8551.

- Agente retenedor a título de renta - Art. 368-1 del Estatuto Tributario.

- Agente retenedor del impuesto sobre las ventas - art. 437-2 del Estatuto Tributario.

No obligados a facturar electrónicamente, capítulo 4, sección 1, artículo 1.6.1.4.1.3 del Decreto Único Reglamentario 1625 de 2016.

\section{Calidad tributaria, Cajicá - Cundinamarca}

- No es sujeto de impuesto de industria y comercio - numeral 4 del artículo 115 del Acuerdo 05 de 2018.

- No es sujeto del impuesto complementario de aviso y tableros, al no generarse las condiciones de causación por no ser responsable del impuesto de industria y comercio - artículo 156 del Acuerdo 05 de 2018.

- Exenta del impuesto predial - parágrafo 4 del artículo 86 del Acuerdo 05 de 2018.

- Exención parcial del 0\% del impuesto de delineación y construcción (diez años), numeral 03 del artículo 193 del Acuerdo 05 de 2018.

- Agente retenedor del impuesto de industria y comercio - literal A del artículo 140 del Acuerdo 05 de 2018. 


\section{Calidad tributaria, Bogotá Distrito Capital}

- No es sujeto del impuesto de industria y comercio, al no realizar actividades sujetas a este - literal C del artículo 39 del Decreto 352 de 2002.

- No es sujeto del impuesto complementario de avisos y tableros - artículo 58 del Decreto 352 de 2002.

- Agente retenedor permanente de industria y comercio - numeral 1 del artículo 3 del Decreto 187 de 2005.

- No contribuyente de estampilla pro cultura - artículo 7 del Acuerdo 187 de 2005.

- No contribuyente de estampilla adulto mayor - artículo 4 del Acuerdo 669 de 2017.

Preparación y presentación de información tributaria

\section{GRI 207}

\section{Tributarios nacionales}

- Presentación, gestión y atención para los trámites de devolución de IVA ante la DIAN (cinco bimestres).

- Presentación de las declaraciones mensuales de retención en la fuente.

- Presentación de las declaraciones bimestrales de retenciones de industria y comercio para Bogotá.

- Traslado de los recursos de forma mensual por concepto de seguridad democrática. 
- Traslado semestral de los recursos pro-estampilla universidades.

- Presentación de la información exógena 2018 a nivel nacional.

\section{Tributarios municipales}

- Trámite de exención del impuesto predial de Cajicá para la vigencia 2019.

- Presentación de las declaraciones bimestrales de retenciones de industria y comercio para Cajicá.

- Presentación de la información exógena 2018 a nivel nacional.

\section{Socialización y ampliación de la información reportada}

- Actualización de información en el portal web (https:// www.umng.edu.co/la-universidad/financiera).

Visita de la Contraloría General de la República

La última la visita de la Contraloría General de la República fue realizada entre julio y noviembre de 2018 y en ella se abordaron aspectos asociados a la auditoría financiera de la vigencia 2017, la cual fue fenecida.

Conforme a información remitida por la Contraloría General de la República para el primer semestre del año en curso no se encuentra programada visita por este organismo de control. 


\section{Preparación y presentación de información presupuestal 2019}

- Presentación de la ejecución de ingresos y gastos consolidada de la vigencia 2019 al Consejo Superior Universitario.

- Transmisión de la ejecución presupuestal consolidada a 31/12/2019 en el consolidador de hacienda e información pública (CHIP) de la Contraloría General de la República.

- Transmisión de la ejecución presupuestal trimestral a la Contraloría General de la República.

- Presentación de la cuenta anual consolidada, vigencia 2017, al Sistema de Rendición Electrónica de la Cuenta e Informes (Sireci).

- Transmisión de la ejecución presupuestal mensual de enero a diciembre de 2019 al Ministerio de Educación Nacional.

- Presentación de informe de situación fiscal de universidades de 2018 al Ministerio de Educación Nacional.

- Presentación de informe de ejecución de recursos pro-estampilla Universidad Nacional y otras universidades de Colombia al Ministerio de Educación Nacional. 
En atención a las gestiones adelantadas por la sección de Tesorería, para la vigencia 2019, se destacan las siguientes:

Total de transacciones de desembolso: fueron 2.330 desagregadas en 545 cheques girados y 1.785 lotes de trasferencias procesados a través de canales electrónicos. En lo que se relaciona al manejo del portafolio de inversión, para el caso su gestión se muestra en la Tabla 65.

TABLA 65. Manejo de portafolio de Inversiones (cifras en pesos).

\begin{tabular}{|c|c|r|}
\hline FECHA & CONCEPTO & \multicolumn{1}{|c|}{ VALOR } \\
\hline $31 /$ dic/2018 & Saldo inicial & 120.000 .000 .000 \\
\hline $30 /$ ene/2019 & Inversión & 38.000 .000 .000 \\
\hline $31 /$ ene/2019 & Inversión & 9.000 .000 .000 \\
\hline $1 /$ mar/2019 & Redención & 20.000 .000 .000 \\
\hline $30 / a b r / 2019$ & Redención & 19.000 .000 .000 \\
\hline $8 /$ may/2019 & Inversión & 18.500 .000 .000 \\
\hline $8 /$ may/2019 & Redención & 40.000 .000 .000 \\
\hline 9/may/2019 & Inversión & 21.500 .000 .000 \\
\hline $6 / j u n / 2019$ & Redención & 3.000 .000 .000 \\
\hline $17 / j u n / 2019$ & Inversión & 10.000 .000 .000 \\
\hline $17 / j u n / 2019$ & Redención & 10.000 .000 .000 \\
\hline $29 /$ jul/2019 & Inversión & 35.000 .000 .000 \\
\hline $30 / a g o / 2019$ & Inversión & 42.000 .000 .000 \\
\hline $30 / a g o / 2019$ & Redención & 47.000 .000 .000 \\
\hline $1 /$ cct/2019 & Redención & 10.000 .000 .000 \\
\hline
\end{tabular}


CONTINUACIÓN TABLA 65. Manejo de portafolio de Inversiones (cifras en pesos).

\begin{tabular}{|c|c|r|}
\hline FECHA & CONCEPTO & VALOR \\
\hline $8 /$ nov/2019 & Redención & 18.500 .000 .000 \\
\hline $12 /$ nov/2019 & Inversión & 21.500 .000 .000 \\
\hline $12 /$ nov/2019 & Redención & 21.500 .000 .000 \\
\hline $29 /$ nov/2019 & Inversión & 35.000 .000 .000 \\
\hline $29 /$ nov/2019 & Redención & 35.000 .000 .000 \\
\hline $17 /$ dic/2019 & Redención & 10.000 .000 .000 \\
\hline $31 /$ dic/2019 & Saldo final & $\$ 116.500 .000 .000$ \\
\hline
\end{tabular}

Fuente: División financiera. 


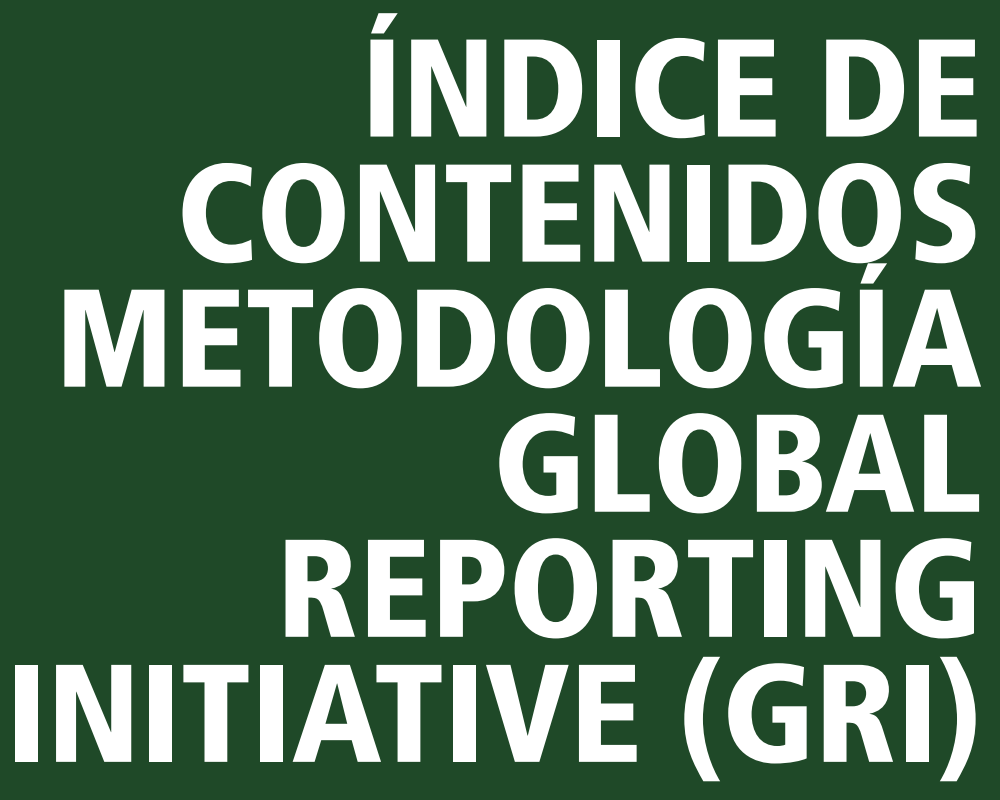





\section{GRI 102-55}

Los contenidos planteados en la agenda global 2030 exhortan procesos de cambio transformador, donde los actores de la sociedad se mueven en la misma dirección concertadas por la Organización de las Naciones Unidas (ONU). El compromiso de la Universidad Militar Nueva Granada, es seguir enfocada en liderar mediante el rol como productor de base de conocimiento para la sociedad en la investigación y a través de la difusión de este conocimiento a los grupos de interés, en impulsar en su gestión a través de su enseñanza, plan de estudios y elección de temas para la investigación, demostrar que somos una voz dentro de la sociedad que se responsabiliza por el cambio transformador requerido como parte del accionar en el desarrollo de nuestra Responsabilidad Social Universitaria (RSU), la 
expresión del control social por medio de la rendición de cuentas y dando los aportes pertinentes demandados por la sociedad colombiana. 


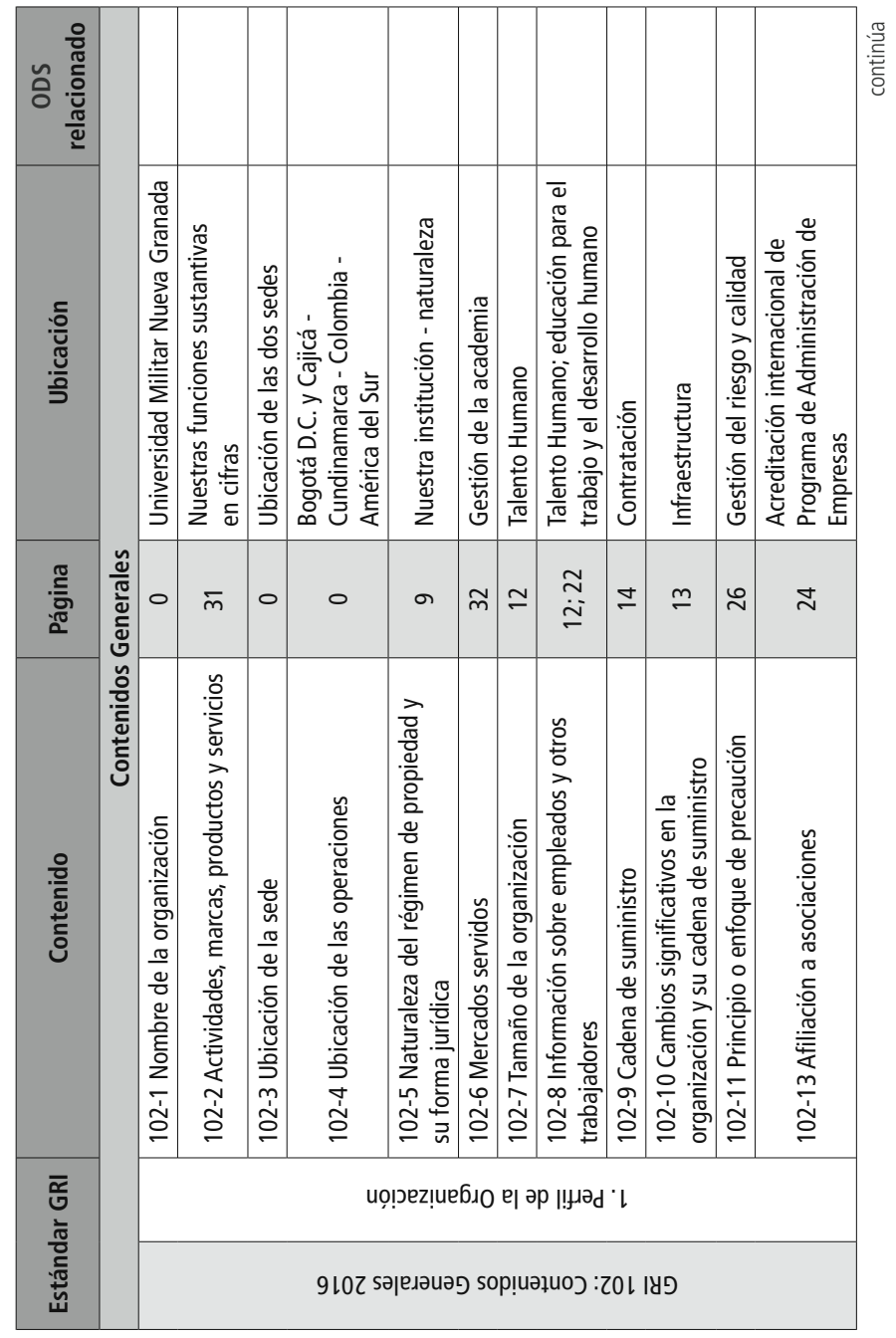

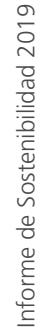




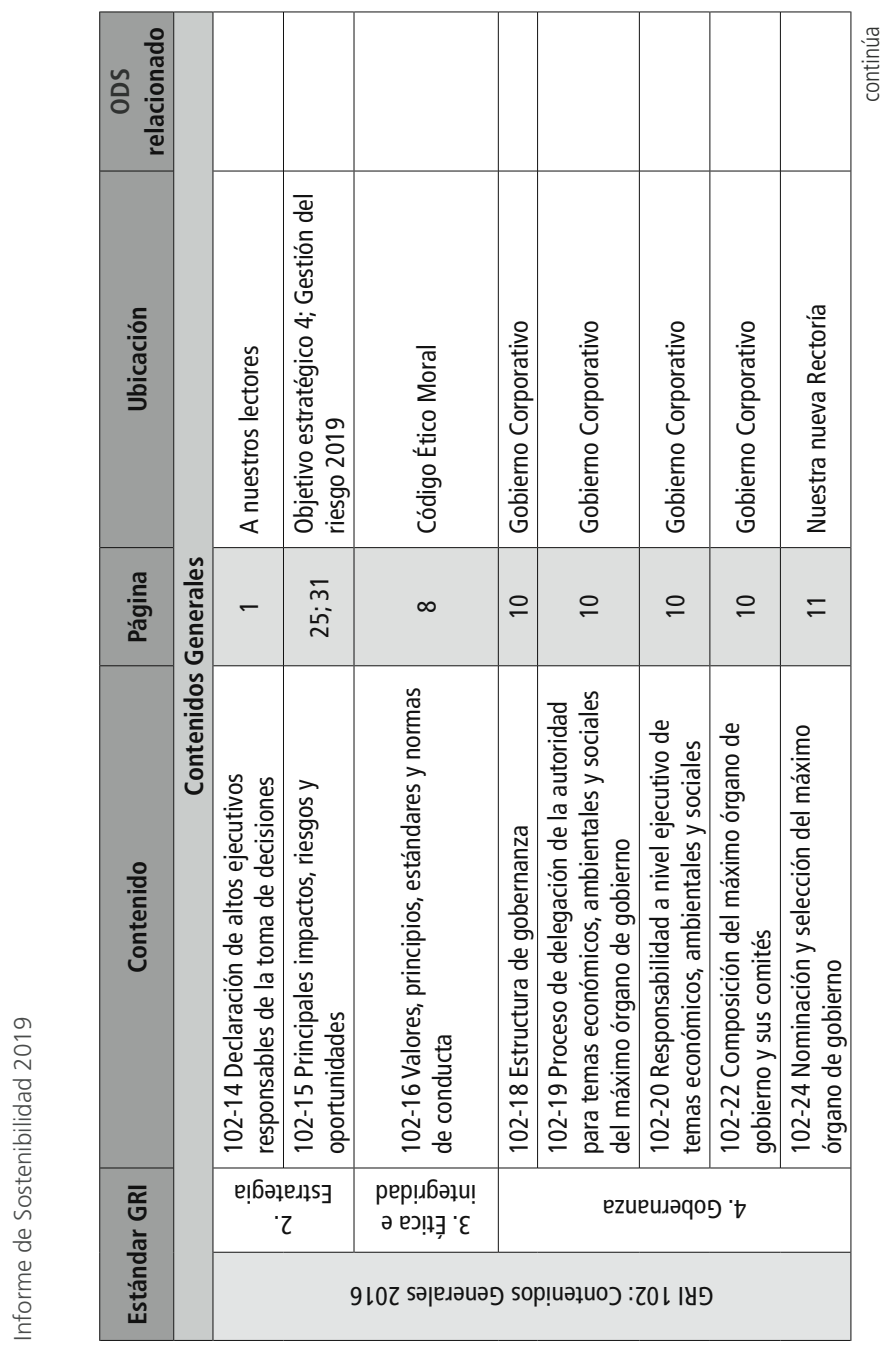




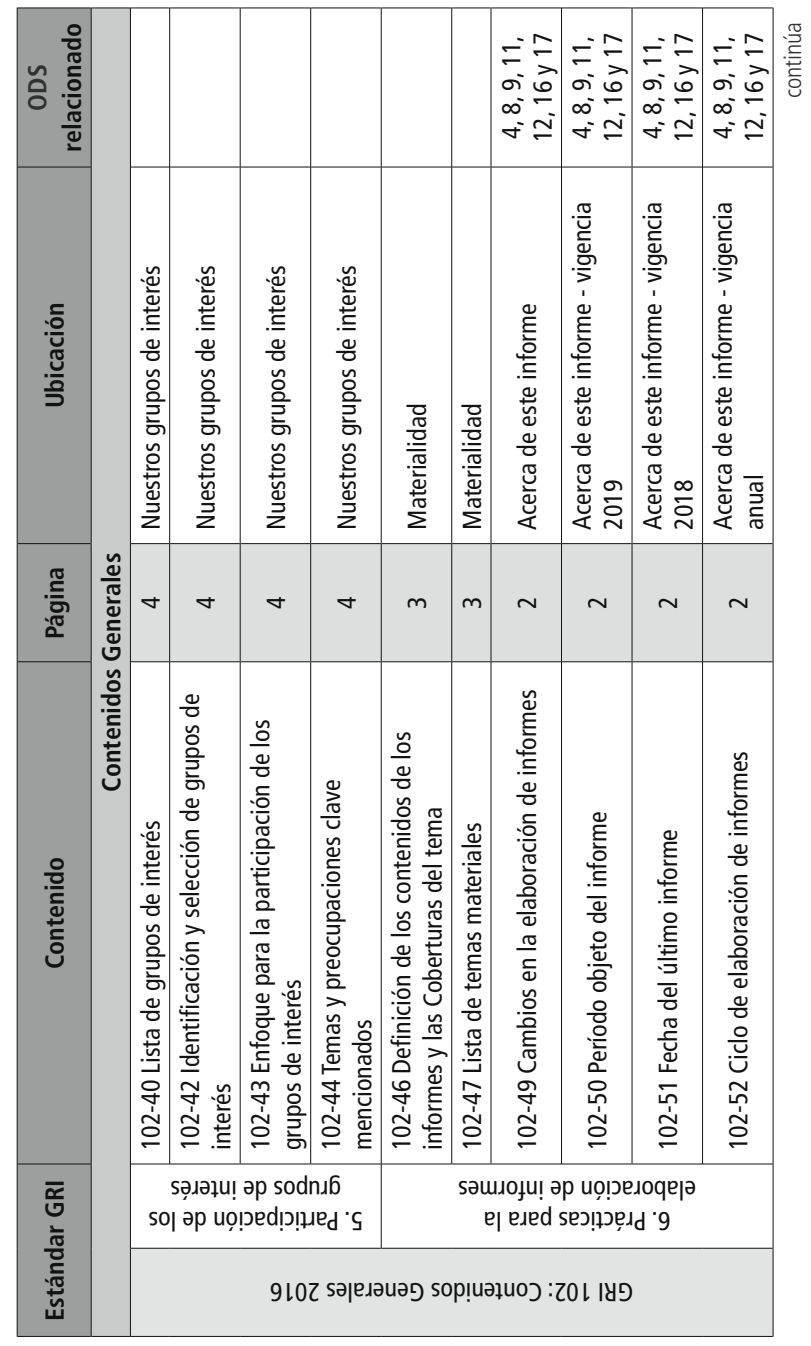




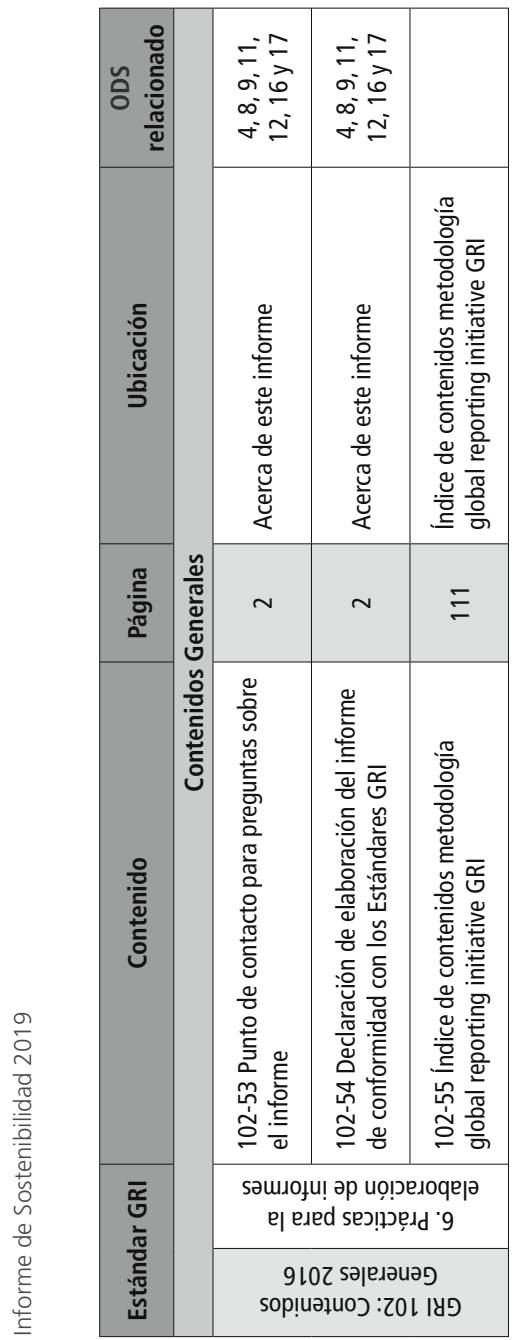




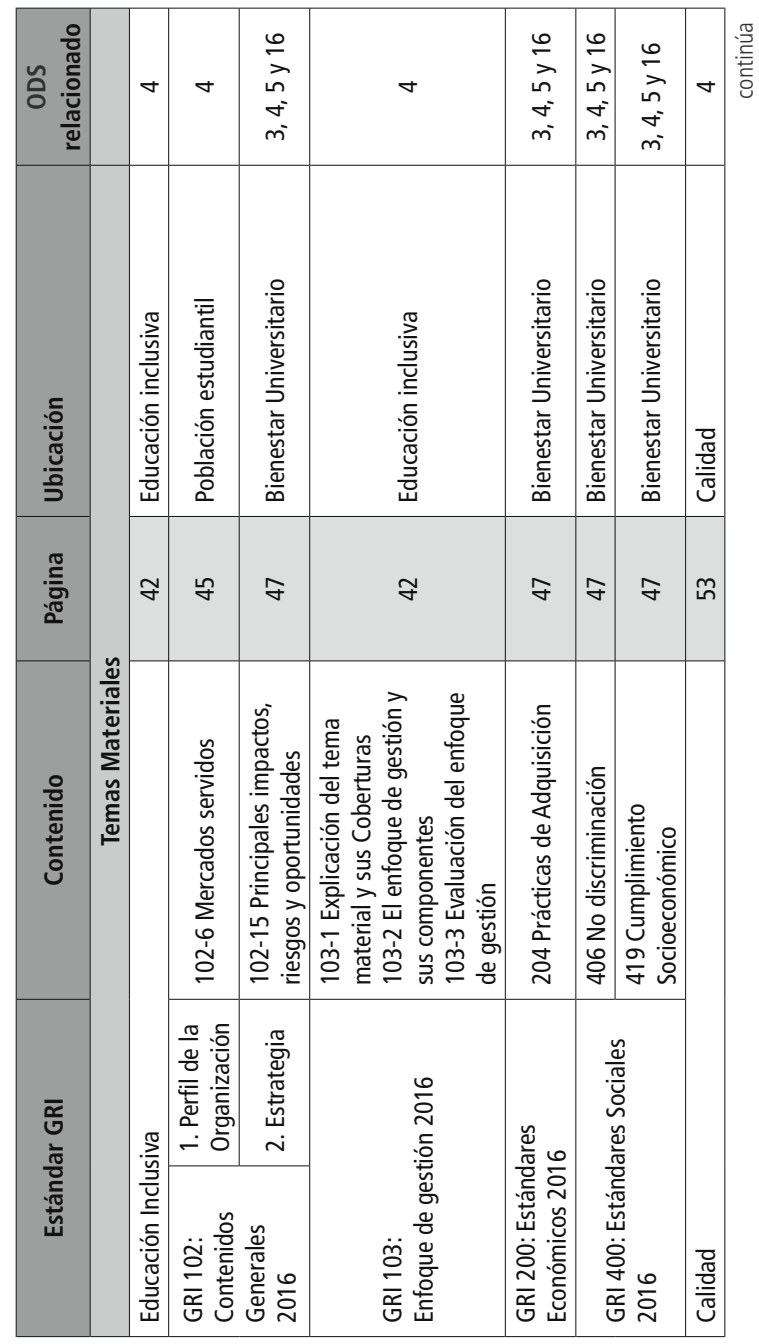

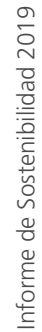




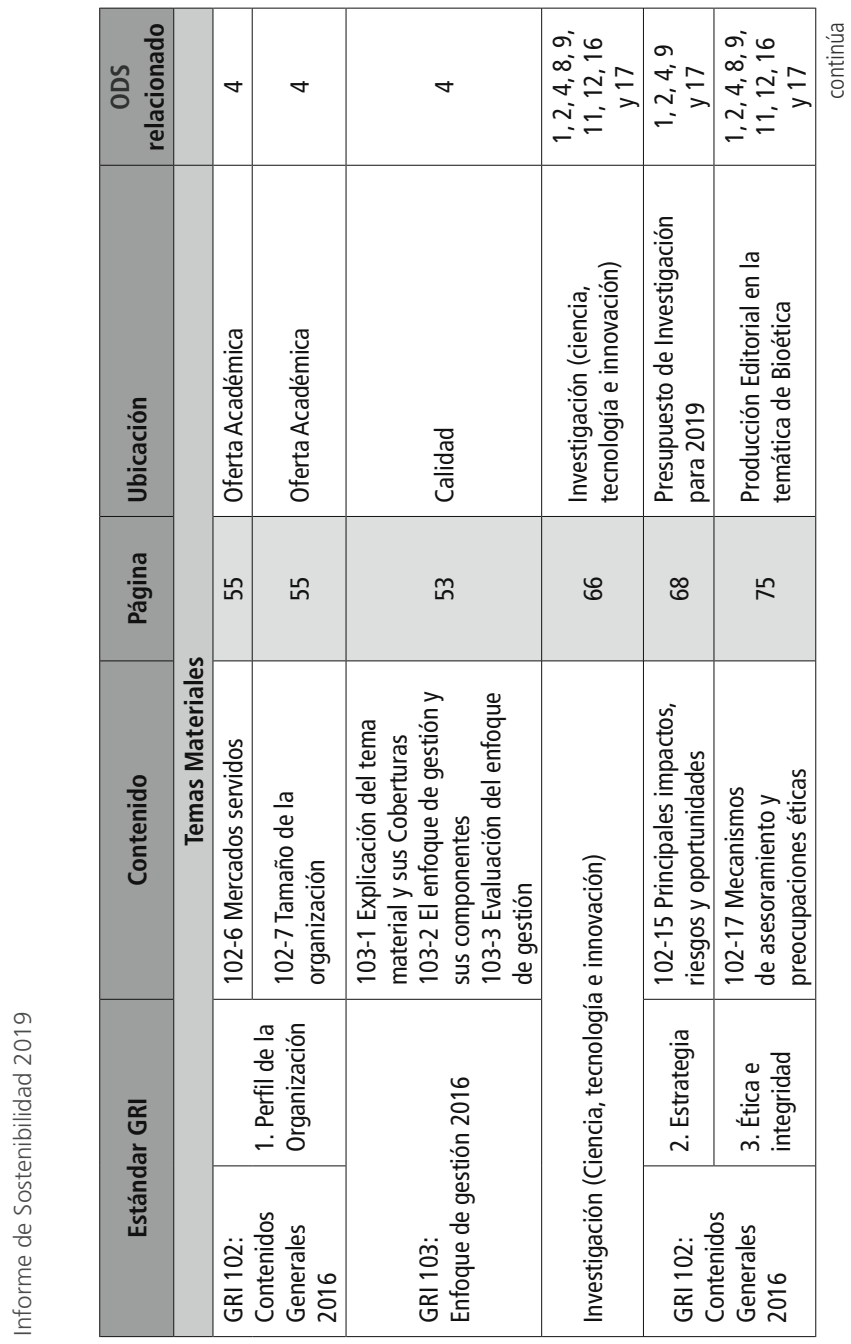




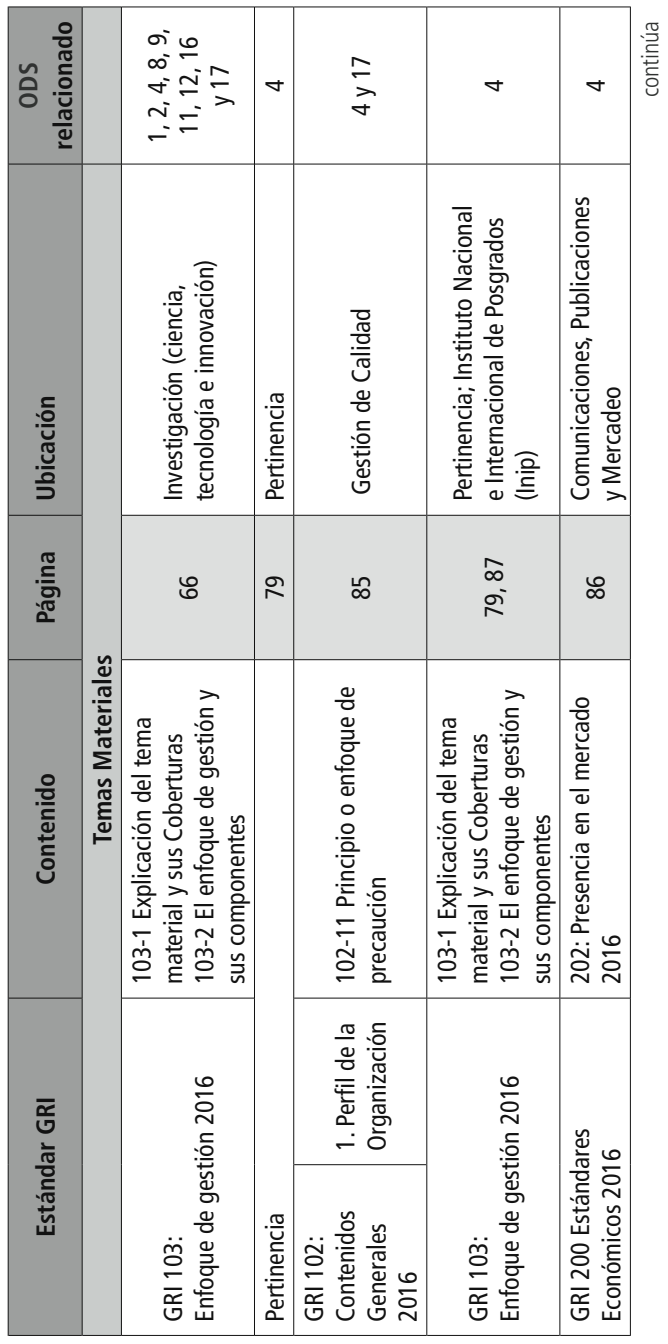

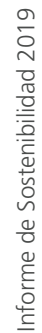




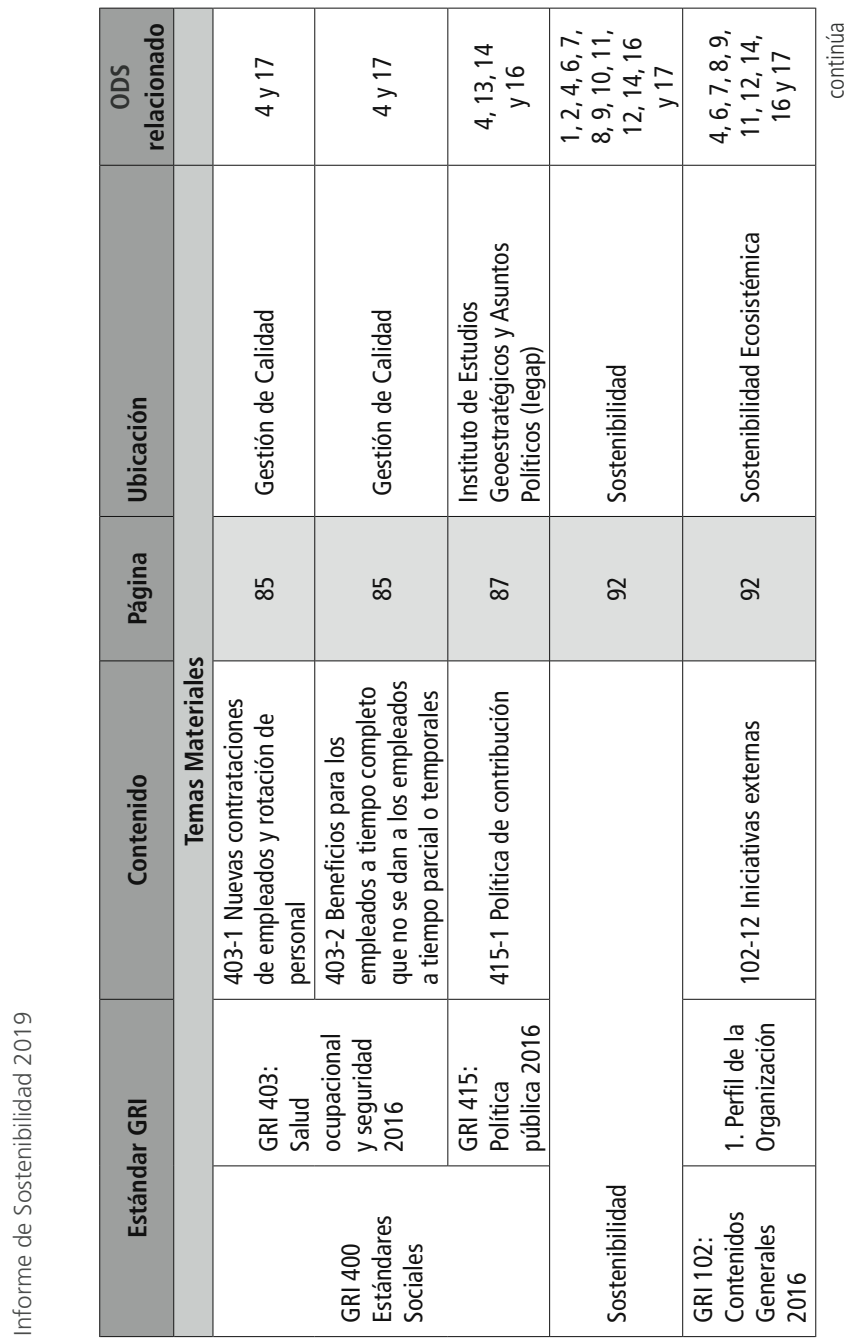




\begin{tabular}{|c|c|c|c|c|c|c|c|}
\hline 乞 $\frac{\substack{\frac{0}{0} \\
0}}{\frac{0}{0}}$ & & 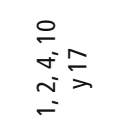 & 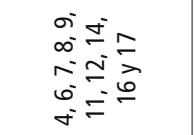 & $\begin{array}{l}0 \\
\dot{5}= \\
\approx= \\
=\end{array}$ & 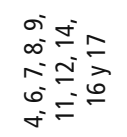 & 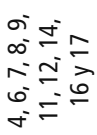 & $\begin{array}{l}\sigma \pm \\
\infty \simeq \approx \\
\sigma=6 \\
\sigma=\end{array}$ \\
\hline 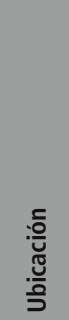 & & 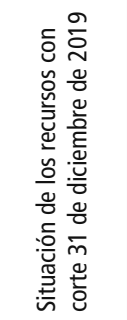 & 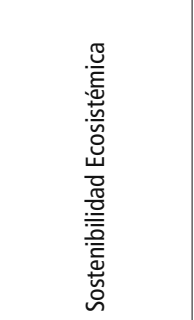 & 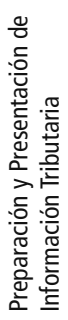 & 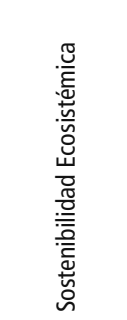 & 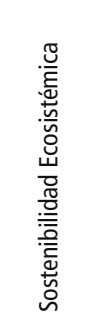 & 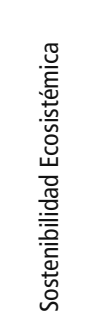 \\
\hline$\frac{\text { ర్ }}{\frac{5}{5}}$ & & $\stackrel{m}{\circ}$ & ๙ & 으 & ภ & ๙ & శี \\
\hline 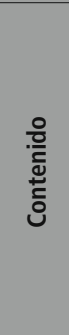 & 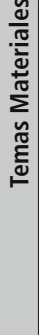 & 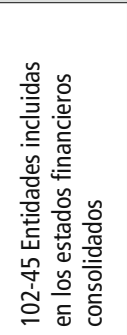 & 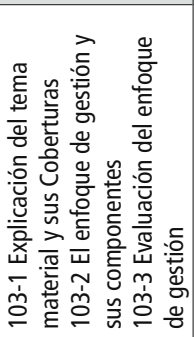 & 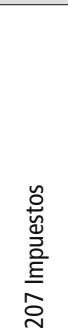 & 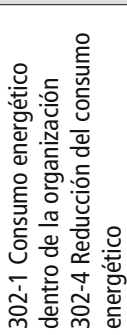 & 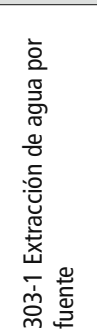 & 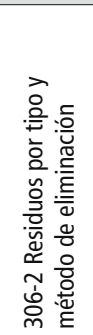 \\
\hline 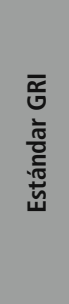 & & 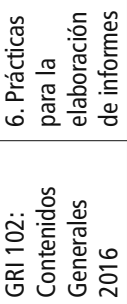 & 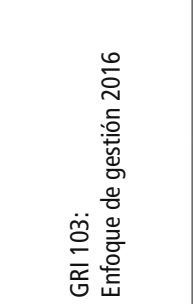 & 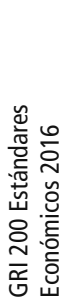 & 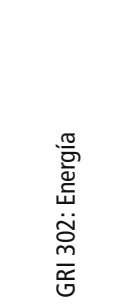 & $\begin{array}{l}\frac{\pi}{J} \\
\frac{0}{x} \\
\dot{m} \\
\frac{m}{m} \\
\frac{0}{0}\end{array}$ & 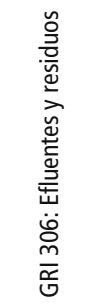 \\
\hline
\end{tabular}



REFERENCIAS 

Consejo Nacional de Educación Superior. (s. f.). Acuerdo por lo superior 2034. Propuesta de política pública para la excelencia de la educación superior en Colombia en el escenario de la paz. Recuperado de https://www.dialogoeducacionsuperior. edu.co/1750/articles-321515_recurso_1.pdf

Global Reporting Initiative. (GRI). (2016). Metodología Global Reporting Initiative GRI. Recuperado de https://www.globalreporting.org/standards/gri-standards-translations/gri.standards.spanish-translations.download.center/

Organización de Naciones Unidas. (2015). La Asamblea General adopta la Agenda 2030 para el Desarrollo Sostenible. Imagen recuperada de https://www.un.org/sustainabledevelopment/ es/2015/09/la-asamblea-general-adopta-la-agenda-2030-para-el-desarrollo-sostenible/

Organización de Naciones Unidas. (2016). 17 objetivos para transformar nuestro mundo. Logo recuperado de https:// www.un.org/sustainabledevelopment/es/ 
Presidencia de la República. (s. f.). Legalidad + Emprendimiento = Equidad. Recuperado de https://id.presidencia.gov.co/ especiales/190523-PlanNacionalDesarrollo/index.html

República de Colombia. Ministerio de Educación Nacional. (2017). Plan Nacional Decenal de Educación 2016-2026. El camino hacia la calidad y la equidad. Recuperado de http://www.plandecenal.edu.co/cms/media/herramientas/ PNDE\%20FINAL_ISBN\%20web.pdf

República de Colombia. (2019). Presidencia de la República. Plan de Desarrollo 2018-2022. Pacto por Colombia, pacto por equidad. Ley 1955 de 2019. Recuperado de https://id.presidencia.gov.co/especiales/190523-PlanNacionalDesarrollo/documentos/BasesPND2018-2022.pdf

Sustainable Development Solutions Network (SDSN) Australia / Pacífico en colaboración con los ACTS (Australian Campuses Towards Sustainability) y la Secretaria Global de SDSN. (2017), Cómo empezar con los ODS en las universidades. Una guía para las universidades, los centros de educación superior y el sector académico. Recuperado de https://redssdsn.es/wp-content/uploads/2017/02/Guia-ODS-Universidades-1800301-WEB.pdf

Universidad de Barcelona y Universitat Pompeu Fabra Barcelona. (Noviembre, 2018). Adaptación de los estándares GRI para la elaboración de informes de sostenibilidad en universidades. Recuperado de http://www.ub.edu/responsabilitatsocial/docs/ca/ok_gri\%20adaptat\%20definitiu_desembre.pdf 
Universidad Militar Nueva Granada. (2018). Informe de Sostenibilidad 2018. Recuperado de https://www.umng. edu.co/documents/20127/154380/Informe_Sostenibilidad_2018_UMNG.pdf/33635ef9-2e7b-1b87-7ea9-c64a1cbe$3 f 35 ? t=1576762810007$

Universidad Militar Nueva Granada. (2019, 30 de mayo). Twitter @lamilitar. Recuperado de https://twitter.com/lamilitar/ status/1134178537534042112/photo/1

Universidad Militar Nueva Granada. (2019, 15 de agosto). Twitter@lamilitar. Recuperado de https://twitter.com/lamilitar/ status/1162031810903269376/photo/1

Universidad Militar Nueva Granada. (2019, 11 de octubre). Twitter@lamilitar. Recuperado de https://twitter.com/lamilitar/ status/1182701422107856902/photo/1

Universidad Militar Nueva Granada. (2019, 11 de octubre). Twitter@lamilitar. Recuperado de https://twitter.com/lamilitar/ status/1182701422107856902/photo/2

Universidad Militar Nueva Granada. (2019, 11 de octubre). Facebook. Recuperado de https://www.facebook.com/ photo?fbid=2577824448966273\&set=a.300601016688639

Universidad Militar Nueva Granada. (2019, 11 de octubre). Facebook. Recuperado de https://www.facebook.com/ photo/?fbid=2577825092299542\&set=a.300601016688639

Universidad Militar Nueva Granada. (2019, 11 de octubre). Facebook. Recuperado de https://www.facebook.com/ photo?fbid=2577824955632889\&set=a.300601016688639 
Universidad Militar Nueva Granada. (2020). Autoevaluación y acreditación. Recuperado de https://www.umng.edu.co/ autoevaluacion-y-acreditacion

Universidad Militar Nueva Granada. (s. f.). Sistema integrado de gestión. Recuperado de https://www.umng.edu.co/ sistema-de-gestion-de-calidad

Universidad Militar Nueva Granada. (s. f.). Mecanismos para la atención al ciudadano. Recuperado de https://www.umng. edu.co/atencion-al-ciudadano

Universidad Militar Nueva Granada. (s. f.). Organigrama. Recuperado de https:/www.umng.edu.co/transparencia/ estructura-organica-y-talento-humano/organigrama

Vallaeys, F.; de la Cruz, C.; y Sasia, P. M. (2009). Responsabilidad social universitaria: Manual de primeros pasos. Recuperado de https://publications.iadb.org/es/publicacion/14191/responsabilidad-social-universitaria-manual-de-primeros-pasos 

